Florida International University

FIU Digital Commons

FIU Electronic Theses and Dissertations

University Graduate School

2-22-1994

\title{
An evaluation of depression, self-efficacy, satisfaction with life and perceived access to medical care across stages of HIV infection
}

Toni Marie DiDona

Florida International University

DOI: $10.25148 /$ etd.FI14062287

Follow this and additional works at: https://digitalcommons.fiu.edu/etd

Part of the Social Welfare Commons

\section{Recommended Citation}

DiDona, Toni Marie, "An evaluation of depression, self-efficacy, satisfaction with life and perceived access to medical care across stages of HIV infection" (1994). FIU Electronic Theses and Dissertations. 2815.

https://digitalcommons.fiu.edu/etd/2815

This work is brought to you for free and open access by the University Graduate School at FIU Digital Commons. It has been accepted for inclusion in FIU Electronic Theses and Dissertations by an authorized administrator of FIU Digital Commons. For more information, please contact dcc@fiu.edu. 
FLORIDA INTERNATIONAL UNIVERSITY

Miami, Florida

An Evaluation of Depression, Self-Efficacy, Satisfaction with Life and Perceived Access to Medical Care Across Stages of HIV Infection

A dissertation submitted in partial satisfaction of the requirements for the degree of DOCTOR OF PHILOSOPHY

IN

SOCIAL WELFARE

by

Toni Marie DiDona 
To: Dean Alan Rosenbaum, Ph.D.

School of Public Affairs and Services

This dissertation, written by Toni Marie DiDona, and entitled An Evaluation of Depression, Self Efficacy, Satisfaction with Life and Perceived Access to Medical Care Across stages of HIV Infection, having been approved in resect to style and intellectual content, is referred to you for judgement.

We have read this dissertation and recommend that it be approved.

Fred Becker

Betty Blythe

Scott Briar

Anne Humphrey

Betsy Smith

Karen Sowers-Hoag, Major Professor

Date of Defense: February 22, 1994

The dissertation of Toni Marie DiDona is approved.

Dean Allan Rosenbaum

School of Public Affairs and Services

Dr. Richard L. Campbell

Dean of Graduate Studies

Florida International University, 1994 
COPYRIGHT 1994, by Toni Marie DiDona

All rights reserved

iii 
DEDICATION

I would like to dedicate this dissertation to the past three generations of successful women in my family that gave me all that is important in life. My mother, Catherine, her fortitude and love of learning taught me that I could be anything. My grandmother, Mary Didona, her constant love and keen insight gave me strength and perspective. My great grandmother, Maria zuccaro, her courage taught me that I could surmount any odds. They are the most remarkable women I have ever known (or read about) and I have been truly blessed to have had them in my life. They have all contributed greatly to who I am today and this degree.

I would also like to dedicate this dissertation to my husband, Ronald Black, the best man I have ever known. His support, humor and patience helped make this work possible. 


\section{ACKNOWLEDGEMENTS}

I wish to thank the members of my committee; Fred Becker, Betty Blythe, Scott Briar, Ann Humphrey and Betsy Smith, for their time and patience.

Most of all, I wish to extend my deepest gratitude to my major professor, Dr. Karen Sowers-Hoag, for her complete support, timely corrections, guidance and encouragement. Her dedication to the profession and scholarship will always be the benchmark by which I guide my career. 


\begin{abstract}
OF THE DISSERTATION
AN EVALUATION OF DEPRESSION,

SELF EFFICACY, SATISFACTION WITH LIFE

AND PERCEIVED ACCESS TO MEDICAL CARE

ACROSS STAGES OF HIV INFECTION

by
\end{abstract}

Toni Marie DiDona

Florida International University, 1994

Professor Karen Sowers-Hoag, Major Professor

This survey was designed to identify the incidence and scope of depression, satisfaction with life, self-efficacy and perceived access to medical care for those who are infected with the HIV virus. It also determined whether or not factors such as sexual orientation, ethnicity and socioeconomic status are intervening variables with respect to mental health issues.

Subjects were recruited through a purposive sample from South Florida. A total of 871 surveys were used in the analysis. The overall response rate was nearly 908.

The incidence of depression was found to be higher than $75 \%$ across all stages of HIV infection. Furthermore, the incidence of depression increased as HIV disease progressed. Satisfaction with life and for the most part, self efficacy vi 
were found to decrease slightly as HIV disease progressed. Significant variance in depression, life satisfaction and self efficacy were found across stages of HIV infection. No significant differences between groups that were HIV infected, were found for depression, life satisfaction and self efficacy.

The severity of depression was found to vary significantly with self efficacy, life satisfaction and access to medical care but not with socioeconomic status. Life satisfaction was found to vary significantly with socioeconomic status, depression and self efficacy but not with access to medical care. Self-efficacy was found to vary significantly with socioeconomic status, depression and life satisfaction but not with access to medical care. Gender and ethnicity were not found to be significant precedent variables in depression for HIV infected individuals. Sexual orientation was found to be a significant precedent variable for depression, life satisfaction and self efficacy. 


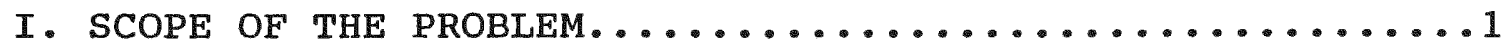

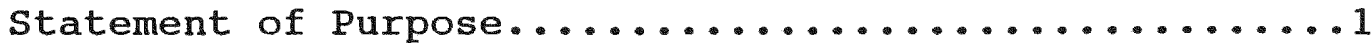
Social Welfare Issues and Contribution to the Field...6

II. LITERATURE REVIEW....................... 14

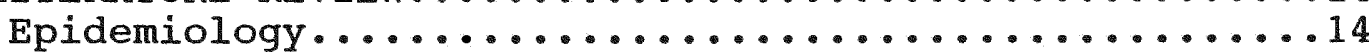

Proposed Variables for Evaluation..............38

III. HYPOTHESIS AND METHODOLOGY................ 52

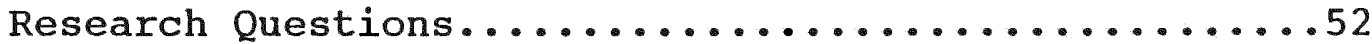

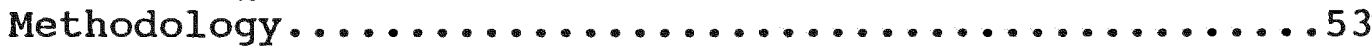

IV. RESULTS...........................68

Response Rates..........................69

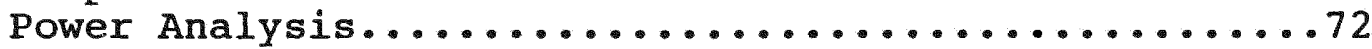

Description of the Entire Sample...............73

HIV Negative Respondents...................78

HIV Positive Respondents...................81

Respondents with AIDS Related Complex...........85

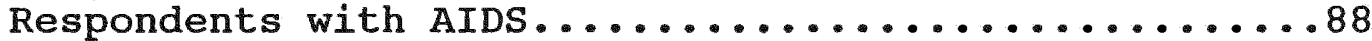

Reliability Analysis.....................92

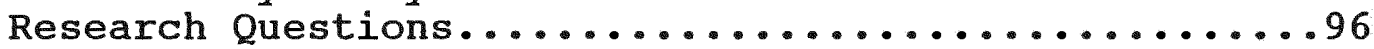

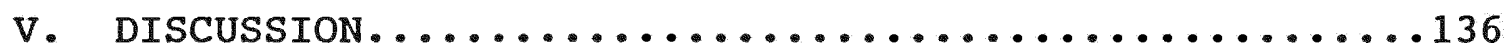

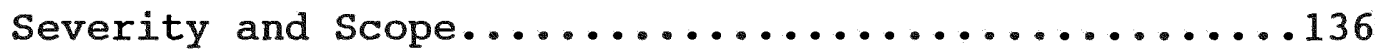

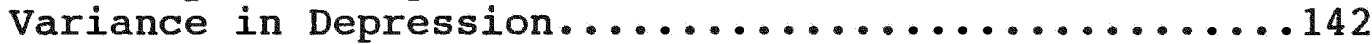

Variance in Life Satisfaction and Self Efficacy....145

Precedent Variable Effects..................149

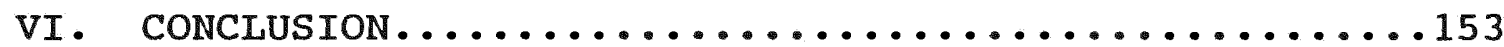

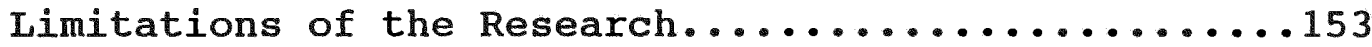

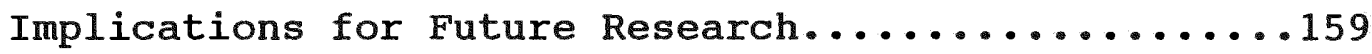

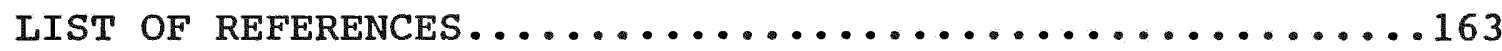


LIST OF TABLES

Table 1 Response Rates......................... 71

Table 2 Mean Depression Scores Across Stage of

Infection........................97

Table 3 Depression Score Severity Across Stage of

Infection.......................... 99

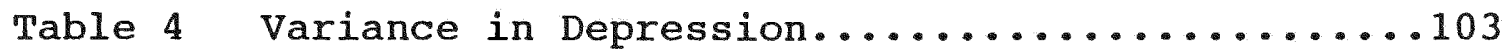

Table 5 Mean Life Satisfaction Scores Across Stage of

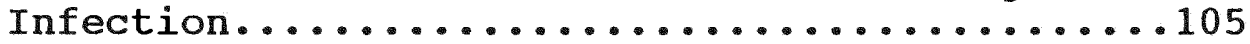

Table 6 Life Satisfaction Across Stage of Infection....106

Table 7 Variance in Life Satisfaction................110

Table 8 Mean Self-Efficacy Scores Across Stage of

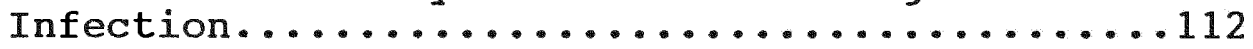

Table 9 Variance in Self-Efficacy................116

Table 10 Mean Depression Scores by Stage of Illness and

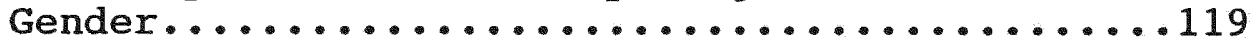

Table 11 Mean Depression Scores by Stage of Illness and

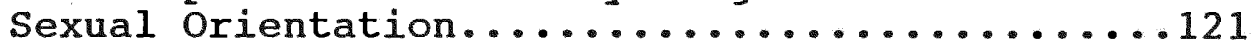

Table 12 Mean Depression Scores by Stage of Illness and

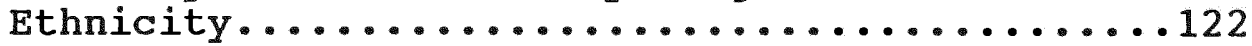

Table 13 Mean Life Satisfaction Scores by Stage of Illness

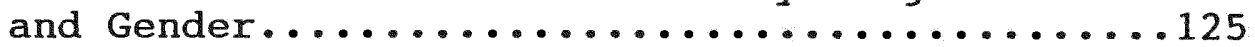

Table 14 Mean Life Satisfaction Scores by Stage of Illness

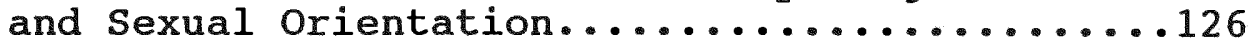

Table 15 Mean Life Satisfaction Scores by Stage of Illness

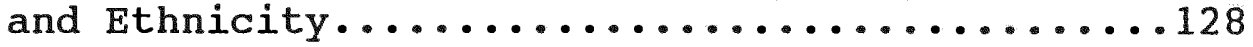

Table 16 Mean Self-Efficacy Scores by Stage of Illness and

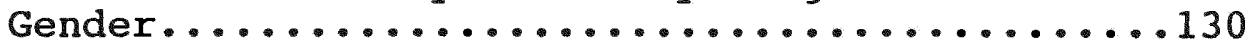

Table 17 Mean Self-Efficacy Scores by Stage of Illness and

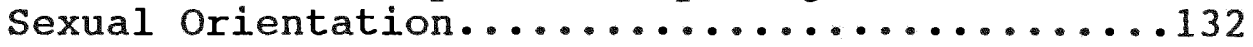

Table 18 Mean Self-Efficacy Scores by Stage of Illness and

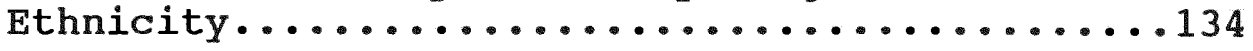

Table 19 Correlation Coefficients for Depression, Life Satisfaction, and Self-Efficacy............154 


\section{CHAPTER I \\ SCOPE OF THE PROBLEM \\ statement of Purpose}

Research reported in this paper is designed to describe perceived access to medical care across stages of HIV infection and its relationship to some of the psychological components experienced by HIV infected individuals. The variables analyzed will include depression, self-efficacy and satisfaction with life. Race, ethnicity, education and socioeconomic status are also studied. These variables are analyzed in order to gain a better understanding of the scope of the psychosocial problem and may help to determine what interventions are most needed. This study is conducted to identify which HIV infected individuals may be at risk for depression and lack of access to medical services. History of HIV Infection

Since its discovery in 1981, the human immunodeficiency virus (HIV) and acquired immune deficiency syndrome (AIDS) have had effects throughout the world. Although there is evidence that HIV appeared during the late 1970's (Evatt et al., 1983), it was not isolated until mid 1984. HIV, formally known as HTLV-III, HTLV-II and LAV, has been determined to be the cause of AIDS. AIDS is a debilitating disease in which the immune system is destroyed, thereby leaving the individual susceptible to thousands of infections and diseases that most individuals can ward off 
easily. HIV disease progression has been broken down into five (Lloyd, 1990) or three separate stages (Ozawa, Auslander \& Slonim-Nero, 1993) by different authors. Those who organize disease progression into five stages separate them into the following categories: exposure to the virus and rapid viral replication; immune system response and production of antibodies; asymptomatic period; progression of clinical symptoms; and symptoms of AIDS (Lloyd, 1990). These discrete stages are difficult if not impossible to pinpoint since the exact time of infection is rarely known. The stages of the three stage topology are as follows: HIV infection asymptomatic; development of symptoms otherwise known as AIDS related Complex (ARC); and finally the development of opportunistic disease formally known as AIDS (Ozawa et al., 1993). The three stage topology is more helpful because these stages are easier to identify due to the clinical symptoms and biological signs that accompany them.

Individuals with AIDS do not die from the virus itself, but rather from the infections and diseases that they contract and cannot fight due to the inadequate function of their immune system. It was initially postulated that all individuals with HIV infection would get sick and die in a matter of a few years (Centers for Disease Control, 1982). Although a diagnosis of AIDS brings with it a poor prognosis (Handler, Ho, Whelan \& Budzilovich, 1983), HIV infected 
individuals may not develop AIDS, or show any symptoms at all, for 10 years or more (cf. Imagawa, et al., 1989; Kaplan, Spira, Fishbein \& Lynn, 1992; Montaner, Le, Craib \& Schechter, 1992; Weber et al., 1986). Today, HIV infection is considered to be a chronic, albeit incurable condition (Sheridan, Phair \& Sheridan, 1990). Disease progression in HIV infection is best described as a continuum ranging from initial infection to asymptomatic infection, then to the development of symptoms and finally to immune system failure (Sheridan et al., 1990). This continuum parallels the three stage topology (Ozawa et al., 1993).

Scope of the Disease

Only estimates of the number of people infected are available, since there is no systematic reporting of HIV infection. Estimates of over 2 million cases world wide are not uncommon (Curran, Morgan \& Hary, 1985; Sivak \& Wormser, 1984). There is, however, systematic reporting of AIDS. With over 300,000 cases of full blown AIDS reported in the U.S. alone (Centers for Disease Control, 1993a), there is clearly a large group of infected individuals in this country even if accurate statistics are not available. These estimates understate the number of people affected, for two important reasons. First, most individuals remain asymptomatic for a long period of time after contracting the virus (Lloyd, 1990). Second, the clinical definition of full blown AIDS has been 
exclusionary of the diseases that women with HIV infection typically contract (Rosser, 1991). More specifically, Rosser (1991) reported that all of the 26 opportunistic infections that are necessary for a diagnosis of AIDS (concurrent with HIV infection) are more common in men and only recently have these criteria been updated to include a gynecological condition related to AIDS.

Although the current definition has been revised to include all individuals who have a T-cell count of less than 200, this definition has only recently been employed, thereby excluding thousands of women from the reports of earlier years (Rosser, 1991). Many individuals begin to get opportunistic infections long before their T-cells drop below 200, and the infections that are common to women still are not included in the Centers for Disease Control case definition of the syndrome (Rosser, 1991). Since the federal government and the Social Security Administration utilize the Centers for Disease Control's clinical definition of AIDS to determine who qualifies for disability benefits, including Medicare and Medicaid, there are serious social welfare implications associated with the historic and current underrepresentation of HIV infected in the numbers of reported cases of AIDS.

Preliminary evidence suggests that the Centers for Disease Control data on prevalence of HIV infection may be an underestimate of several important areas in the U.S. 
(Laumann, Gagnon, Michaels, Michael \& Coleman, 1989).

Laumann et al. report that the Centers for Disease Control data may be a significant underestimate of the actual prevalence in the Midwest as well as in the white and upper socioeconomic populations. AIDS crosses sexual orientation, gender and race. The number of HIV infected IV drug abusers continues to increase (Politzer \& Davis, 1992). In addition, Politzer and Davis (1992) reported that the virus is spreading rapidly among young adults (18-24 year olds), women and the poor.

Factors Contributing to the Problem

With an HIV positive diagnosis, there are a number of psychosocial problems. This may be due to several factors including the stigma attached to having an AIDS diagnosis, the helplessness associated with an incurable illness and the hopelessness that accompanies a terminal condition (Lloyd, 1990). The financial burden of medical care and loss of income may occur contributes to the psychosocial problems. Unfortunately, little is known about the relationship between access to medical care and depression, satisfaction with life, or self-efficacy for those infected with the HIV virus. 
Social Welfare Issues and Contribution to the Field Initially, it appeared that only gay men were victims of this disease, and in fact it was originally called gay related immune deficiency (GRID). As heterosexual cases, first in Africa, then worldwide were discovered however, it became clear that the world had a new "slow plague" (McLaughin, 1988, p.19). As the number of individuals infected with the virus continues to grow, HIV is one of the most important health issues of the nineties. The medical care, financial and psychosocial needs of individuals who are infected will drain the health care system, social security system and mental health system in the United states. With the exorbitant cost of medical care, the loss of productivity from individuals typically at their prime, and the social stigma associated with the disease, mental health needs and access to medical care for HIV infected individuals must be empirically evaluated. This survey is designed to identify the incidence and severity of depression, satisfaction with life and self-efficacy for those who are infected with the HIV virus. These variables were chosen because there is some literature to suggest that they may be important and empirical literature is lacking (Beckham, 1988; Carballo-Dieguez, 1998; Cohen, 1990; Gambe \& Getzle, 1989; Lloyd, 1990). In addition, this survey measures HIV infected individuals' perceived access to medical care. It also attempts to determine whether or not 
factors such as sexual orientation, ethnicity, education and socioeconomic status are intervening variables with respect to mental health issues and perceived access to medical care. These data may suggest an intervention package for alleviating the psychological problems associated with HIV infection and improving the satisfaction with life for these individuals.

Clearly, HIV infection and AIDS have had an enormous effect on social welfare programs since it was discovered in 1984. This effect has created an increased demand for services and programs as well as the creation of new policies. Social security, food stamp and other federal and state systems that are designed to provide assistance are being drained. In order to fully evaluate the scope of this effect, as well as implications for the results of this study, the three major areas of social work will be addressed: education and training, research and practice. Education and Training

As the number of HIV infected individuals rises, so does the likelihood that every social worker will at some point have HIV infected clients. This has serious implications for social work education as a whole, particularly because evidence suggests that social work educators may not yet have expanded their coursework on HIV and AIDS sufficiently (Diaz \& Kelly, 1991). Specifically, Diaz and Kelly (1991) surveyed 70 master of social work 
(MSW) programs and found that although the majority (848) offered courses about practice in health care systems, only 98 offered a full course on practice with HIV infected or persons with AIDS (PWAs). Although many of the programs incorporated AIDS content into the courses, many schools did not offer any training on counseling about AIDS risk to clients who abuse intravenous (IV) drugs or heterosexual clients ( 438 and 388 respectively). Furthermore, 188 did not offer any training in clinical services to clients with HIV or AIDS (Diaz \& Kelly, 1991). Diaz and Kelly (1991) conclude that students will be better prepared to work with HIV infected and PWAs as more social work programs introduce training specific to AIDS.

The research reported here provides a foundation of knowledge that is important in educating social work students about the relationships between access to services, such as medical care and mental health. By demonstrating the relationship between access to medical care and depression, life satisfaction and self-efficacy, this study may also stimulate an interest in social policy among social work students who are focused on direct practice. An increase in knowledge about HIV infection is particularly important given that all social work practioners will probably have HIV infected clients at some point in their practice and that it has been demonstrated that the amount 
of knowledge about HIV and AIDS among social workers is quite small (Peterson, 1991).

The amount of knowledge about HIV and AIDS was demonstrated to be inadequate by Peterson in 1991. In a random sample of members of the National Association of Social Workers (NASW), Peterson (1991) found that respondents were unable to correctly answer just over half (538) of the questions about AIDS. In addition, it was found that social workers who identified themselves as direct service providers had significantly more "don't know" responses than those who identified themselves as supervisors or administrators. There is other supporting evidence that social workers' knowledge about HIV and AIDS is limited (Dhooper, Royse \& Tran, 1987-88; Wexler, 1989). High levels of fear about HIV and AIDS was reported by 678 of the respondents in a survey by Dhooper et al. (1987-88). The information obtained by this study will be helpful for the education and training of social workers in the area of clinical practice with HIV infected individuals. It will also increase the knowledge base in the area of concrete service delivery and social policy. This increase in the knowledge base may be important in the education and training of social work students.

$\underline{\text { Research }}$

Certainly the body of knowledge about HIV infection and AIDS has increased dramatically over the past decade. New 
discoveries are being made in the areas of medical treatment, prevention, education and mental health (American Foundation for AIDS Research, 1992). Among these areas, mental health has been perhaps the slowest in the development of new knowledge, perhaps due in part to the difficulty and expense involved in intervention research (cf. DiPasquale, 1990; Ussher, 1990). Clearly it is important to develop correlational knowledge before moving to more costly outcome research. It is important to develop correlational knowledge to guide outcome research due to limits in funding for research. This survey will provide valuable information about relationships between access to medical care and depression, satisfaction with life and self-efficacy. This information can lead to outcome studies that evaluate causal relationships between these variables. This information may play a key role in the development and evaluation of social policy changes that are needed as the incidence of HIV infection increases and a national health care plan is debated. This study addresses two areas of social work focus at one time, namely policy and practice. It increases understanding about how social policies, such as Medicare and Medicaid as well as other services, correlate with psychosocial difficulties in the HIV infected population.

This survey may also provide information for empirical clinical practice. The information may be helpful in the 
development of assessment measures for clinical practice. There is a growing trend in the field of social work practice towards greater accountability and empirical practice (Penka \& Kirk, 1991). This trend is supported by numerous social work educators (cf. Harrison, Hudson \& Thyer, 1992; Ivanoff, Blythe \& Briar, 1987). By providing correlational knowledge about the relationships between psychosocial difficulties and social policy, this survey may lead to the development of assessment tools that can be incorporated into empirical clinical practice.

\section{Practice}

The practice of social work can occur on many different levels. Social policy is perhaps one of the most important of these levels. Social work's tradition is to assist and aid in social action as well as policy development so as to help and protect the rights of clients (Reamer, 1993). In fact, change in social policy may be the most efficient means of effecting change for large groups of individuals. Changes in social policy can arise from social action.

Reamer (1993) states that social workers have frequent contact with populations that have a disproportionately high rate of HIV infection. Furthermore, he argues that social workers have an obligation to be aware of the ethical and civil liberties issues that affect this population and that social work practitioners' familiarity with these issues can enhance the quality of services provided to these clients. 
Certainly, access to medical care plays a key role in the ethical care of HIV infected individuals. The results of this study will provide information that is sorely needed by social work practitioners and may enhance the quality of service to this population.

Since social workers are currently working with HIV infected individuals and will continue to do so into the future, the knowledge produced by this study may increase the effectiveness of interventions with HIV infected clients. Although correlational knowledge does not equate to causal knowledge, it does provide the basis for estimating risk probabilities. More specifically, the knowledge obtained in this survey may assist social work practitioners in evaluating the risk of serious mental health problems associated with lack of concrete services and medical care across all stages of HIV infection. It may also provide markers which could indicate the need for further evaluation in the assessment of HIV infected individuals and their families. Assessment is an important component of clinical practice. Social workers are employed by all major hospitals in the United States and, as a result, are also involved in the treatment and case management of individuals who are hospitalized. As the number of AIDS cases grows, more and more of these individuals will be HIV infected. Certainly the data gathered in this study will be helpful for this population. 
It not only provides information about the incidence of depression, life satisfaction and self-efficacy across stages of HIV infection, but also demonstrates relationships between these variables and access to medical care.

Subsequent chapters will provide a thorough literature review and the methodology for the study. Results and implications for practice, education and research will also be addressed. 


\section{LITERATURE REVIEW}

In order to fully understand the implications for the proposed research, it is important to understand what is currently known about HIV. This includes, but is not limited to, medical and psychological information that is not specifically of interest in this investigation, but rather lays the foundation of what is known and provides a direction for future research. A definition of HIV, the manner in which the immune system functions, the impact of HIV on the immune system and current medical treatments are provided in Appendix A. This medical information is of importance because it provides the basis on which measurements for this survey were chosen. More specifically, affective measures of the psychosocial variables were chosen in order to eliminate the potential for confounded results. This is due to the fact that the medical components of HIV infection and the medications that are prescribed to treat it are similar in some respects the psychosocial variables measured in this study.

\section{Epidemiology}

\section{Current Incidence}

By July of 1993 the Centers for Disease Control had received reports of 315,390 cases in the United States and its related territories (1993a). These are the most recent data currently available and represents the cumulative total 
number of cases reported to the Centers for Disease Control. This number is nearly equal to the 359,271 cases reported world wide as of 1991, only 2 years earlier (World Health Organization, 1991). Of these reported cases, 273,990 were men, 36,690 were women and 4,710 were children under 13 years of age. Most men with AIDS have been white nonHispanic $(151,446)$, but most women $(19,544)$ and children $(2,574)$ with AIDS are reported to be black, non-Hispanic (Centers for Disease Control, 1993a). Although most of the reported cases of AIDS have been between the ages of 20 and 44, a substantial number of cases have been reported in the 20- to 24-year old $(11,840)$ and 13- to 19-year old ranges (1,301). Between July of 1992 and June of 1993, California reported the largest numbers of AIDS cases $(15,402)$ of all the states, but the District of Columbia had the highest reported rate per 100,000 population (183.6) (Centers for Disease Control, 1993a).

Note that these numbers, although the most current available today, do not accurately represent the number of AIDS cases or the prevalence of HIV infection. According to the Centers for Disease Control (1993a), reporting delays vary widely among the categories of exposure, geographic region, racial and ethnic and age. Unfortunately, the Centers for Disease Control does not report exactly which groups among each of these categories is most likely to be underrepresented. They do state that almost $55 \%$ of all 
cases are reported within the first 3 months following diagnosis, but that as many as $20 \%$ are reported over a year after diagnosis (Centers for Disease Control, 1993a). Moreover, the Centers for Disease Control does not provide an estimate of the number of cases that go unreported.

In these reports, only individuals who were diagnosed with AIDS are included. Many individuals die before ever meeting this criteria. The Centers for Disease Control criteria for diagnosis of AIDS has in fact, been changed three times, in 1985, 1987 and again in 1993.

In short, it is not possible to report an accurate number of people who are infected with the AIDS virus. Although the Centers for Disease Control and the World Health Organization (WHO) keep records of the numbers of AIDS cases, there is no systematic collection of incidence of HIV infection. Therefore, it is necessary to limit the discussion of incidence to known cases of full blown AIDS. This is clearly an underestimate of the numbers of people affected for three important reasons. First, most individuals remain asymptomatic for a long period of time after contracting the virus. Second, there is a large number of individuals who do not have access to medical care and are not be diagnosed. Therefore, these individuals are not included in these reports. Third, the definition of AIDS has historically been exclusionary of the diseases that women with HIV infection typically contract. The current 
definition includes all individuals who test positive for the HIV virus and have had an opportunistic infection or a T-cell count of less than 200 (Centers for Disease Control, 1993a). Since this definition is new, thousands of women have been excluded from earlier reports. In addition, many individuals begin to contract opportunistic infections long before their T-cells drop below 200, and only one of the infections that is common to women, invasive cervical cancer, are now included in the Centers for Disease Control case definition of the syndrome.

This change in the definition of AIDS creates several problems in understanding both incidence and trends. First, it is difficult to accurately discuss transmission trends when the definition has been changed. Second, many doctors are confused about the new definition and continue to classify cases by the older definition, leading to inaccuracy in the current incidence reports.

In terms of social welfare policy, it is particularly significant to note that large numbers of women were excluded from the previous definition of AIDS (Lloyd, 1990). Hence, these women were routinely and systematically excluded from the receipt of social security benefits such as disability and SSI. They were also denied access to Medicare and Medicaid respectively. In addition, these women were denied certain drug treatments that were approved only for patients with AIDS. This clearly presents a 
serious social problem for the nation. Transmission Trends

Although AIDS was initially believed to affect only homosexual men, it was soon discovered that the virus crosses sexual orientation, gender and race (Lloyd, 1990). Prevalence among IV drug abusers is at an all time high in the United States (Centers for Disease Control, 1993a). In addition, the rate of transmission of the virus is increasing rapidly among young adults (18-24 year olds), women and the poor (Politzer \& Davis, 1992).

Within inner cities, where IV substance abuse is high, the incidence of transmission in minorities is increasing at an alarming rate (Politzer \& Davis, 1992). In a study of the monthly incidence of AIDS, Politzer and Davis (1992) produced means across race and risk factors and found no systematic autocorrelation. This study also found that blacks had the single highest monthly incidence of HIV, that behavior change in the homosexual community has led to a decrease in the rate of transmission via homosexual intercourse and that IV drug abusers (IVDA) are forecasted to predominate the transmission trends across all races in upcoming years.

The rate of transmission of $\mathrm{HIV}$ in women is increasing at an alarming rate, perhaps because there are more HIV infected men than women and more women are infected by heterosexual intercourse than men, particularly with respect 
to the partners of IV drug abusers (Politzer \& Davis, 1992; Stuntzner-Gibson, 1991). According to Stuntzner-Gibson in 1991, most HIV literature and research has ignored women. HIV positive women get ill and die more quickly and are typically poorer than HIV positive men. It has even been suggested that HIV may be a fundamentally different disease in women. Most HIV positive women are poor, uneducated and of color (black and hispanic) (Stuntzner-Gibson, 1991) and women are one of the largest growing HIV populations (Politzer \& Davis, 1992). Health Care System

The effects of the HIV epidemic are perhaps most readily apparent in the health care system (Lloyd, 1990). Clearly the financial cost of providing medical treatment to HIV infected individuals and persons with AIDS is enormous, especially in light of the most recent incidence reports. The lifetime cost of medical treatment for a patient with AIDS has been estimated by several authors and ranges from $\$ 19,400$ to $\$ 147,000$, depending on who did the research and when and where it was done (Scitovsky, 1989). Although there seems to be agreement that the HIV infected individual is better off at home than in an institution if their medical condition does not require hospitalization (Sheridan et al., 1990), for most victims of AIDS hospitalization will eventually be required.

The cost of treatment is a particularly important issue 
for HIV infected individuals. They are typically in the most productive years of their lives and have a high probability of losing their jobs due to prejudice or disability (Lloyd, 1990). If unemployment occurs for any reason, most individuals lose theix insurance coverage. Even if the individual procures social security disability, Medicare does not go into effect until 29 months from the qualifying date, resulting in a period of 2 years without insurance coverage. It is inconceivable to think that most persons could afford the cost of ongoing medical care, let alone hospitalization, without insurance coverage. On the other hand, insurance companies will have difficulty if they insure many AIDS patients. It has been suggested that the financial impact on most commercial insurers nationwide has not yet become pronounced (Ozawa et al., 1993). Unfortunately, medical costs are not the only costs created by AIDS. The overall financial impact of AIDS also includes the cost of cash assistance to AIDS patients, research, education and prevention (Ozawa et al., 1993).

Direct costs of treatment represent one factor impacting the health care system. The system is also affected by health care providers' fears of infection and attitudes towards the infected. This is a perplexing dilemma because fears of infection are not based in fact, the AIDS virus is more difficult to contract than many other potentially fatal diseases, such as hepatitis $B$ and 
tuberculosis which are not associated with extreme fear. Health care provider's fears are probably due to the stigma associated with AIDS that does not allow for the usual associations with the medical model of the sick role wherein people are not responsible for being ill. McDonell (1993) argues that the attribution of responsibility toward HIV infected people is inherently discriminatory and in conflict with social work values. He also argues that HIV infected individuals affect all levels of social work practice. Fortunately, change in.the attitudes of health care workers towards HIV infected individuals is possible.

Educational programs about HIV have been shown to have a positive effect on the attitudes of health care service providers about HIV infected and AIDS clients (Riley \& Greene, 1993). It is important to note that the researchers found that educational programs that did not contain information about the psychosocial needs of the HIV infected or AIDS client did not have as great of a positive effect on the attitudes of the health care providers. In other words, programs that contained information about the psychosocial needs of HIV infected clients reduced fear substantially more than programs that did not contain psychosocial information. This may lead to the conclusion that psychosocial information about HIV infected individuals is important in educational programs for health care providers. 
It may also play a significant role in the formation of social policy.

Social Policy

Perhaps the most important of all social policies that relates to AIDS is the Ryan white Comprehensive AIDS Resources Emergency (CARE) Act. This Act became the first AIDS care law in the United States in August 1990 (United States Conference of Mayors, 1990). This legislation attempted to formulate a means by which the federal government, in conjunction with state and local governments, would finance services for persons with AIDS and HIV infection. The Act provided for emergency assistance to metropolitan areas with large HIV infected populations and support for states to finance care related and early intervention programs. In addition, the Act set research priorities, notification guidelines and demonstration grants for pediatric AIDS (United States Conference of Mayors, 1990). It was hoped that this Act would play a key role in the administration of health care and research grants in the future, as well as in the delivery of social services to HIV positive and AIDS patients.

Concrete social services are needed by HIV infected individuals (Lloyd, 1990). They would include, but are not limited to, assistance in procuring social security disability, subsidized housing, medical insurance, Medicare or Medicaid and food stamps or meals on wheels. These 
services are needed due to the debilitating nature of the disease and loss of capacity to perform activities of daily living. From a social work perspective, these services are fundamental and need to be addressed before psychological components such as depression and anxiety. Maslow's (1970) Hierarchy of Needs supports this assumption. According to Maslow's theory, individuals must first meet primary needs such as food and shelter before emotional needs. If basic needs such as food and safely are not met, then emotional well being is not possible.

There are social policies that are limiting the capacity of persons with AIDS to meet the most basic of needs (Ozawa et al., 1993). For example, individuals cannot qualify for food stamps until their income and assets are below the poverty level. Ozawa et al. (1993) further stated that Medicare does not go into effect for patients diagnosed with AIDS until 29 months after initial entitlement to social security disability insurance. These policies make it more difficult for PWAs to get food and medical care once they are disabled or unemployed.

Social policy also plays a direct role in the prevention of HIV infection. Although the incidence of HIV infection is spreading rapidly in the IV substance abusing population it is unlikely that syringes will become legally available without a prescription (Feldman \& Biernacki, 1988). According to Feldman and Biernacki, clean needles 
and education might be able to decrease the spread of HIV in the IVDA population, but getting funding for this type of research is difficult at best.

The Ryan white CARE Act (1990) has resulted in a social policy on providing clean needles, such that it is illegal for any agency receiving Ryan white funds to provide clean needles. Kelly (1987) argues that developing social policies about devoting tax dollars to support activities that are illegal is an ethical debate. Furthermore, Kelly argues that social workers should be involved in the development of social policies regarding PWAs so as to protect the rights of these individuals.

Social workers also need to be involved in the developing of social policies that discourage discrimination associated with HIV (Lloyd, 1990). Social policies that prohibit discrimination can help HIV positive individuals who have been barred from schools, employment, housing and medical insurance. Unfortunately, there are only a few states that impose restrictions on screening prospective clients with the HIV antibody test before selling insurance (Faden \& Kass, 1988). Discrimination keeps HIV infected individuals from medical, dental and life insurance. It also keeps them out of certain jobs and reduces their access to travel, such as entering the United States. 
Psychological Components

Although the stigma, helplessness and hopelessness associated with an HIV positive diagnosis have already been addressed (Lloyd, 1990), there are a number of other problems that may exist. The fact that the virus occurs most often in those who are young and at a productive stage of their life is problem proposed by Lloyd (1990). Clearly there are social implications for the disability of the those in their productive years just as there are financial ones.

Other social problems are also a typical result of HIV infection. Theories suggest that social isolation and loss of social support are consequences of HIV infection (Cohen, 1990; Lloyd, 1990) and the empirical literature supports this (Donlou, Wolcott, Gottlieb \& Landsverk, 1985). Evidence of the significance of social support can also be found in the literature.

The relationship between social support and other emotional components of HIV infection has been investigated. Nicholson and Long (1990) evaluated the relationship between social support, coping strategies, self-esteem and internalized homophobia. They found that homophobia, selfesteem and time since diagnosis were predictive of coping styles. It was reported that over $90 \%$ of the homosexual men in the United Kingdom have access to some type of social support (Hart, Fitzpatrick, McLean, Dawson \& Boulton, 1990). 
Unfortunately, this type of investigation has not been carried out in the United States to date.

Loss of social support has been noted in the treatment literature as a presenting problem as well (Brody, 1989, Triggs \& McDermott, 1991). Treatment articles focusing on family therapy (Ackerman, 1989; Sholevar \& Perkel, 1990) suggested that the family, the most traditional social support, may be important in coping with HIV infection and AIDS. Ussher's (1990) study on couples therapy implied that social support from a partner may also be important. DiPasquale (1990) evaluated support groups in the treatment of HIV infection and found them to be effective as a means of supplementing social support.

Grieving issues are one of the often theoretically suggested problems in HIV (Beckham, 1988; Carballo-Dieguez, 1989; Cohen, 1990; Gambe \& Getzel, 1989; Lloyd, 1990). In fact, grieving has been suggested to be a problem as often as depression in the theoretical literature. Unfortunately, there is no empirical evidence that grieving is one of the more important issues in HIV. The treatment literature does report its existence, although only through a case study (Brody, 1989).

Anger has also been suggested as a particularly important component for HIV infected individuals (Beckham, 1988; Carballo-Dieuguez, 1989; Cohen, 1990; Lloyd,1990). Since the mode of transmission of $\mathrm{HIV}$ is predominantly 
sexual in pattern 1 countries (i.e. the United States and Eastern Europe), the fact that most HIV infected individuals participated in an act, sexual intercourse or sharing IV needles, that caused the infection is likely to increase the anger in this population. The reasoning behind this assumption is two fold. One, the person that is infected may blame themselves or the other participant. Two, at least within the United States, society has classified two groups of HIV infected individuals, those who deserve it and the blameless victims, specifically children infected by their mothers and recipients of blood before 1985. The fact that large groups of people blame the victims of this disease provides those who are victims with reason to be angry •

Stress is another psychological component of HIV infection. Donlou et al. (1985) reported profound illness related stress in homosexual men. In addition, O'Dowd (1988) focused on stress in a discussion of disease progression and reports that it is a key psychosocial issue. The treatment literature provides further evidence that this psychological component exists within this population. In a report on the Gay Men's Health Crisis (GMHC) model for intervention, stress reduction training played a key role (Katoff \& Dunne, 1988). Crisis intervention services, case management and mental health groups were also offered. Group stress reduction training was also examined as a means 
by which to reduce unsafe sexual practices and improve immune system functioning in HIV positive men (Coates, McKusick, Kuno \& Sites, 1989). It was found to be effective in reducing the number of sexual partners of participants, but did not effect immune functioning. Orgero and Rodway (1991) provided further evidence that stress is a psychological component of AIDS. Stress and anxiety are conceptually related components and anxiety has also been noted in the literature.

In a longitudinal survey of 56 gay men, Huggins et al. (1991) found that there was a significant decrease in anxiety in all groups (22 HIV positive; $22 \mathrm{HIV}$ negative; 12 did not learn). However, there was also a significant difference in the amount of change in anxiety after the results between positives and negatives with negatives having a much larger reduction in stress. The decrease in stress over time has also been noted by Rabkin et al. (1991) despite a decrease in health status. Their longitudinal survey, (pretest and at 6 months) also found a significant association between psychosocial distress and HIV related symptoms (by clinician ratings only, not self report). These findings suggest that stress may decrease over time in HIV infected individuals with or with out treatment.

Psychological problems that have been theoretically suggested to result from HIV infection are fear (Cohen, 1990); loss of social support, (Cohen, 1990; Lloyd, 1990); 
stress and anxiety, (Carballo-Dieguez, 1998; Cohen, 1990; Lloyd, 1990), anger, (Beckham, 1988; Carballo-Dieguez, 1998; Cohen, 1990; Lloyd, 1990) grieving issues and depression, (Beckham, 1988; Carballo-Dieguez, 1998; Cohen, 1990; Gambe \& Getzle, 1989; Lloyd, 1990). Although depression is the most noted psychological problem in the theoretical literature, stress has been better documented in the empirical literature. Stress has been noted in several surveys of HIV infected gay men (Donlou et al., 1985; Huggins et al., 1991). Depression has also been found (Huggins et al., 1991).

\section{Treatment Literature}

Depression, illness related stress and social isolation have been found to exist in HIV positive homosexual men (Donlou et al., 1985). Since these psychological problems appear to be prominent in the HIV positive population, it is important to review existing treatments with this population as well as to investigate models of intervention that can alleviate these problems. A review of all existing empirical treatment literature uncovered several different models of intervention. These models include: existential/behavioral therapy, electroconvulsive therapy, chemotherapy, family therapy and cognitive-behavioral therapy. Poor research methodology was found in almost all of these studies. 
In evaluating the outcome research on the treatment of the psychological sequelae of HIV infection, many of the investigations were lacking in research methodology. Brody (1989) detailed a case description of a white woman partner of an IVDA whom he treated for over 2 years and did not define the treatment. He does report the woman had depression, grieving issues, rage and an inability to tolerate or reduce short term stress. Other case studies provide additional information about the treatment of the psychological components of HIV infection.

In fact, most of the treatment literature in this area consists of case studies. Triggs and McDermott (1991) reported that short term existential/behavioral therapy was a success in treating a gay man at a university clinic. The objectives of this approach were to reduce stress and anxiety; increase control of thoughts and feelings; and enhance the quality of life. Success was described as the patient feeling more stabilized and utilizing behavioral contracts for stress management. As with all case studies, there were no standardized measures or clear operational definitions of objectives, treatment or outcome. Multiple case studies have been employed in other treatment literature.

In evaluating the effectiveness of electroconvulsive therapy (ECT) with HIV positive patients who had depression that was previously treated unsuccessfully, Schaerf, Miller, 
Lipsey and McPhearson (1989) reported four case studies. They evaluated right unilateral ECT and reported success for all four patients with no side effects. They did a followup at 21 months and found that three had no relapse of depression. One participant had died at 4 months post treatment with no relapse. Fernandez, Levy and Galizzi (1988) also detailed four case reports. They evaluated the psychostimulant methylphenidate in the treatment of four HIV positive men with depression and decreased cognitive ability. They reported success for all four and no side effects for three. One participant had dyskinesia prior which got worse with the medication so they lowered his dose. They also reported improvement of cognitive function as well as a decrease in depression in 1 day not 2 to 3 weeks like antidepressants. Although these reports are better in that it is clear what the treatment was, they still lack internal and external validity due to the research methodology employed. Systems interventions have also been reported to be effective in a case study.

Ackerman (1989) reported that Bowen's multigenerational family therapy was successful in treating a 35 year old gay man with HIV. It should be noted that he provided family therapy in an individual modality. He found that the patient had improved coping skills. Specifically, the patient had a better relationship with his family, increased ability to view himself and others accurately and decreased 
reactivity. Unfortunately, none of these goals were measured or defined. Other means of improving coping skills have also been evaluated.

Orgero and Rodway (1987) employed 7 single-subject ABA designs to study the effectiveness of the Human Social Functioning Method. The Heimler scale of social functioning was the only standardized measurement. Orgero and Rodway incorporated both visual and statistical analysis. They only reported the data of 4 cases however and evaluated the effectiveness of treatment with different statistical procedures for each subject (proportion frequency approach, Shewart chart statistic, celeration line approach). In addition, they did not report exactly what was better. The graphed data show only the coping index of the Heimler scale. The length of the phases were not equal and, although they reported no autocorrelation, there were only three points in the baseline. Busk and Marascuilo (1987) state that many more observations are needed in order for autocorrelation statistics to have sufficient power to evaluate autocorrelation accurately. Replication of results was not achieved because each subject had different trends and responses to treatment. Positive change was also slow. These limitations cast doubt on the conclusion that the treatment was effective for HIV positive patients. Although the external validity of this study was low, group designs 
which are more generalizable, have also been utilized in the treatment literature.

DiPasquale (1990) measured the effectiveness of support group therapy with 3 groups (men with AIDS; men with AIDS or ARC; minority women with AIDS or ARC). The state Trait Anxiety Inventory (STAI) and Hopelessness Scale (HS) were employed in a pretest-posttest design. Following the 5 week treatment, none of the groups had significantly different STAI scores and groups of men did not have significantly different HS scores. The group of minority women had a significant decrease in HS at posttest. Although DiPasquale reported that 548 of the 32 subjects had improvement on either the STAI or the HS, the minority women had better results. There was no control group in this study and therefore the threat of history is strong. Nonetheless, the study had reliable and valid measures. Couples therapy has also been investigated as a treatment for HIV infected individuals.

Ussher (1990) evaluated Beck's cognitive therapy with ten male gay couples in which one partner had been referred for therapy for reasons such as anxiety, phobia, depression and substance abuse. This study employed a pretest-posttest design. Treatment lasted for 10 weeks and t-test results indicated that there was a significant increase in relationship satisfaction $(p=.001)$. Also nine of the ten couples in the study reported that the problem that one of 
them had been referred for was resolved. The substance abuser was the only one that did not resolve the initial problem. Unfortunately, a visual analog of relationship satisfaction was the only measure. This measure did not have demonstrated reliability or validity. Ussher (1990) justified his reliance on only this instrument by stating that measures of relationship satisfaction are hetero biased. While this was a good point, a measure without demonstrated reliability weakens the validity of the conclusion. There was no control group so history is a threat. In addition, in the one case that Ussher detailed treatment was provided to the individual for 3 weeks followed with a couple modality for 7 weeks. This raises the question of whether or not other parts of the study were not performed exactly as reported. Cognitive-behavioral models of treatment have also been investigated.

Antoni et al. (1991) randomly assigned 47 gay men to either a control group or cognitive-behavioral stress management group (CBSM). The measures included; the state Trait Anxiety Inventory (STAI), Profile of Mood States (POMS), Life Experiences Survey (LES), sleep, sex and physical activity behaviors and multiple measure of immune status. Repeated measures split plot analysis of variance (ANOVA) analyzed the results. Treatment was 2 times a week for 10 weeks. After 5 weeks of treatment, measurement was taken and the participants were notified of their serostatus 
3 days later. Measurement occurred again 1 week post notification. Although there were no differences in the pretest, all HIV positives had significant increases in depression post notification. The CBSM group had less than half the increase of controls. There was no significant effect on anxiety. The CBSM therapy included information about HIV, cognitive restructuring, behavior change strategies, assertiveness skills and progressive relaxation and imagery. Although the times of measurement were unusual, this study had a control group and multiple measures. Data analysis was performed with repeated measures split plot ANOVA and the treatment was clearly defined. Derivations of cognitive-behavioral models, such as stress prevention training have also been investigated. Perry, Fishman, Jacobsberg, Young and Frances (1991) randomly assigned 307 (103 HIV positive, 204 HIV negative) individuals to one of three treatment conditions. Standard counseling, standard counseling and stress prevention training and standard counseling and an interactive video program were evaluated. The Beck Depression Inventory (BDI), STAI and the Hamilton measured anxiety and depression. Analysis was performed with multiple analysis of variance (MANOVA), repeated measures MANOVAs and chi square (for the categorical variables). Measurements were taken at pretest and 6 months later. They found different treatment effects based on HIV infection. Participants who 
were HIV negative had no treatment effects where as participants who were HIV positive were effected by treatment. The best treatment outcomes were from standard counseling plus stress prevention training. HIV positives in the stress prevention training program had a decrease in trait anxiety, decrease in reported HIV symptoms and a decrease in the cognitive items on the BDI, not the somatic items. The finding appears logical because of the nature of HIV and the physical symptoms that occur with it. The stress prevention training program had four main components: information about AIDS and HIV; enhancement of belief in personal control and perceived self-effectiveness; training to identify and correct dysfunctional thoughts; and training to better manage negative situations. The training included problem solving, behavior change strategies, assertiveness skills and progressive relaxation. In the study there was a relatively large sample size, random assignment, reliable and valid measurements, a control group of sorts and appropriate statistical analysis (i.e. ANOVA). These factors increased the strength of the findings of the study. of those studies in which the treatment methods were shown to be effective (cf. Antoni et al., 1991; Perry et al., 1991), one major problem associated with the findings was that subjects treated were individuals who were tested and told the results during the study. It has been shown that anxiety decreases over time in HIV positive individuals 
(Huggings et al., 1991; Rabkin et al., 1991). Evaluation of the effectiveness of these treatments later in the disease process is indicated for future research. The treatment modality employed for the delivery of services may also be important in future research.

Support groups are perhaps the most common treatment modality for HIV infected individuals (cf. Antoni et al., 1991; DiPasquale, 1990; Katoff \& Dunne, 1988). This is due to the large number of clients that utilize agencies based on the Gay Men's Health Crisis model. These agencies are typically found in large metropolitan areas within the United States and serve thousands of individuals. The model for treatment is based on a support group facilitated by volunteers (Katoff \& Dunne, 1988). This treatment appears to be effective in reducing social isolation. DiPasquale (1990) reported that support groups are effective in decreasing anxiety and hopelessness in AIDS patents. Although there were only 22 subjects in three groups in a quasi-experimental design, her study provided evidence that warrants further investigation. Ussher (1990) proposed that it is important to treat couples with HIV infection. In addition, he reported in a pilot study that a cognitivebehavioral approach may be effective and warrants further research.

In sum, the treatment literature provides additional evidence of the psychological problems that exist in a HIV 
infected population. Furthermore, the treatment literature indicates that cognitive-behavioral interventions have been found to be effective in alleviating some of these psychological problems (Antoni et al., 1991; Perry et al., 1991; Ussher, 1990). A group modality for the treatment of these problems is not only cost effective but also partially supported by existing treatment literature (Antoni et al., 1991; Dipasquale, 1990).

\section{Proposed Variables for Evaluation}

Unfortunately, there is little empirical literature that documents the incidence, scope, or severity of depression in this population. There are, however, several articles in the literature that discuss the treatment of depression in HIV infected individuals (Hintz, Kuck, Peterkin \& Volk, 1990; Schaerf et al., 1989; White, Christensen \& Singer, 1992). These studies are not generalizable to all HIV infected individuals, however, they represent additional evidence that depression exists within this population. There is little empirical literature currently available on depression and satisfaction with life and there is no literature on self-efficacy in HIV infected populations. There is however, preliminary evidence that supports the inclusion of the dependent variables that are proposed in this survey (Beckham, 1988; Carballo-Dieguez, 1989; Catalan, Klimes, Bond, Day, Garrod \& Rizza, 1992; Cohen, 1990; Donlou et al., 1985; Gambel \& Getzle, 1989; 
Green, 1989; Hintz et al., 1990; Huggins et al., 1991; Lloyd, 1990; Nicholson \& Long, 1990; Sadovsky, 1991; Shaw, 1985; Schaerf et al., 1989; White et al., 1992). Because the current literature is limited in scope and the potential benefit of this information is large, it is of vital importance to determine the nature and scope of depression, satisfaction with life and self-efficacy in HIV infected individuals. Specific attention will now be paid to each of the proposed variables. Depression

For the purpose of this study, depression is defined as an emotion characterized by sadness, discouragement, despair and hopelessness about the future. Depression has been theoretically suggested as a component of HIV infection by numerous authors (Beckham, 1988; Carballo-Dieguez, 1989; Cohen, 1990; Gambel \& Getzle, 1989; Lloyd, 1990). It has also been documented empirically to a lesser degree in the HIV positive population, both in homosexual men and men with hemophilia (Catalan et al., 1992; Donlou et al., 1985; Huggins et al., 1991).

In a pilot study of the psychosocial aspects of HIV and AIDS in homosexual and bisexual men, marked mood disturbance (ie depression) and low self-esteem as well as other psychological problems were found (Donlou et al., 1985). Although this evaluation only included 21 subjects and is 
quite limited in scope, it is one of the few empirical studies on the psychological components of HIV infection. Nicholson and Long (1990) found that lower levels of selfesteem were negatively associated with worsened mood states in a study of $89 \mathrm{HIV}$ positive homosexual men. In a study that evaluated the psychosocial impact of HIV infection with hemophiliacs, HIV infected individuals were found to have significantly higher levels of hopelessness than those who were HIV negative. In addition, individuals with symptoms had higher depression scores than asymptomatics (Catalan et al., 1992). Significant differences in levels of depression were also found by Huggins et al. (1991). Although the overall sample size of this study was higher than others $(\mathrm{N}=56)$, the comparison was made between only $22 \mathrm{HIV}$ positive and $22 \mathrm{HIV}$ negative individuals. Again, this study supports the inclusion of depression as a psychological component of HIV infection but is of limited external validity and therefore not generalizable to all HIV infected individuals. Shaw (1985) argues that the study of individuals who may be at risk for depression deserves careful attention.

There are also several articles in the literature that discuss the treatment of depression in HIV infected individuals. Major depression within this population has been successfully treated with ECT (Schaerf et al., 1989), as well as antidepressant medication (Hintz et al., 1990; White et al., 1992). Although these studies are not 
generalizable to all HIV infected individuals, they represent evidence that depression exists within this population. In a comprehensive review of the literature, Cohen (1990) notes that AIDS patients are overwhelmed and suffer from depression.

Depression may be accompanied by several behavioral disturbances such as sleep disturbance, reduced energy and fatigue. In fact, Beck (1976) argues that depression is not solely an affective disorder and that the physical symptoms and distortions in thinking cannot be attributed to affect alone. The physical symptoms of depression however, are similar to the physical symptoms of HIV infection as well as the side effects of various anti-viral drugs for the treatment of HIV (see Appendix A).

More specifically, the most current treatments (AZT, Ddi, Ddc) employed to slow the progression of the disease have serious side effects. These side effects are similar in nature to the physical symptoms of depression. Nausea and weakness or lack of energy are relatively common side effects. Loss of appetite and interest in the normal activities of life are common symptoms of depression.

Since it is not possible to determine the cause of the physical symptoms, they must be excluded from this construct in this study. If these symptoms were included in the operational definition of depression for this survey, it would be impossible to know whether or not these were a 
result of HIV disease, medication or depression itself. This would result in a confound that would be impossible to unravel in post hoc analysis. To date, none of the empirical literature has addressed this confound. Therefore, it is of critical importance to ensure that the measure of depression is not confounded with these physical symptoms. It is not currently known whether or not all HIV infected individuals are depressed.

Satisfaction with Life

A diagnosis of HIV infection often creates a variety of psychological symptoms that are severe and interfere with the satisfaction with life (Green, 1989; Sadovsky, 1991). Satisfaction with life is defined as a construct that describes an individual's perception about the emotional, physical and social components of their life. It may be viewed as an overall effect of numerous psychosocial components. In a sense, this construct may be the most important from a clinical standpoint as well as from the client's perspective. The inclusion of the social component of this definition is supported by the work of Baker, Curbow and Wingard (1991) who found that maintenance of social roles was significantly related to higher levels of life satisfaction and lower levels of negative mood.

Carlson and Videka-Sherman (1990) found that satisfaction with family life was the best predictor of overall life satisfaction for men and women of all ages. 
This may be an important finding for HIV infected individuals in light of the fact that many are isolated from their families (Lloyd, 1990). Krause (1990) found that perceived health problems had a deleterious effect on life satisfaction and that support from formal sources reduced the effects on changes in life satisfaction. Health and well being, the physical component of the construct, is further supported by Holahan (1988). These findings are important in any physically ill population. Wood and Johnson (1989) evaluated life satisfaction by comparison of satisfaction with housing, family, spouse, self-esteem, health and friends. They also evaluated loneliness, social activities and social relationships as other components of life satisfaction. An evaluation of all of these factors is not within the scope of this survey.

Therefore this construct will be limited to an individual's perception of their life satisfaction. This is due to the fact that all individuals value the components of this construct differently. In other words, one individual may value a life free of pain more than any other component while another may value independence more than anything else. Sadovsky (1991) supports the definition of this construct. Since, the scope of this study does not permit an analysis of all possible components, nor would it be accurate to weight the components in the same way for all subjects, perceived life satisfaction will be evaluated. 
It is proposed that the individual's perceived life satisfaction is the key variable rather than an artificially weighted conglomeration of various components. High satisfaction with life is proposed to be positively correlated with access to medical care and self-efficacy. Conceptually, it is negatively correlated with depression. There is some evidence to suggest that satisfaction with life may interact with some of the precedent variables in this survey. Carlson and Videka-Sherman (1990) found that life satisfaction changed little for whites across age but increased for Blacks with age. Race and sex role identity, but not gender, interacted with age to predict life satisfaction (Carlson \& Videka-Sherman, 1990). Self-Efficacy

The construct of self-efficacy is defined as an individual's perceived ability to accomplish a given task. This definition is in accordance with Bandura (1977) who is perhaps the most cited author on this topic. It relates to an individual's perception of self and his or her perceived relationship with the world around him or her but is different than outcome expectations (Bandura, 1977). Higher levels of self-efficacy are indicative of a perceived ability to positively effect the surrounding world or competency in achieving what is desired. It is included because it specifically relates to perceived access to medical care and access to experimental treatments. 
Self-efficacy may even play a role in outcome. Murphy (1984) found that self-efficacy buffered the effects of stress on illness in a study of the effects of a natural disaster. Campbell \& Hackett (1986) found that selfefficacy decreased with failure at a task and increased with task success. Although this is expected from self-efficacy theory, it may also apply to the acquisition of medical care for HIV infected individuals. Since it has been documented that HIV positive individuals are denied insurance coverage (Ozawa et al., 1993), the failure to obtain it may decrease self-efficacy with respect to access to medical care.

Belief in personal control has been thought to be adaptive in populations with health problems (Taylor, Hellgeson, Reed \& Skokan, 1991) however, it has also been found that women and people with good prognosis profit more form feelings of control, men and people with poorer prognosis do not (Taylor et al., 1991). Their study included 47 subjects with cardiac disease, 78 breast cancer patients, 25 AIDS patients and 55 male and female cancer patients with varying prognosis.

It is proposed that this variable will be positively correlated with perceived access to medical care as well as access to the latest experimental treatments. It is also proposed that self-efficacy will be negatively correlated with depression. Although there is no empirical evidence to date to document levels of self-efficacy in the HIV positive 
population, it is believed to be a key variable and therefore worthy of inclusion.

\section{Sexual Orientation}

Sexual orientation is defined as a construct describing the relationship between the gender of an individual and the gender of the person to whom that individual is attracted. Heterosexual, homosexual, bisexual and other are the four possible categories. Although there is a great deal of literature about homosexual men with HIV infection, there is no literature that evaluates this variable with respect to HIV infection and psychological components of HIV or access to medical services, nor is there any literature to report whether or not the psychological components of HIV infection are different with respect to this variable. Since there are differences in the culture of individuals with respect to their sexual orientation, it seems that this may be an important variable with respect to intervention for HIV infected individuals. There is no reason to assume that heterosexuals and homosexuals respond in the same manner to HIV infection. In fact, when considering the concept of grief overload, which has been reported to affect numerous homosexual men due the large number of deaths in their social system, there is reason to believe that there would be differences in both the types of interventions needed and severity of depression across this variable. 


\section{Ethnicity}

Ethnicity is reported to be an important factor in knowledge about HIV infection (Alcalay, Sniderman, Mitchell \& Griffin, 1990; Harrison, Wambach, Byers \& Imershein, 1991; Lewis \& Watters, 1991). It is also reported to be a significant variable with respect to sexual practices (Alonso \& Koreck, 1989) and IV drug abuse (Singer, 1991). It is not currently known how this factor affects the psychological components of HIV infection or whether or not it effects perceived access to medical care. However, available evidence indicates that it may be an important variable in this study.

Race, a component of ethnicity, is becoming an important variable in interventions aimed at reducing risk of HIV infection due to the increasingly large number of minorities infected with the HIV virus. Harrison et al. (1991) found no differences across race in perceived ability to protect oneself from contracting AIDS. Unfortunately, amount of AIDS knowledge has been found to be significantly different by race, with minorities scoring lower than whites in AIDS-related knowledge (Bell, Feraios \& Bryan, 1990; Passannante et al., 1991; Schilling, El-Bassel, Schinke \& Nichols, 1991; Seltzer, 1989; Seltzer \& Smith, 1988). In addition, racial differences have been found in drug abuse and in seroprevalence rates (Brown, Chu, Nemoto \& Ajuluchukwu, 1989; Lewis \& Watters, 1989; Peterson \& 
Bakeman, 1989; Schoenbaum, Hartel, Selwyn \& Klein, 1989; Watters, Cheng \& Lorvick, 1991). This evidence indicates that race may be an important variable in self-efficacy, depression and access to medical care for HIV infected individuals.

Socioeconomic Status

Socioeconomic status will be evaluated in two ways. First, this construct will be measured with the latest edition of the Hollingshead's (1975) index of socioeconomic status. Hollingshead's index has been a standard in the field since the publication of his first work on socioeconomic status (Hollingshead, 1958). His most current index provides a list of levels of socioeconomic status for various occupations and a formula for weighting the occupation and education of each respondent. Data regarding level of education completed and occupation will be gathered, coded and weighted according to the guidelines of Hollingshead's index. In addition, data about an individual's annual income will also be collected. For some individuals, annual income maybe a better predictor of socioeconomic status than any other single variable. Clearly, socioeconomic status plays a role in the availability and utilization of medical services for everyone and therefore for those who are infected with HIV as well (Honig, 1984). Therefore, it will be included in this survey to determine to what extent it correlates with 
severity of depression and perceived self-efficacy in HIV infection.

Access to Health Care

Access to medical care will also be measured in two ways in this study. First, information will be gathered about the respondent's current type of insurance coverage. Secondly, and perhaps more importantly, the participant's perception of access will be assessed. This will include general access, quality of medical services received and access to the latest experimental treatments. There may be a relationship between depression, life satisfaction or self-efficacy and the quality and type of medical care received. Unfortunately, little is known about the relationship between access to medical care and depression, satisfaction with life or self-efficacy for those infected with the HIV virus.

The inclusion of general access and quality of care components is supported by Taylor, Aday and Anderson (1975). They found that nonwhites, rural farm people and the poor had less access than was needed. Their means of measuring access to medical care is not suitable for a survey of this type as it involves documentation of the actual number of visits during a given period of time. It does support the inclusion of the variables of cost of medical care and cost of medicine. The inclusion of the experimental treatment 
component is appropriate because most treatments for HIV and AIDS are considered experimental.

This proposal hypothesizes that this variable will be negatively correlated with depression and positively correlated with satisfaction with life and self-efficacy. Although this variable is proposed to be highly correlated with socioeconomic status, it is not synonymous with it and is of key interest in this study. HIV Status and Stage of Illness

Although there is empirical literature to support classifying this disease into five stages (Lloyd, 1990), it is not possible to effectively identify all of these stages. Therefore, one stage, the infection initial immune response stage, will be excluded. This stage is excluded from this research because the time of infection is rarely known for certain and would for most individuals be, at best, a guess. Only the stages of HIV negative, HIV positive asymptomatic, ARC and AIDS will be utilized. The Centers for Disease Control classification system for ARC and AIDS will be employed, such that if a participant is HIV infected and has ever had an opportunistic infection or currently has less than 200 T-cells, they will be classified as having full blown AIDS. It has been found that the clinical definitions for HIV disease by the World Health Organization (WHO) as well as Caracas, are specific but not sensitive enough for the advanced stages of disease (Gallant et al., 1992). 
Immune system status and with it disease progression are most often monitored by the CD4 T helper cells. The CD4 cell is one of a number of cells that make up the immune system in humans. Individuals with healthy immune systems normally have CD4 cell counts between 800 and $1200 / \mathrm{mm} 3$ (Sheridan et al., 1990). As the virus replicates within the immune system the CD4 cells are destroyed, thus rendering the immune system incapable of fighting off even the most benign of antigens, bacteria or infections. In order to monitor disease progression, $\mathrm{T}$-cell (or $\mathrm{CD} 4$ cell) counts are taken on a regular basis. Unfortunately for most individuals infected with HIV, a drop in T-cell counts can be devastating even if they are feeling well (Sheridan et al., 1990). Although treatment with zidovudine, better known as AZT, can prolong life on average by 18 months (Fischl et al., 1987), it is not yet known if all individuals infected with HIV will eventually become ill. 


\section{CHAPTER III}

\section{RESEARCH QUESTIONS AND METHODOLOGY}

This chapter outlines the research questions that were proposed in this study. It also reports the sampling and recruitment methodology that was employed for data collection. Potential limitations and plans for data analysis are also detailed.

\section{Research Questions}

Due to the lack of empirical literature to determine the incidence and severity of depression, satisfaction with life and self-efficacy in HIV infected individuals, little is known about these variables and their relationships with perceived access to medical care. Since HIV infection is a chronic incurable illness and full blown AIDS a terminal disease, access to medical care is especially important to this population. Therefore, it is the intent of this study to answer a number of research questions.

1) What is the incidence and severity of depression across the sampled population of HIV infected individuals?

2) Does the incidence or severity of depression vary with respect to: illness stage, self-efficacy, life satisfaction, socioeconomic status or access to medical care?

3) What is the average level and scope of life satisfaction for surveyed HIV infected individuals? 
4) Does life satisfaction vary with: illness stage, depression, self-efficacy, socioeconomic status or access to medical care?

5) What is the average amount and scope of self-efficacy in surveyed HIV infected individuals?

6) Does self-efficacy vary with respect to: illness stage, socioeconomic status, depression, life satisfaction or access to medical care?

7) Are there differences in these relationships with respect to the precedent variables of gender, sexual orientation and ethnicity?

\section{Methodology}

Research Design

The research questions posed are answered by a cross sectional survey. This survey evaluated one point in time and therefore can only provide information about the correlational relationships between the variables that were evaluated.

Subjects

In order to answer the research questions, it was necessary to include subjects from each point along the HIV disease process. It was also important to obtain some variability along the demographic characteristics that were evaluated. These demographic characteristics included, but were not limited to, gender, ethnicity, sexual orientation, socioeconomic status and risk factor. Therefore all clients 
at participating agencies were recruited.

Recruitment Procedures

Subjects were recruited by either the author or various agents of the author. Individuals who agreed to collect data for this study came from the following sources: secretaries of doctors or agencies that agreed to participate, social workers, psychologists and social work students. Social work students were only allowed to collect data if they had genuine access to a pool of suitable respondents and demonstrated a sincere interest in data collection. These students were offered extra credit for data collection. It was made clear on more than one occasion that there were at least three other possible alternatives for extra credit and that they were under no obligation whatsoever to collect data. As an incentive for data collection, other mental health or medical

professionals were offered separate statistical analysis of the group of responses that they collected from their respective agencies.

Subjects who were recruited by the author were asked to participate verbally. Specifically, the author said the following:

Hi, My name is Toni DiDona. [extend hand for handshake and wait for verbal response to greeting by proposed subject] I am a doctoral student at FIU and I am doing a survey on HIV, depression and access to medical care. It is completely anonymous, takes ten minutes to fill out and I'd like your response regardless of your HIV status. [If proposed subject refuses] Thanks anyway. 
[Click counter and walk away to next subject] [If proposed subject agrees, hand them the survey on a clipboard with a pen or pencil] Thank you so much, I will pick it up from you in a few minutes. [After 10 to 15 minutes return, if subject has completed the survey and hands it back remove it from the clipboard] Thank you so much for your help. Would you like to keep the cover sheet so that you can call me for the results? [If they say yes, tear it off and hand it to them. Regardless of response fold completed survey in half immediately so as not to see individual responses and place directly in box or backpack.]

Subjects who were recruited by other individuals were also recruited verbally. Individuals who collected data for this survey were given the following instructions.

Please ask everyone [at the agency, office, etc.] to participate regardless of their HIV status or risk factor. It is important that the confidentiality of those who are HIV infected be maintained and asking everyone to participate helps to insure this. Please make it clear that they are not required to participate and that nothing will happen if they chose not to participate. Please keep a running tabulation, on paper (or with the tally counter), of the number of people who refuse. [Secretaries at the various offices who pass the surveys out will be asked to place a blank form in a separate box for each refusal] Under no circumstances may you look at the responses from any given individual. The responses should be returned in either a box that is left in the waiting room or a pile from a group that participated. If this is not possible, then it is important to fold the survey in half and immediately place it in a pile of other completed surveys.

This is what I would like you to say:

$\mathrm{Hi} I$ I'm [Extend hand and wait for verbal response to greeting] Would you like to participate in a survey about HIV, depression and access to medical care? It is completely anonymous, takes ten minutes to fill out and I'd like your response regardless of your HIV status. [If proposed subject refuses] Thanks anyway. [Click counter or mark tally sheet and walk away to next subject] [If proposed subject agrees, hand them the survey on a clipboard with a pen or pencil] Thank you so much, I pick it up from you in a few minutes. 
[After 10 to 15 minutes return, if subject has completed the survey and hands it back remove it from the clipboard] Thank you so much for your help. Would you like to keep the cover sheet so that you can call the author for the results? [If they say yes, tear it off and hand it to them. Regardless of response fold completed survey in half immediately so as not to see individual responses and place directly in box or pile.]

\section{Sampling}

Subjects were recruited through a purposive sample from two metropolitan areas. These areas are Fort Lauderdale, Florida and Miami, Florida. Fort Lauderdale and Miami Florida have the third and fourth highest reported rates of AIDS cases respectively, of any metropolitan area in the United States (Centers for Disease Control, 1993a). Participants in this study were clients of medical doctors, therapists and social service agencies and individuals at an event called "Gay Pride" at the Broward County convention center. Although only HIV infected individuals were recruited, HIV negative individuals were not excluded. They served as a comparison group since the sample was drawn from agencies and offices where there is a predominance of HIV infected individuals.

In support of this sampling strategy, it is important to note that purposive samples are the most common sampling strategy in survey research on such sensitive social issues as lesbianism, incest, battering and criminal behavior (cf. 
Anthony, 1982; Dancey, 1992; Deevey, 1990; DeMaris \&

Jackson, 1987; Hedblom \& Hartman, 1980; Kurdek, 1991; Lynch

\& Reilly, 1986; Rosenzweig \& Lebow, 1992; Rose \& Roades,

1987; Trute, Sarsfield \& McKenzie, 1988; Van-Burskirk \&

Cole, 1983; Wasileski, Callaghan-Chaffee \& Chaffee, 1982).

In fact, except in cases where entire populations within a

particular area or when criminal records are utilized as the sampling frame, no other sampling strategy was found in the literature on other sensitive subjects.

\section{Data Collection strategy}

Patients of medical doctors who specialize in the treatment of HIV infection and AIDS were recruited because this pool provides the greatest concentration of HIV infected individuals and persons with AIDS (PWAs) without known emotional problems. Although this pool of subjects may be biased by an over representation of individuals who have access to and are currently seeking medical care, it was not confounded with individuals who have a higher incidence of depression than other pools of HIV infected individuals or PWAs.

The three major nonprofit agencies in Dade and Broward counties that were founded to service HIV infected individuals and PWAs were asked to participate. These agencies were: Body Positive, Health Crisis Network and Center One. Data from these agencies was either collected by the author or her agents or by the secretaries or 
therapists of these agencies. The decision about who will collect the data at each agency was made by the executive or clinical director of that agency. The director of each of these agencies was offered separate statistical analysis of the group of responses from their agency as an incentive to encourage participation.

Patients of social workers and psychologists at various agencies that treat a large number of HIV infected individuals also collected data. Although this pool of respondents may be biased with respect to having at least one emotional problem and seeking help for it, it is far less biased on the variable of access to medical care. This is due to the fact that many nonprofit or United Way funded agencies treat individuals who cannot receive care from any other source due to lack of insurance or money for treatment.

The convention event "Gay Pride" was included in the recruitment procedures because it provided the best opportunity to recruit from the least biased pool of subjects. It has drawn a wide variety of homosexual and bisexual participants in the past who did not necessarily have any medical, emotional or financial problems. It is suggested that this pool was the least biased of all pools of subjects due to the fact that the individuals were not there for any specific medical or psychological problem. Participants were recruited verbally as outlined previously 
in this paper. Surveys were passed out attached to clipboards so that the respondents could complete the surveys immediately.

The survey literature on lesbians supports collecting data at an event that is likely to bring large number of respondents from a particular group. Lie and Gentlewarrier (1991) published a study on lesbians with a pool of respondents that attended a women's music festival. There is also support for utilizing members of a particular type of organization. In addition, survey research has been published that drew only from a group of members of lesbian or gay organizations (Comstock, 1989; D'Augelli, 1988).

\section{Response Rate}

In this survey response rates were calculated for two categories. An overall response rate for all participants included was calculated. A response rate was also calculated for each source of data, in other words, each agency. Individuals who refused to participate were tallied by the individual collecting data. Secretaries at doctor's offices were asked to place a blank survey in a separate box each time a potential respondent refused. Data collectors at agencies tallied the number of refusals on paper or with a tally counter. Counselors who did not receive specific instructions on how to tally nonresponse received an additional cover letter, with a self-addressed envelope, that asked them to write down the number of refusals. At 
the event Gay Pride, the number of refusals will also be tallied.

The information gathered in response rates was utilized in the evaluation of potential bias. It was proposed that the response rate for most agencies will be $70 \%$ or greater. There is some evidence in the literature that this high of a response rate can be achieved (Califia, 1979; Eldridge \& Gilbert, 1990; Duffy \& Rusbult, 1986; Finkelhor, 1980; Harrison \& Gfroerer, 1992; Schneider, 1987; Schullo \& Alperson, 1984).

\section{Sample Size}

The majority of surveys in the area of sensitive subjects that employed advanced statistical procedures for the analysis of data had a sample size that was too low to be of sufficient power for the types of analysis that the researchers were performing (Dancey, 1992; Duffy \& Rusbult, 1986; Gibbons, Gibbons \& Kassin, 1981; Kurdek, 1988; Kurdek, 1991; Peplau, Cochran, Rook \& Padesky, 1978; Rose \& Roades, 1987; Scheider, 1986; Schullo \& Alperson, 1984). In fact, not one of the surveys found in an extensive review of the literature on sensitive topics mentioned the statistical power of the sample size (cf. Califia, 1979; Chapman \& Brannock, 1987; Comstock, 1989; Gibbons et al., 1981; Hedblom \& Hartman, 1980; Jennison, 1986; Kirkpatrick, Smith \& Roy, 1981; Loulan, 1988; Luengo-Martin, 1985; Martin, 1985; Pirog-Good \& Stets, 1985; Rosenzweig \& Lebow, 1992; 
Rose \& Roades, 1987; Shichor \& Korbrin, 1978; Townsend, Wallick \& Cambre, 1991). Therefore it was important to perform a power analysis and recruit enough subjects so as to have sufficient power for the types of statistical analysis that were planned for this data. The number of subjects needed to answer the research questions of this study will be addressed in detail later.

Limits of Methodology

Although information gathered from a purposive sample cannot be generalized to the entire population of HIV infected individuals, or even those in the South Florida area for that matter, it is hoped that this information will serve as the basis for other studies in this area. It provides a much needed beginning in the investigation of these important variables. Limitations of the methodology employed in this study are outlined in more detail later.

It is clear from the sampling procedures that the purposive sample obtained in this survey may have several biases. Pools of respondents from each of the sources may have their own unique bias. In an attempt to reduce the overall bias, multiple sources were utilized. Each source should be unbiased in terms of at least one of the variables under consideration. For example, although the clients of social service agencies, whose purpose is to provide emotional support and counseling, may be more likely to have an emotional problem, like depression, they are less likely 
to have private health insurance and therefore access to medical care. This potential bias was balanced with the patients of medical doctors, who do not necessarily have emotional problems but more likely to have medical insurance and are obviously receiving medical care. In addition, participants recruited from the event Gay Pride should not have any biases with respect to depression or access to medical care.

The methodology of this study builds on and attempts to improve the methodology of other studies of sensitive subjects. More specifically, existing survey literature with purposive samples from only one agency have been employed in research on sensitive subjects (DeMaris \& Jackson, 1987; Descher \& McNeil, 1986; Hollin, 1983; Kirkpatrick et al., 1981; Stark \& Campbell, 1991; Stein, de-Miranda \& Stein, 1988; Wasileski et al., 1982). Multiple agencies of one specific type have also been employed in this literature (Harwood "Hubbard \& Collins, $1988)$.

Some of the literature on criminal behavior have had sampling methods that are less biased than the proposed methodology. For example, surveys on criminal behavior have included all individuals in a given area as the sampling frame (Kolvin, Miller, Fleeting \& Kolvin, 1988), data from crime statistics (Hindberg, 1988; Shichor \& Kobrin, 1978) or old survey data (Chapman \& Brannock, 1987). Other 
potentially less biased methodologies have also been utilized, such as the national survey, (cf. Gelles \& Harrop, 1989; Harrison \& Gfroerer, 1992; Kehoe, 1988; Loulan, 1988; Smith, 1989).

Although these methodologies probably produce less bias than the proposed methodology, they were not appropriate for this topic due to the comparatively small ratio of HIV infected individuals in the general population and the exorbitant cost of such methods.

Criminal records have also been utilized to identify potential participants of surveys on criminal behavior (Jennison, 1986; Kolvin et al., 1988; Luengo-Martin, 1985; Shichor \& Korbrin, 1978). This methodology probably produces a less biased pool of potential participants than the proposed methodology. However, no such records of HIV infected individuals exist. In fact, the parameters of the population of HIV infected individuals is not empirically known, nor can it ever be due to numerous factors such as the inability to test everyone, confidentiality and irregular reporting. In addition, the legal restraints of "super confidentiality" which make it a federal offense to disclose the HIV status of an individual to another professional without their written permission, make obtaining lists of those known to be HIV infected illegal. Therefore, this methodology was not applicable to the proposed survey . 
Much of the literature on lesbianism, in support of the snowball sampling methods employed by the researchers, cites a seminal article on bias in homosexual and lesbian survey literature by Morin (1977). Morin argues that ". . it should be realized that there is no such thing as a representative sample of lesbians or gay men. Researchers are sampling what is essentially a hidden or invisible population" (1977, p 636). Certainly the population of HIV infected individuals is as hidden as the population of gay men and lesbians if not more so.

With the literature on other sensitive topics in mind it is argued that the methodology of this survey is not only substantially less biased than most other research on sensitive topics, but is also the best available methodology given the constraints of cost and a population with no empirically known parameters.

\section{Instrumentation}

A two page demographic sheet captured detailed demographic data with respect to: sexual orientation, ethnicity, socioeconomic status, education, insurance and perceived access to medical care. Questions were also asked in order to determine stage and duration of illness (see Appendix B)

The Satisfaction with Life Scale (SWLS) (Diener, Emmons, Larsen \& Griffin, 1985) was utilized to measure life satisfaction. This instrument has an alpha of .87 
demonstrating very good internal consistency and a testretest correlation of .82 for a 2 month period indicating that it is stable. Validity ratings for this instrument are based on high correlations with self-esteem, a checklist of clinical symptoms, emotionality and neuroticism. The SWLS has been normed on both undergraduate and geriatric populations.

The Generalized Contentment Scale (GCS) (Hudson, 1982) measured depression in this study. This scale is stable demonstrated by a 2 hour test-retest correlation of .94 . It is also internally consistent and reliable with a mean alpha of .92. The GCS correlates with the Beck Depression Inventory (.85 and .76) and the Zung Depression Inventory (.92 and .81$)$. It has been tested for known groups validity and demonstrated that it can discriminate between groups at a significant level.

The Self Efficacy Scale (SES) (Sherer, Maddux, Mercandante, Prentice-Dunn, Jacobs \& Rogers, 1982) measured self-efficacy. Due to the fact that the full scale is rather long and includes seven filler items that are not scored as well as two subscales, only the generalized selfefficacy subscale was included. This was due to the necessity to keep the overall survey brief. The reliability of the generalized subscale is high, with an alpha of .86 . This is better than the alpha of the social subscale $(.71)$. The measure is also reported to be valid, with criterion- 
related validity as well as construct validity. It is correlated with measures such as the Rosenberg Self Esteem Scale and the Ego Strength Scale (Corcoran \& Fischer, 1987). The SES has been normed on undergraduate and psychiatric populations.

Data Analysis

All of the standardized scales in this survey were tested on a post hoc basis for reliability by alpha coefficients and the Guttman split-half method to ensure that the measures retain their reliability. Descriptive statistics were employed to describe the demographic characteristics of the respondents. All other data analysis revolved around answering the research questions posed earlier in this paper.

Questions about the incidence and severity of depression, life satisfaction and self-efficacy were answered by descriptive statistics. The clinical cutting score for each of the standardized measures created categorical variables so that incidence could be expressed as a percentage of the sample with scores that are indicative of problems with depression, life satisfaction and self-efficacy respectively. Specifically, this analysis addressed the following research questions: 1) What is the incidence and severity of depression across the sampled population of HIV infected individuals? 3) what is the average level and scope of life satisfaction for surveyed 
HIV infected individuals? 5) What is the average amount and scope of self-efficacy in surveyed HIV infected individuals?

Questions about differences between groups across categorical variables were addressed with ANOVA. Depression, life satisfaction and self-efficacy were analyzed across stages of HIV infection and socioeconomic status respectively. Regression analysis evaluated the significance of interval level variables for depression, life satisfaction and self-efficacy. This analysis answered the following research questions: 2) Does the incidence or severity of depression vary with respect to: illness stage, self-efficacy, life satisfaction, socioeconomic status or access to medical care? 4) Does life satisfaction vary with: illness stage, depression, self-efficacy, socioeconomic status or access to medical care? 6) Does self-efficacy vary with respect to: illness stage, socioeconomic status, depression, life satisfaction or access to medical care?

ANOVAs were employed to evaluate questions about differences in depression, life satisfaction, self-efficacy and access to medical care with respect to precedent variables, such as gender, race and sexual orientation. This analysis answered the research question 7) Are there differences in these relationships with respect to the precedent variables of gender, sexual orientation and ethnicity? 


\section{CHAPTER IV}

This chapter details the results of this study. Response rates and descriptions of the sample obtained are included. In addition, the results of the research questions posed in this study are provided.

\section{RESULTS}

A total of 966 completed surveys were collected from 12 sources over a period of 6 months. These sources included two conventions, Gay Pride and Living with HIV. In addition, surveys were collected from three nonprofit agencies for HIV infected individuals, two HIV community action organizations, drug treatment programs, hospitals and medical doctors who specialize in treating HIV infection. Only 95 of the collected surveys were not included in the analysis because they did not fit the parameters specified for this study. More specifically, 63 surveys were collected from locations where there was not a high proportion of HIV infected individuals or individuals in high risk groups (as classified by the Centers for Disease Control). Another 32 surveys were collected from areas outside of South Florida and were therefore also excluded. This resulted in a total of 871 completed surveys for the analysis. 


\section{Response Rates}

An attempt was made to collect and calculate response rates from all sources. There were a few problems in data collection at two of the sources that resulted in an inaccurate tally of refusals and therefore an inability to calculate response rate.

\section{Sources without Response Rates}

The secretaries at the medical doctors offices recorded the number of refusals initially. Unfortunately, they did not continue to record refusals throughout the period of data collection. More specifically, in one instance the secretary went on vacation for 2 weeks and forgot to ask her replacement to document refusals. Upon returning she did not continue to document refusals. The secretary responsible for data collection at the other medical doctor's office reported that she did not always record refusals and that after a week she lost her tally sheet. since it is not known how many patients were asked but refused to participate, it is impossible to calculate the response rate from the medical doctor's offices.

The number of refusals was not calculated at the agency called Infusion Therapies because the clinical director of the agency did not want anyone to collect the surveys in person. Therefore, at this agency blank surveys were left on a table in the center of the waiting room and clients who chose to participate could complete them while waiting and 
place the completed surveys in a box with a small opening at the top which was located in the waiting room. A total of 15 surveys were collected from this agency.

In addition, there were three social work students who forgot to document refusals, therefore a response rate cannot be calculated for the surveys they collected. These students collected a total of 31 surveys. The number of refusals was documented from all other sources. In fact the total number of cases in which there was no response rate calculated was only 58. Response rates are available for the most (93.348) of the surveys collected.

\section{Response Rates by Source}

Response rates were calculated by dividing the total number of refusals by the total number of individuals asked to participate. This number was multiplied by 100 and then subtracted from 100. This resulted in the percentage of respondents who agreed to participate.

Response rates were high for most agencies (see Table 1). In fact only one agency had a response rate of less than $85 \%$. This agency was Center One and it had a response rate of only $64.91 \%$. It is unclear why the response rate was so much lower at this agency. However, even at the substantially lower rate, over half of the respondents asked at this agency chose to participate. The response rates at all other agencies were quite high, ranging from 100.08 to $84.57 \%$. 
Table 1

Response Rates

\begin{tabular}{|c|c|c|c|}
\hline Source & ised & Total Asked & Response Rate \\
\hline Gay Pride Convention & 8 & 147 & 94.568 \\
\hline Student's Extra Credit & $50 *$ & $443 *$ & $88.718 *$ \\
\hline Infusion Therapies & $\mathrm{N} / \mathrm{A}$ & $\mathrm{N} / \mathrm{A}$ & $\mathrm{N} / \mathrm{A}$ \\
\hline Body Positive & 29 & 188 & 84.578 \\
\hline Living with HIV Conference & 2 & 21 & $90.48 \%$ \\
\hline People with AIDS Coalition & 2 & 28 & 92.868 \\
\hline Cure AIDS Now & 0 & 8 & 100.008 \\
\hline Drug Treatment Programs & 0 & 23 & 100.008 \\
\hline Hospitals & 0 & 26 & 100.008 \\
\hline Health Crisis Network & 3 & 21 & 85.718 \\
\hline Doctor's Offices & $\mathrm{N} / \mathrm{A}$ & $\mathrm{N} / \mathrm{A}$ & $\mathrm{N} / \mathrm{A}$ \\
\hline Center One & 20 & 57 & $64.91 \%$ \\
\hline
\end{tabular}

* These figures exclude the 31 surveys collected by three social work students who did not tally refusals. 


\section{Overall Response Rate}

The overall response rate was calculated after excluding the surveys that were collected at sources where no refusal rate was collected. Specifically, surveys collected at medical doctors' offices, one agency for HIV infected individuals and those collected by the three social work students who forgot to tally refusals were excluded from this calculation. The number of refusals from each source was then summed. This total number of refusals (114) was then divided by the total number of individuals asked to participate (962). This number was multiplied by 100 and then subtracted from 100 . This resulted in the percentage of respondents who agreed to participate for the entire survey. The overall response rate for the survey was quite high $(88.158)$.

\section{Power Analysis}

Power analysis was performed to determine the appropriate sample size for this survey. Level of significance was set at .05 . It was also determined that a power of $90 \%$ was desirable. Since the relationship between the probabilities of Type I and Type II errors is inverse, a moderate effect size was also estimated. Although there is no literature to support this in the HIV infected population, a moderate effect size is recommended in general (Hinkle, Wiersma \& Jurs, 1988) and is necessary for clinical significance. Therefore, the effect size in this analysis 
was set at .20 and .50 (for the general and ANOVA analysis respectively). With these estimates, it was determined that a sample size of 263 subjects would be necessary for the survey. Since ANOVA was the primary means of analysis, however, a separate power function was also performed, based on comparing four groups (HIV status and illness stage). This analysis revealed that 114 subjects were needed in each group, or an overall sample size of 456. A total of 871 completed surveys were collected. This is considerably higher than the 456 surveys which were required in order to have sufficient power for the analysis performed. Therefore the likelihood of a Type II error is very small. In other words, it is not likely that results found to be statistically not significant in this study are in fact significant in the population.

\section{Description of Entire Sample}

\section{Demographic Characteristics of Entire Sample}

The majority of the 871 respondents for the entire survey were male $(\mathrm{N}=654 ; 76.7 \%)$. There were 199 (23.8\%) female respondents (see Appendix C).

Although the majority of respondents ( $N=481 ; 56.38)$ were white non hispanic, 158 (18.5\%) were Hispanic and 109 (12.88) were African American. Twenty one respondents (2.58) were Hispanic nonwhite and 24 (2.8\%) were Caribbean Black. There were 30 (3.5\%) Native American respondents. The rest of the participants were either Asian $(\mathrm{N}=8 ; .9 \%)$, 
Pacific Islander $(\mathrm{N}=3 ; .48)$, or reported their race to be other $(\mathrm{N}=18 ; 2.18)$ or that they did not know $(\mathrm{N}=2 ; .28)$. The majority of the respondents $(\mathrm{N}=490 ; 58.28)$ were homosexual. However there was a relatively high number of heterosexual respondents $(\mathrm{N}=250 ; 29.78)$ and bisexual respondents $(\mathrm{N}=93 ; 11 \%)$.

More than half $(52.68)$ of all respondents reported that their risk factor for contracting HIV was being a homosexual male. However, there were also a number of respondents $(10.28)$ who reported multiple heterosexual partners as their risk factor. Sixty-six (7.7\%) of the respondents were bisexual males and $54(6.38)$ were intravenous substance abusers. Thirty-six $(4.28)$ reported that they were the partner of either an intravenous substance abuser or a bisexual male. Fourteen respondents reported that they had received blood or blood products before 1985. This is when HIV antibody testing of the blood supply was begun. Many respondents $(N=40 ; 4.78)$ reported that they did not know their risk factor, or that they had no risk factor $(\mathrm{N}=107$; 12.5 이).

The age of respondents ranged from 17 to 74 , with the majority of the respondents being between the ages of 22 and 48. The average age of respondents in the entire sample was $35(\mathrm{SD}=9.81)$. Although $45(5.28)$ of the respondents did not know their HIV status and 295 (34.3\%) were HIV negative, the majority $519(60.48)$ of the respondents in the sample 
reported that they were infected with HIV.

Socioeconomic Factors of Entire Sample

Reported annual income of the sample varied widely and ranged between zero and $\$ 150,000$. The average annual income for the entire sample population was a little over $\$ 22,000$; however, there was a great deal of variation between reported incomes $(S D=17,805)$. In order to consolidate the information obtained about income, an ordinal level variable of income was created. This allows for greater ease in viewing and understanding the distribution of income among the entire population sampled (see Appendix D). The largest proportion $(\mathrm{N}=231 ; 29.98)$ of the sample reported an annual income of less than $\$ 10,000$. Almost $208(N=153)$ reported annual incomes of between $\$ 10,001$ and $\$ 20,000$. Slightly over 20\% ( $\mathrm{N}=183)$ reported incomes of between $\$ 20,001$ and $\$ 30,000$. About equal numbers of respondents from the entire sample reported annual incomes of between $\$ 30,001$ and $\$ 40,000$ and over $\$ 40,000$ (13.38 and 13.28 respectively). Most respondents (25.8\%) had some college education but had not received an associates degree. Amount of education was relatively well distributed in the sample with 102 (11.8\%) having less than a high school diploma and 152 (17.7\%) having a high school diploma or equivalent. One hundred and one respondents $(11.7 \%$ ) had received an associates degree and 194 (22.5\%) had received a bachelors degree. A smaller proportion of the sample had higher 
education with $66(7.7 \%)$ having a masters degree and 24 (2.88) having a medical degree or some other form of doctorate.

Hollingshead (1975) developed an index for measuring social status. In his index he developed categories of status for occupations. His list includes nine different categories of occupational status that are rank ordered and equidistant. These categories were utilized to calculate overall social status and are presented in Appendix D. Again, categories were grouped together in this table to aid in readability and understanding of the data presented. Most of the respondents $(22.48)$ in the entire sample reported having occupations that were categorized as semiskilled and skilled manual labor (see Appendix D). Clerical and sales occupational categories accounted for close to nine percent $(8.78)$ of the responses of the entire sample. A larger group of respondents reported occupations that were categorized as semiprofessional (12.0\%), minor professional (9.48) or lesser and major professionals $(9.78)$. It is interesting to note that a very large proportion of the sample population reported that they were either retired or disabled $(17.7 \%)$. In addition, 6.28 reported that they were unemployed.

The index that Hollingshead developed in 1975, was employed to create an interval level variable that reflects social status. This index provides a list of levels of 
socioeconomic status for various occupations and a formula for weighting occupation and education. Possible scores on this socioeconomic status scale range from a low of 8 , which is indicative of a menial laborer with less than a high school diploma, to a high of 66 , which is indicative of a major professional with advanced education. Actual scores obtained from the entire sample ranged from 14 to 66 . The average score for the entire sample was 39.74. There was some variation in scores $(S D=12.60)$.

Medical Insurance and Financial Assistance for Entire Sample Most participants $(\mathrm{N}=573 ; 66.5 \%)$ reported that they had some type of medical insurance, however $(\mathrm{N}=261 ; 30.6)$ reported that they had no medical insurance. Most respondents had private medical insurance $(N=239 ; 28.18)$. However, $142(16.38)$ reported belonging to an health maintenance organization (HMO) and $52(6.1 \%)$ reported that they had Medicare. Ninety-three (10.98) reported that they had Medicaid and $63(7.48)$ reported that they had some other type of medical insurance.

The majority of the participants $(N=571 ; 66.68)$ in this survey reported that they received no financial assistance from the government. However, 285 (33.3\%) of the respondents do receive some type of assistance. For the entire sample population, $103(12 \%)$ reported that they received more than one type of financial assistance, including but not limited to social security disability, 
food stamps, Aid to Dependent Families with Children and subsidized housing. Many participants ( $N=113 ; 13.28)$ reported that they received social security disability only and $43(5.08)$ reported that they only received food stamps.

\section{HIV negative Respondents}

Demographic Characteristics of HIV negative Respondents

Most respondents who reported being HIV negative were male $230(69.3 \%)$. One hundred and two (30.78) HIV negative respondents were female (see Appendix E). In addition, the majority of HIV negative respondents were white $(\mathrm{N}=215$; 64.48). However, there were enough Black ( $N=34 ; 10.28)$ and Hispanic ( $\mathrm{N}=61 ; 18.38)$ HIV negative respondents for analysis.

The sexual orientation of the HIV negative respondents was predominantly homosexual (56.68). However, there were 109 (32.98) heterosexual and 34 bisexual (10.38) HIV negative respondents.

Nearly half of all HIV negative respondents (44.3\%) reported that their risk factor for contracting HIV was being a homosexual male (see Appendix E). Although a substantial proportion of the HIV negative population $(25.48)$ reported that they had no risk factor, there was a large group of individuals $(11.4 \%)$ who reported that multiple heterosexual partners was their risk factor.

The average age of HIV negative respondents in this survey was 35. Reported age in this group ranged from 17 to 
74 and varied to a certain degree $(S D=11.1)$. The most commonly reported age of HIV negative respondents was 32 . Socioeconomic Factors of HIV negative Respondents

Fewer HIV negative respondents, $(\mathrm{N}=49 ; 15.78)$ reported earning annual incomes of less than $\$ 10,000$ (see Appendix F). In fact the mean income for HIV negative individuals was about $\$ 25,500$, which was the highest average income for any of the groups. There was greater variation in income levels among HIV negative respondents $(S D=19,692)$. A larger proportion of the HIV negative respondents (17.48) reported earning more than $\$ 40,000$ annually. An annual income of between $\$ 20,001$ and $\$ 30,000$ was the most commonly reported income category $(26.3 \%)$.

The HIV negative group also appeared to be more educated than the entire sample as a whole, with a greater proportion having advanced degrees (14.58) and fewer having less than a high school diploma or equivalent (6.28). The majority of HIV negative respondents had a bachelors degree $(24.98)$.

There were also substantial differences between the HIV negative respondents and the entire sample in occupational categories of social status (see Appendixes C and E). Most notable perhaps is the fact that only $3 \%$ of the HIV negative respondents were disabled or retired and only $6 \%$ were unemployed. In addition, a larger proportion reported having occupations that were associated with higher levels 
of social status, such as those classified as lesser and major professionals (118) than the entire population sampled. On the whole the HIV negative subgroup of the sample had higher levels of occupational status.

The average score on Hollingshead's (1975) social status index for HIV negative respondents was 39.64 , although there was some variation $(S D=12.45)$. This is nearly exactly the same average as for the entire population sampled. Social status index scores for HIV negative individuals ranged from 14 to 66 . Medical Insurance and Financial Assistance for HIV negative The majority of HIV negative respondents (69.08) reported that they had some type of medical insurance. Although most HIV negative individuals reported having private insurance $(32.8 \%)$, nearly as many reported that they had no medical insurance $(31.0 \%)$. An additional $20.8 \%$ reported that they belonged to an health maintenance organization, while only $1.8 \%$ reported having Medicare and 3.38 reported having Medicaid.

Most respondents $(87.58)$ who reported that they were HIV negative also reported that they received no financial assistance from the government. A little over $2 \%$ of this group reported that they only received social security disability, but 5.18 reported that they received food stamps. Less than 18 reported that they received support from the special supplemental food program for women, 
infants and children (WIC) or money for housing. Only 2.48 of HIV negative respondents reported that they received more than one type of assistance from the government.

\section{HIV positive Respondents}

Respondents who reported that they had tested positive for the human immunodeficiency virus and also reported that they were asymptomatic were included in this category. Due to the fact that a few respondents reported that they were asymptomatic and that they had full blown AIDS it was necessary to clarify this group further. In an effort to exclude respondents who reported conflicting stages from this category, those who reported that they had AIDS related complex were excluded from this category. In addition, those who reported that they had less than $200 \mathrm{~T}$-cells or that at sometime had an opportunistic infection were also excluded. This resulted in an HIV positive group of respondents who reported that they were asymptomatic and had not progressed into later stages of disease.

\section{Demographic Characteristics of HIV positive Respondents}

As with the entire sample population and HIV negative respondents, respondents who were HIV infected and asymptomatic were predominately male (81.48) with only 42 HIV infected women respondents who did not have advanced stage disease (see Appendix G). HIV infected asymptomatic respondents were predominately white (55.38) although there was sufficient numbers of Black (18.4\%) and Hispanic (19.3\%) 
respondents for the analysis.

The sexual orientation of the asymptomatic group was mostly homosexual $(57.28)$. Heterosexual HIV infected respondents accounted for $27.9 \%$ of the group. This is a particularly large number of heterosexual HIV infected respondents $(\mathrm{N}=62)$. In addition, 29 (13.18) of the HIV infected respondents who were asymptomatic reported their sexual orientation to be bisexual.

As with the other groups, most of the HIV infected respondents (55.18) reported that their risk factor for contracting HIV was being a homosexual male. There was however, adequate representation of the other risk factors with 10.28 of the HIV infected group reporting that they were IV substance abusers and 12.08 reporting that their risk had been multiple heterosexual partners. Seven HIV infected respondents (3.18) reported that they had no risk factor and eight $(3.68)$ reported that they did not know their risk factor.

The average age of HIV infected respondents was 34.62 and there was less variation in reported age in this group $(S D=8.77)$. Ages of HIV infected respondents ranged from 17 to 66 .

Socioeconomic Factors of HIV positive Respondents

More of the HIV infected respondents (29.18) reported annual incomes of less than $\$ 10,000$ than those who were HIV negative. Although the greatest number of HIV positive 
respondents $(30.1 \%)$ reported annual incomes of between $\$ 20,001$ and $\$ 30,000$, there were fewer HIV infected respondents with incomes of over $\$ 40,000$ (see Appendix H). The average annual income for HIV infected respondents was nearly $\$ 23,000$. There was considerably less variation in reported annual income for this group $(S D=15,620)$.

HIV positive respondents who had not yet progressed to later stages of disease had the largest group of respondents with less than a high school diploma. This comparison is true across all stages of disease progression and for the entire sample as well. Although $23.3 \%$ of HIV infected respondents reported having some college education but no degree, only $22.0 \%$ reported having bachelors degrees and 9.28 reported having graduate degrees.

Most HIV infected respondents $(26.08)$ reported having occupations that were classified as semi-skilled and skilled manual labor. Fifteen percent reported occupations that were classified as menial and unskilled (see Appendix H). Semiprofessionals $(9.88)$ and lesser and major professionals (12.78) were reported by the HIV infected sample. Although there was more reported unemployment $(6.98)$ and disability or retirement $(9.28)$ in the HIV infected population, these numbers were not nearly as high as those reported by respondents in later stages of disease progression.

HIV infected respondents who had not yet developed symptoms had an average social status index score 
(Hollingshead, 1975) of 40.06. This score is indicative of social status that is slightly above average. The scores ranged from 19 to 66 in this group with some variation (SD = $12.72)$.

Medical Insurance and Financial Assistance for HIV infected

Most (65.18) HIV infected asymptomatic respondents who had not yet developed symptoms reported that they had some type of medical insurance. However, there were 80 (34.9\%) respondents who reported that they had no medical insurance. The most commonly reported type of insurance was private with 29.38 of HIV positive respondents. Health maintenance organizations were reported with the second highest frequency $(15.7 \%)$. Very few respondents in this group reported having Medicare (4.48) or Medicaid (7.98).

Nearly three quarters (71.48) of HIV infected respondents reported that they received no financial assistance from the government. A little over 108 reported that they received more than one type of assistance. Less than 18 reported that the only type of assistance they received was transportation, special supplemental food program for women, infants and children (WIC) or money for housing. Social security disability was reported as the only type of financial assistance by 8.58 of HIV infected respondents. 


\section{Respondents with AIDS Related Complex}

Individuals who reported that they had tested positive for the human immunodeficiency virus and also reported having AIDS Related Complex (ARC) constitute this group. Conceptually, they have progressed past the HIV infected asymptomatic stage and have begun to develop some symptoms. They have not yet had an opportunistic infection and have more than 200 T-cells.

Demographic Characteristics of Respondents

with AIDS Related Complex

Respondents who reported being HIV infected and having AIDS related complex, a condition where symptoms from the infection begin to develop but no opportunistic infection has yet occurred, were predominately male (85.78). Only 15 (14.38) of the respondents with AIDS related complex were female (see Appendix I). As with the other subgroups, the respondents with AIDS related complex were predominantly (40.48) white, with Hispanics (34.68) and Blacks (18.38) being the next largest groups.

A lager proportion of the AIDS Related Complex group reported being homosexual (63.78) than heterosexual (21.68) or bisexual (13.7\%). In fact homosexual male was the most often reported risk group $(66.7 \%)$ of the AIDS related complex population sampled (see Appendix I). Bisexual male (9.58) and multiple heterosexual partners (5.7\%) were the next largest groups of risk factors for the AIDS related 
complex population. Interestingly, 3.88 of respondents with AIDS related complex reported that they had no risk factor for HIV and $4.8 \%$ reported that they did not know their risk factor.

The average age of respondents with AIDS related complex was 36. Age in this group ranged from 19 to 62 with little variation $(S D=8.67)$.

Socioeconomic Factors of Respondents with AIDS Related

Complex

By far the largest numbers of respondents reporting annual incomes of less than $\$ 10,000$ were in the AIDS Related Complex (ARC) group (58.38). Only 15.68 of this group reported income of between $\$ 10,001$ and $\$ 20,000 ;$ while only $12.5 \%$ reported income of between $\$ 20,001$ and $\$ 30,000$ (see Appendix $J$ ). In addition, a very small percentage of this group reported income of more than $\$ 40,000$ a year. In fact respondents with AIDS related complex had the lowest average annual income of any group. The average income was more than $\$ 14,000$, nearly $\$ 9,000$ less than the average for HIV positive respondents.

Most of the respondents who reported having AIDS Related Complex also reported having some college education but no degree $(33.38)$. The second most frequently reported level of education in the AIDS related complex group was high school graduate and bachelors degree, with each category having 19.08 of the respondents (see Appendix J). 
Only 6.78 of the respondent with AIDS related complex reported having a graduate degree of some type.

A large proportion of the respondents with AIDS related complex reported that they were disabled or retired (46.08). In fact the percentage of respondents in this category is higher than in any of the other stages of disease progression, including the later stage of full blown AIDS. Another $11.5 \%$ of the AIDS related complex group reported that they were unemployed. Very few in this group of respondents had occupations that were categorized as lesser and major professionals (3.48), or minor professionals $(5.7 \%)$.

Most respondents who reported having AIDS Related Complex had a social status index score (Hollingshead, 1975) of 35. This is social status score is barely above average. The average social status score for this group was 38.36 , with some variation $(S D=11.76)$. Scores for this index ranged between 19 and 61 for respondents with AIDS related complex. This range is quite large, as a social status score of 19 is indicative of a semi-skilled job with a high school education while a score of 61 is indicative of a professional with graduate education.

Medical Insurance and Financial Assistance for Respondents with AIDS Related Complex

More than one quarter (26.08) of respondents with AIDS related complex reported that they had no medical insurance. 
In addition, fewer respondents in this group had private medical insurance $(23.1 \%)$. Most respondents with AIDS

Related Complex (ARC) reported having Medicaid (27.98), even though 10.68 reported that they had Medicare.

The majority $(74.3 \%)$ of respondents who have AIDS related complex reported that they receive some type of financial assistance from the government. the most commonly reported type of assistance in this group was Social Security disability with 37.18 reporting that this was the only type of assistance that they receive. A large proportion (32.4\%) of this population reported that they received more than one type of assistance. Less than $2 \%$ reported that they received only food stamps and less than 18 reported that they only received transportation or Aid to Dependent Families with Children.

\section{Respondents with AIDS}

Respondents that reported being HIV positive and having full blown AIDS, as well as those who reported that they had had an opportunistic infection or less than $200 \mathrm{~T}$-cells (the most common immunological marker of disease progression) were classified as having AIDS. The immunological and infection markers that delineate this stage of disease progression are those employed by the Centers for Disease Control and the Social Security Administration in the United States. Conceptually, AIDS is at the far right of the 
disease progression continuum. The prognosis for individuals with full blown AIDS is poor.

Demographic Characteristics of Respondents with AIDS

The majority of respondents with full blown AIDS $(\mathrm{N}=152)$ were male $(80.9 \%)$ with only $19.1 \%$ being female (see Appendix K). As with the other groups of disease progression, respondents with AIDS were more likely to be white $(52.68)$ than Hispanic $(18.5 \%)$ or Black (18.58). They were also more likely to be homosexual (56.28). There was a large proportion of respondents with AIDS that reported their sexual orientation to be heterosexual (32.7\%) and to a much lesser degree bisexual (9.28).

Again, as with the other groups the most commonly reported risk factor category was homosexual male (56.28). However, there were a large number of respondents who reported their risk factor for contracting HIV as being an IV substance abuser (10.5\%) or multiple heterosexual partners $(9.88)$. Interestingly, 2.68 of the respondents with AIDS reported that they did not have a risk factor and 6.58 reported that they did not know their risk factor for contracting HIV (see Appendix K).

The average age of respondents with AIDS was 36 . There was not a great deal of variation in age in this group ( SD = 8.2). Reported ages for respondents with AIDS ranged from 18 to 74 years. 
Socioeconomic Factors of Respondents with AIDS

Although not the poorest of all of the groups of disease progression, almost half $(45.5 \%)$ of respondents with AIDS reported that they had annual income of less than $\$ 10,000$ (see Appendix L). Very few in this group (9.08) reported income of more than $\$ 40,000$ annually. Nearly one fourth $(19.78)$ reported earning between $\$ 20,001$ and $\$ 30,000$ a year. Respondents with AIDS reported an average annual income of nearly $\$ 19,000$. There was some variation in reported income $(S D=15,841)$ with a wide range of none to $\$ 75,000$ annually.

The amount of education for respondents with AIDS was fairly evenly distributed with $18.1 \%$ having less than a high school diploma, 27.48 having some college but no degree and 20.08 having a bachelors degree. A little over 78 of respondents with AIDS reported having a graduate degree of some type.

A large proportion of the respondents with AIDS (34.78) reported that they were disabled or retired. This figure may appear high, but given the fact that any individual with full blown AIDS qualifies for social security disability, this number is remarkably low. Only $1.6 \%$ of respondents with AIDS reported being unemployed. Menial and unskilled labors (12.98) and semi-skilled and skilled manual labors (12.1\%) were the second and third most commonly reported types of occupations. 
According to Hollingshead's (1975) Index of Social Status, the average score for respondents with AIDS was 40.0. This score is slightly above average. There was a little more variation of index scores in this group (SD $=$ 12.63). Index scores ranged from 17 to 61 . This range is quite large, as a social status score of 17 is indicative of a semi-skilled job with a high school education while a score of 61 is indicative of a professional with graduate education.

Medical Insurance and Financial Assistance for Respondents with AIDS

A little over one quarter of respondents with AIDS reported that they had no medical insurance. However, a large proportion of this population (21.98) reported that they had private medical insurance. Medicaid was reported as the type of insurance by $21.2 \%$ of respondents with AIDS, while only 11.38 reported that they had Medicare.

Most respondents (61.3\%) with AIDS reported that they received some type of financial assistance from the government. The most commonly reported type of assistance was Social Security disability, with 27.78 of this group reporting this as their only type of assistance. A little over $5 \%$ reported that they received food stamps. Less than 18 reported that the only type of assistance they received was transportation or housing. Nearly one quarter (23.28) reported that they received more than one type of assistance 
from the government. Given that all persons who are in the United States legally qualify for disability upon diagnosis of AIDS makes the number of those actually receiving this benefit appear relatively small.

\section{Reliability Analysis \\ Generalized Contentment scale}

The Generalized Contentment Scale was developed by Hudson (1982). It is a 25 item self administered measure of depression. It was chosen primarily because it is the only standardized measure which does not include somatic complaints in the measurement of depression. This is extremely important with populations where disease progression may cause some of the physical symptoms that are often considered markers of depression such as insomnia, weight loss and loss of appetite. Since HIV, as well as the medications that are commonly prescribed to treat it, can cause these specific physical complaints it was of vital importance to utilize a measure of depression that is not confounded by these physical symptoms. The Generalized Contentment Scale is a standardized measure of depression which is not confounded for medical populations by somatic complaints.

The 25 items that make up the Generalized Contentment Scale are affective statements. They are assigned a number, on a scale of 1 to 7 , by the participant to indicate the degree to which their feelings agree with the statement. 
Nearly half (12) of the statements are reversed scored. The response for each item is then summed and from that sum 25 is subtracted. This produces the depression score which is utilized in all of the following analysis. Higher scores on this scale are indicative of higher levels of depression. Hudson (1982) developed norms for this scale. The clinical cutting score for depression is 30. A Generalized Contentment Scale score of between 30 and 49 would indicate that the respondent had mild clinical depression. Clinical depression is different than just feeling sad. It is a level of affective feeling that can inhibit normal activities of daily living, job performance and enjoyment of anything. Hudson (1982) found that scores on the Generalized Contentment Scale that were between 50 and 69 were indicative of moderate depression and that scores above 70 were indicative of severe depression. These clinical cutting scores were employed to create an ordinal level variable of depression.

Reliability of Generalized Contentment Scale in This Survey

Although this measure has been demonstrated to be reliable (Hudson, 1982), reliability of this measure was assessed for this sample population. Cronbach's alpha coefficient for the Generalized Contentment Scale was .94. The Guttman split half coefficient, in which the scale is split at random and correlations between each half are determined, was .94 as well. These coefficients are very 
high. Therefore, the Generalized Contentment Scale is concluded to be a reliable measure of depression for this study •

\section{Satisfaction with Life Scale}

The Satisfaction with Life Scale was developed by Diener et al., (1985). It is a 5 item scale of subjective statements about satisfaction with life. Each item is assigned a number from 1 to 7 by the participant. The items are then summed which produces a score. Higher scores are indicative of greater life satisfaction.

Norms have been developed for the Satisfaction with Life Scale (Pavot \& Diener, 1993). Potential scores range from 5 to 35. Pavot and Diener (1993) report that scores of less than 14 are indicative of being mostly dissatisfied with life, while scores between 14 and 19 are indicative of slight dissatisfaction. Scores of 20 to 25 are considered to indicate slight satisfaction with life and scores above 26 are indicative of being mostly satisfied. Reliability of the Satisfaction with Life Scale in This Survey

This scale has also been demonstrated to be reliable (Diener et al., 1985). Reliability of this scale was also assessed. Cronbach's alpha coefficient for this scale was .86. The Guttman split half coefficient was .77 . Although these coefficients are lower than those obtained by the Generalized Contentment Scale, they are certainly within 
acceptable limits for social science. Therefore this scale is concluded to be a reliable measure of life satisfaction in this research.

\section{Self Efficacy Scale}

The Self Efficacy Scale is a self administered measure of self-efficacy (Sherer et al., 1982). It is a 25 item scale that consists of subjective statements about selfefficacy. Respondents report their level of agreement with each statement on a scale of 1 to 5 . The Self Efficacy Scale has two subscales, general and social. Due to the need to limit the length of the questionnaire, only the general subscale was included. Seventeen items comprise the general subscale of the Self Efficacy Scale. Approximately half of the items are reversed scored and the items are then summed to produce a general self-efficacy score. The general self-efficacy subscale score is the measure of selfefficacy that will be employed in all of the following analysis. It will be referred to as the self-efficacy score because it is the only measure of self-efficacy in this study.

Reliability of the general subscale of the Self Efficacy Scale in This Survey

Although this scale has been demonstrated previously to be reliable, it was very important to assess the reliability of the general subscale by itself. The general subscale of the Self Efficacy Scale had a Cronbach's alpha coefficient 
of .89. It also had a Guttman split half coefficient of .85. Therefore, it is concluded that the general selfefficacy subscale of this measure was reliable in this study.

\section{Research Questions}

1) What is the incidence and severity of depression across the sampled population of HIV infected individuals?

In investigating this question it is helpful to evaluate each stage of HIV disease progression separately, so as to give a more complete answer to the question posed. Of respondents who were not infected with HIV, there were 333 who answered all of the questions on the Generalized Contentment scale (GCS). The average score on this scale for HIV negative respondents was 39.62 (see Table 2).

However, there was a great deal of variation in scores among respondents who were HIV negative $(S D=22.77)$. The range of scores was also very broad, with scores from the lowest possible, 0, to the highest possible, 125. This may partially account for the high mean in depression score for HIV negative respondents. Surveys were only collected from agencies where there was likely to be a high proportion of HIV infected individuals, therefore it is likely that many HIV negative respondents knew many people who were HIV infected. It is also likely that HIV negative respondents were in a high risk group for contracting the virus. This, 


\section{Table 2}

Mean Depression Scores Across Stage of Infection

Stage of

Disease

mean

SD

HIV negative*

39.62

22.77

HIV positive asymptomatic

53.06

24.91

AIDS Related Complex

56.63

26.74

AIDS

52.81

24.43

* This group significantly less depressed than all other groups . 
coupled with knowing many HIV infected persons, may also have contributed to the high average in depression scores for HIV negative individuals. It should be noted however, that most HIV negative respondents (39.38) had Generalized Contentment Scale (GCS) scores that were not indicative of depression (see Table 3).

Respondents who were HIV infected but had not yet developed symptoms or full blown AIDS had a much higher average Generalized Contentment Scale score than HIV negative respondents. In fact the mean depression score for HIV positive asymptomatic respondents was 53.06 . As with the HIV negative respondents, variation in score for this scale was high $(\mathrm{SD}=24.92)($ see Table 2$)$. Scores on the Generalized Contentment Scale for HIV positive asymptomatic respondents varied from 0 to 115 . The largest percentage of these respondents had depression scores that were indicative of severe clinical depression $(32.28)$. However, it should be noted that a significant proportion of this population had scores that were not indicative of depression (23.98), or were indicative of mild clinical depression (20.0\%).

Respondents who were HIV infected and also reported that they had AIDS Related Complex had the highest average depression score of all four groups (mean $=56.63)$. Variation in scores was highest for this group as well $(\mathrm{SD}=$ 26.74). A smaller percentage of the AIDS related complex group had scores that were not indicative of depression 
Table 3

Depression Score Severity Across Stage of Infection Stage of Disease Percent

Severity of Depression

HIV negative

Not depressed

39.3

Mild depression

30.9

Moderate depression

17.4

Severe depression

12.3

HIV positive asymptomatic

Not depressed

23.9

Mild depression

20.0

Moderate depression

23.9

Severe depression

32.2

AIDS Related Complex

Not depressed

17.6

Mild depression

24.5

Moderate depression

27.5

Severe depression

30.4

AIDS

Not depressed

17.3

Mild depression

32.0

Moderate depression

23.4

Severe depression

27.3 
$(17.6 \%)$. Although the largest proportion of this group had scores that were indicative of severe depression, (30.48), there was a larger percentage of HIV positive asymptomatic respondents who were severely depressed (32.28). Overall, respondents who were HIV infected and also reported having developed AIDS Related Complex were on average, the most depressed of any of the stages of disease progression.

Respondents who were HIV infected and also reported having either AIDS or one of the qualifying conditions by Centers for Disease Control criteria for a diagnosis of AIDS had the lowest average depression score of any of the HIV infected groups $($ mean $=52.81)$. As with all other groups of respondents, there was a great deal of variation in scores $(S D=24.43)$. The largest proportion of this group had Generalized Contentment Scale scores that were indicative of mild clinical depression (32.0\%). There was also a large proportion of this population that had scores indicative of severe depression $(27.38)$.

In sum, the incidence of depression was found to be quite high across all stages of HIV infection. The overall incidence of depression in the HIV positive asymptomatic group was found to be 76.18 . The incidence in the groups that reported that they had AIDS related complex was 82.48 . The overall incidence of depression in the group that had progressed to full blown AIDS was 83.38. The proportion of depression scores that were above the clinical cutting score 
of 30 increased as stage of illness progressed. HIV disease progression and depression were found to have a positive correlational relationship. In other words, the incidence of depression increased as HIV disease progressed.

2) Does the incidence or severity of depression vary with respect to: illness stage, self-efficacy, life satisfaction, socioeconomic status or access to medical care?

In evaluating difference in severity of depression across stages of HIV infection, the one way ANOVA was employed. In comparing the variance between groups with the variance within groups, it was found that there was a statistically significant $(p<.0001)$ difference in depression scores between groups of HIV disease progression. In fact, the $F$ ratio was particularly high (22.90). Upon closer analysis, it was found that the only groups that were significantly different were the HIV negative group compared to all three other groups. In other words, HIV negative respondents were significantly less depressed than respondents who were HIV positive regardless of stage of disease (ie asymptomatic, AIDS Related Complex, AIDS). The more stringent Tukey HSD and Scheffe procedures were utilized for this closer analysis to ensure that significant differences were not found merely due to the number of comparisons that were being made. There were no significant differences between groups that were HIV infected but at different stages of disease progression. 
Regression analysis was employed to test the variance in depression with respect to self-efficacy, life satisfaction and socioeconomic status. This is due to the fact that all of these variables are interval level variables. Self-efficacy and life satisfaction were determined though the scales that have already been detailed. Socioeconomic status was determined by Hollingshead's 1975 index for social status. Access to medical care was measured by a likert scale that ranged from 1 to 9 .

The $\mathrm{F}$ for this analysis was exceptionally high, 128.88, which was statistically significant $(p<0001)$. Residuals were fairly well distributed and bell shaped indicating that assumptions of regression analysis were not violated. The adjusted $R$ squared was .54 . This indicates that variance in depression score could be due to variance in self-efficacy, life satisfaction and access to medical care. These variables account for $54 \%$ of the variance in depression. The Betas of these variables were low (see Table 4). Socioeconomic status was the only variable that did not significantly contribute to variance in depression. Selfefficacy and life satisfaction significantly contributed to variance in depression $(p<.0001)$ as did access to medical care $(p=.0120)$. Self-efficacy, life satisfaction and access to medical care all had negative Betas. This indicates that the correlational relationship between these 
Table 4

Variance in Depression

$\begin{array}{lccc} & \text { Beta } & \text { T } & \text { Significance of T } \\ \text { Socioeconomic status } & .02 & .63 & .5287 \\ \text { Self-efficacy } & -.39 & -10.71 & .0000 \\ \text { Access to care } & -.09 & -2.52 & .0120 \\ \text { Life satisfaction } & -.45 & -12.11 & .0000\end{array}$


variables and depression is inverse or negative. In other words, lower levels of self-efficacy, life satisfaction and access to medical care were associated with higher levels of depression.

3) What is the average level and scope of life satisfaction for surveyed HIV infected individuals?

Respondents who reported that they were not infected with HIV had an average life satisfaction score of 21.70 (see Table 5). Their scores ranged from 5 to 35 with a moderate amount of variation $(S D=7.79)$. As compared to other groups, HIV negative respondents had the highest average in life satisfaction scores as well as the highest mode (30) and highest median (23). In addition, the largest proportion ( 37.78 ) of this population had life satisfaction scores that were indicative of being mostly satisfied (see Table 6). However, approximately one fifth (20.28) of this population had scores that were indicative of being mostly dissatisfied.

HIV positive asymptomatic respondents reported an average life satisfaction score of 18.42 . They had about the same amount of variation $(S D=7.94)$ as the HIV negative group as well as about the same range of scores (5 to 35). They had the second highest average score in life satisfaction among all four stages of disease progression. This group also had the lowest mode (9) of any stage of disease progression. The largest proportion (34.1\%) of the 
Table 5

Mean Life Satisfaction Scores Across Stage of Infection

\author{
stage of \\ Disease
}

HIV negative*

HIV positive asymptomatic

AIDS Related Complex

AIDS mean

SD

21.70

18.40

17.83

17.74
7.79

7.94

7.17

7.08

* This group significantly less depressed than all other groups. 
Table 6

Life Satisfaction Across stage of Infection

Stage of Disease

Level of Satisfaction

HIV negative

Mostly satisfied

slightly satisfied

slightly dissatisfied

Mostly dissatisfied

HIV positive asymptomatic

Mostly satisfied

Slightly satisfied

Slightly dissatisfied

Mostly dissatisfied

AIDS Related Complex

Mostly satisfied

Slightly satisfied

Slightly dissatisfied

Mostly dissatisfied
Percent

37.7

26.1

16.0

20.2

20.1

23.6

22.3

34.1

14.7

30.4

20.6

34.3

AIDS

Mostly satisfied

14.9

slightly satisfied

25.7

slightly dissatisfied

30.4

Mostly dissatisfied
29.1 
HIV positive asymptomatic population had life satisfaction scores that were indicative of being mostly dissatisfied. Approximately one fifth of this population had scores that were indicative of being mostly satisfied. These results are exactly opposite those found in the HIV negative population.

Respondents who reported having AIDS Related Complex had a slightly lower average life satisfaction score (mean = 17.83). There was slightly less variation in life satisfaction scores within this group $(S D=7.17)$, but not significantly less. The most common life satisfaction score for respondents with AIDS Related Complex was 22. A small proportion (14.7\%) of this population had scores that were indicative of being mostly satisfied. Respondents with AIDS related complex were more likely (34.3\%) to have scores that were indicative of being mostly dissatisfied with life.

Respondents who were at the last stage of disease progression, AIDS had the lowest average (mean= 17.74) life satisfaction score of any of the groups. It is interesting to note however that a smaller proportion of respondents (29.18) with AIDS had life satisfaction scores that were indicative of being mostly dissatisfied. In fact this population was slightly more likely (30.4\%) to have scores that were indicative of only mild dissatisfaction. There was even less variability in life satisfaction scores for this group ( $S D=7.08)$, although the range of scores was the 
same (5 to 35 ). The most common life satisfaction score for respondents with AIDS was 10 .

In sum, satisfaction with life was negatively correlated with HIV disease progression. The largest decrease in life satisfaction occurred between HIV negative and HIV positive respondents. The most dramatic change in categories of life satisfaction was in the category of mostly satisfied. Although 37.78 of the HIV negative population had life satisfaction scores that indicated that they were mostly satisfied with their life, only 20.18 of the HIV positive asymptomatic group, 14.78 of the AIDS related complex group and 14.98 of the AIDS group had scores as high.

4) Does life satisfaction vary with: illness stage, depression, self-efficacy, socioeconomic status or access to medical care?

In evaluating difference in life satisfaction across stages of HIV infection, the one way ANOVA was employed. In comparing the variance between groups with the variance within groups it was found that there was a statistically significant $(p<.0001)$ difference in life satisfaction scores between groups of HIV disease progression. The F ratio was high (14.82). Upon closer analysis, it was found that the only groups that were significantly different were the HIV negative group compared to all three other groups. In other words, HIV negative respondents had significantly 
higher levels of life satisfaction than respondents who were HIV positive regardless of stage of disease (ie asymptomatic, AIDS Related Complex, AIDS). The more stringent Tukey HSD and Scheffe procedures were utilized for this closer analysis to ensure that significant differences were not found merely due to the number of comparisons that were being made. There were no significant differences between HIV positive asymptomatic, AIDS related complex and AIDS groups. These results are similar to those found when comparing depression (See research question 2)

Regression analysis was utilized to test the variance in life satisfaction with respect to self-efficacy, depression and socioeconomic status. The $\mathrm{F}$ for this analysis was high, 83.47 , which was statistically significant ( $p<0001)$. Residuals were well distributed and nearly perfectly bell shaped indicating that assumptions of regression analysis were not violated. The adjusted $R$ squared was .43 . This indicates that variance in life satisfaction score could be due to variance in selfefficacy, depression and socioeconomic status. These variables account for $43 \%$ of the variance in life satisfaction. The Betas of these variables were low (see Table 7). Access to medical care was the only variable that did not significantly $(p=.1568)$ contribute to variance in life satisfaction. Depression significantly contributed to variance in life satisfaction $(\mathrm{p}<.0001)$ 
Table 7

Variance in Life Satisfaction

$\begin{array}{lccc} & \text { Beta } & \text { T } & \text { Significance of T } \\ \text { Socioeconomic status } & .09 & 2.22 & .0266 \\ \text { Depression } & -.56 & -12.11 & .0000 \\ \text { Access to care } & .06 & 1.42 & .1568 \\ \text { Self-efficacy } & .10 & 2.12 & .0346\end{array}$


as did socioeconomic status $(p=.0266)$ and self-efficacy ( $p$ $=.0346)$. The Beta of depression was negative, indicating that as depression decreases life satisfaction increases. The Betas of socioeconomic status and self-efficacy were positive. This indicates that the correlational relationship between these variables and life satisfaction is positive. In other words as socioeconomic status and self-efficacy increase so does life satisfaction. In sum, HIV negative respondents had significantly higher levels of life satisfaction than all HIV positive respondents regardless of stage of disease progression. In addition, socioeconomic status, depression and self-efficacy all significantly contribute to differences in life satisfaction. Access to medical care does not significantly contribute to differences in life satisfaction. Lower levels of depression lead to higher levels of life satisfaction whereas higher levels of socioeconomic status and self-efficacy lead to higher levels of life satisfaction.

5) What is the average amount and scope of self-efficacy in surveyed HIV infected individuals?

Respondents who reported that they were HIV negative had an average self-efficacy score of 65.47 (see Table 8). There was some variability in this score $(S D=12.09)$, but the mode (66) was very close to the mean, indicating a peak in the number of scores around the mean. Scores of self- 


\section{Table 8}

Mean Self-Efficacy Scores Across Stage of Infection

stage of

Disease

mean

SD

HIV negative*

65.47

12.09

HIV positive asymptomatic

62.04

12.31

AIDS Related Complex

59.89

12.44

AIDS

60.39

13.38

* This group significantly less depressed than all other groups. 
efficacy for the HIV negative group ranged from a low of 30 to a high of 85 .

HIV positive asymptomatic respondents had an average self-efficacy score of 62.04 , slightly lower than the HIV negative group, but higher than other HIV infected groups. Variation about the mean was about the same as for the HIV negative group $(\mathrm{SD}=12.31)$ and the range was a little larger. Scores in this group ranged from 23 to 85 . The mode for self-efficacy scores in the HIV positive asymptomatic group was 65 , which is also slightly lower than the HIV negative group.

Respondents who reported having AIDS Related Complex had the lowest average self-efficacy score of any group $($ mean $=59.89)$. Variation was about the same $(S D=12.44)$ but the range was a little larger for this group, with scores from 17, the lowest possible score, to 85 . The mode self-efficacy score for this group was 63 .

The respondents who had progressed to the last stage of HIV disease, AIDS, had a higher, although barely, average self-efficacy score $($ mean $=60.38)$ than those who reported having AIDS related complex. Variation was greater in this group than any other $(S D=13.38)$ but not appreciably so. Scores for this group ranged from 17 to 85 .

In sum, self-efficacy scores were highest in the HIV negative group. Self-efficacy was lowest in the group that also reported having AIDS related complex, but this average 
$($ mean $=59.89)$ was barely higher than the average for respondents with full blown AIDS (60.39). In fact there was only a .50 difference in average self-efficacy scores between these groups. HIV positive asymptomatic respondents had slightly higher level of self-efficacy than respondents who had progressed to later stages of disease. 6) Does self-efficacy vary with respect to: illness stage, socioeconomic status, depression, life satisfaction or access to medical care?

In evaluating differences in self-efficacy across stages of HIV infection the one way ANOVA was employed. In comparing the variance between groups with the variance within groups, it was found that there was a statistically significant $(p<.0001)$ difference in self-efficacy scores between groups of HIV disease progression. The F ratio (8.97) was much lower than those found in the depression and life satisfaction ANOVAs. Upon closer analysis, it was found that the only groups that were significantly different were the HIV negative group compared to all three other groups. In other words, HIV negative respondents had significantly higher levels of self-efficacy than respondents who were HIV positive regardless of stage of disease (ie asymptomatic, AIDS related complex, AIDS). The more stringent Tukey HSD and Scheffe procedures were utilized for this closer analysis to ensure that significant differences were not found merely due to the number of 
comparisons that were being made. There were no significant differences between groups that were HIV infected but at different stages of disease progression. These results are similar to those found when comparing both depression (See research question 2) and life satisfaction (See research question 4 ).

Regression analysis was utilized to test the variance in self-efficacy with respect to life satisfaction, depression and socioeconomic status. The $F$ for this analysis was high, 66.21, which was statistically significant $(p<0001)$. Residuals were well distributed and nearly bell shaped indicating that assumptions of regression analysis were not violated. The adjusted $R$ squared was lower (.37) than for the regression analysis of depression and life satisfaction. This indicates that although variance in self-efficacy score could be due to variance in life satisfaction, depression and socioeconomic status, these variables only account for 378 of the variance in self-efficacy. Even though variance in life satisfaction, depression and socioeconomic status account for only 378 of the variance in self-efficacy, they do account for more than one third of the variance in self-efficacy. Although this amount may not appear high, it is significant in the social sciences.

The Betas of these variables were low (see Table 9). As with life satisfaction, access to medical care ( $p=$ 
Table 9

Variance in Self-Efficacy

Socioeconomic status

Depression

Access to care

Life satisfaction
Beta

T

.09

$-.55$

$-.06$

.11
2.12

$-10.71$

$-1.45$

2.12
Significance of $T$

.0350

.0000

.1474

.0346 
.1474 ) was the only variable that did not significantly contribute to variance in self-efficacy. Depression significantly contributed to variance in self-efficacy $(\mathrm{p}<$ $.0001)$ as did socioeconomic status $(p=.0350)$ and life satisfaction $(p=.0346)$. The Beta of depression was negative, indicating that as depression decreases selfefficacy increases. The Betas of socioeconomic status and life satisfaction were positive. This indicates that the relationship between these variables and self-efficacy is positive. In other words as socioeconomic status and life satisfaction increase so does self-efficacy.

In sum, HIV negative respondents had significantly higher levels of self-efficacy than all HIV positive respondents regardless of stage of disease progression. In addition, socioeconomic status, depression and life satisfaction all significantly contribute to differences in self-efficacy. Access to medical care does not significantly contribute to differences in life satisfaction. Lower levels of depression lead to higher levels of self-efficacy whereas higher levels of socioeconomic status and life satisfaction lead to higher levels of self-efficacy. 7) And finally, are there differences in these relationships with respect to the precedent variables of gender, sexual orientation and ethnicity?

This question can best be analyzed by means of a two 
way analysis ANOVA. For the purpose of this analysis it will be helpful to look at depression, life satisfaction and self-efficacy separately across each of the precedent variables.

\section{Depression}

In evaluating the relationship between depression and stage of illness across gender, a two way ANOVA was performed. The mean depression scores for each group can be found in Table 10. HIV negative men were slightly more depressed that HIV negative women, but HIV infected women, regardless of stage of illness were more depressed than HIV infected men.

The main effects for this analysis were significant ( $p$ $<.001)$ and the effects of stage of illness were also significant $(p<.001)$. However, the effects of gender were not statistically significant $(p=.138)$. In addition, the two way interaction effects were not significant $(p=.299)$. This means that although there is variation in depression scores by stage of illness, gender is not a significant precedent variable. In other words, a person's gender does not have an effect on the level of depression in an HIV infected population.

The same type of analysis was conducted to evaluate the effects of stage of illness and sexual orientation. It was found that the main effects were statistically significant $(p<.001)$. In this analysis both the effects of stage of 
Mean Depression Scores by Stage of Illness and Gender

Stage of Illness

HIV negative

HIV positive asymptomatic

AIDS Related Complex

AIDS
Male

39.43

51.77

55.26

51.31
Female

38.73

60.05

58.60

57.68 
illness $(\mathrm{p}<.001)$ and sexual orientation $(\mathrm{p}=.001)$ were significant. Table 11 presents the mean depression scores for each group of stage of illness by sexual orientation. At every stage of illness bisexuals had a higher average depression score than heterosexuals and homosexuals. In addition, at every stage of illness heterosexuals had a higher average depression score than homosexuals.

The two way interaction effects of this analysis were not statistically significant $(p=.547)$. In addition, the multiple $\mathrm{R}$ squared for this analysis was particularly low $(.095)$. These findings indicate that although there are differences in depression across both stage of illness and sexual orientation there is not a significant interaction between stage of illness and sexual orientation. Sexual orientation may be an important precedent variable in depression for HIV infected individuals. In addition, it should be noted that very little of the variance in depression can be attributed to sexual orientation and stage of illness.

The mean depression scores can be examined across stage of illness and ethnicity (see Table 12). In reviewing the means, no clear pattern across ethnicity exists. For HIV negative respondents, Blacks had the highest average depression scores but this relationship did not hold true across other stages of illness. At the full blown AIDS stage, whites had the highest average depression scores. 
Table 11

Mean Depression Scores by Stage of Illness and

Sexual Orientation

Stage of IIlness

HIV negative
HIV positive asymptomatic
AIDS Related Complex
AIDS

Sexual Orientation

Hetero

Homo

Bi

43.25

35.27

50.44

54.69

51.62

54.90

55.33

55.11

66.77

53.09

50.86

58.00 
Table 12

Mean Depression Scores by Stage of IIlness and

Ethnicity

Stage of Illness

HIV negative

HIV positive asymptomatic

AIDS Related Complex

AIDS
Ethnicity

White

39.06

49.94

54.49

54.29

Hispanic

Black

35.61

45.79

55.33

53.62

60.57

54.22

47.23

51.16 
The main effects of the analysis of depression by stage of illness and ethnicity were found to be statistically significant $(p<.001)$. In this analysis, the effects of stage of illness were statistically significant $(p<.001)$ but the effects of ethnicity were not $(p=.533)$. In addition the two way interaction between ethnicity and stage of illness was not significant $(p=.280)$. Multiple $R$ squared was also low $(.082)$. This means that although there is variation in depression scores by stage of illness, ethnicity is not a significant precedent variable. In other words, a person's ethnicity does not have an effect on the level of depression in an HIV infected population.

In sum, depression scores were found to vary by stage of illness. As previously noted, in depth analysis revealed that HIV negative respondents were significantly less depressed than all HIV infected respondents, regardless of stage of illness. The two way ANOVA revealed that gender and ethnicity were not significant precedent variables for depression. Sexual orientation however, was found to be a significant precedent variable with bisexuals being the most depressed of all groups. In addition, homosexuals were found to be less depressed than heterosexuals.

\section{Life Satisfaction}

The effects of the precedent variables of gender, sexual orientation and ethnicity across stage of illness were assessed by life satisfaction scores. In evaluating 
the effects of gender and stage of illness the main effects for the analysis were found to be statistically significant $(p<.001)$. Stage of illness was significant $(p<.001)$ in this analysis but gender was not $(p=.887)$. The mean life satisfaction scores can be seen in Table 13. Life satisfaction was lowest in the groups who reported having AIDS related complex for both men and women. The two way interaction effect of this analysis was statistically significant $(p=.001)$, but the multiple $R$ squared was especially low $(.056)$. This means that although there is variation in life satisfaction scores by stage of illness, gender is not a significant precedent variable. There may however be an effect on life satisfaction by the combination of both stage of illness and gender. In other words, a person's gender by itself does not have an effect on the amount of life satisfaction, but there may be an effect in combination with stage of illness, in an HIV infected population.

A two way ANOVA produced slightly different results when evaluating the precedent variable of sexual orientation. Table 14 details the mean life satisfaction scores for each group. Across each stage of illness, respondents who reported that they were homosexual had higher average life satisfaction scores than heterosexual and bisexual respondents. In addition, bisexual respondents had higher average life satisfaction scores than 
Table 13

\section{Mean Life Satisfaction Scores by stage of Illness and Gender}

Stage of Illness

HIV negative

HIV positive asymptomatic

AIDS Related Complex

AIDS
Male

21.11

18.83

18.67

18.14
16.61

Female

23.66

16.23

13.87 


\section{Table 14}

\section{Mean Life Satisfaction Scores by stage of Illness and Sexual orientation}

Stage of Illness

HIV negative

HIV positive asymptomatic

AIDS Related Complex

AIDS
Sexual orientation

Hetero

Homo

Bi

19.06

23.60

19.81

16.52

19.72

16.86

14.29

18.71

17.38

17.65

18.18

18.08 
heterosexual respondents across each stage of illness. HIV negative respondents had the highest life satisfaction scores of any stage of illness.

The main effects of the two way ANOVA of life satisfaction by stage of illness and sexual orientation were statistically significant $(\mathrm{p}<.001)$. In addition both the effects of stage of illness $(p<.001)$ and sexual orientation $(p<.001)$ were statistically significant. However, the two way interaction effects were not significant ( $p=.274$ ) and the multiple $R$ squared was low (.093). This means that there is variation in life satisfaction scores by stage of illness and that sexual orientation is a significant precedent variable. In other words, in an HIV infected population, a person's sexual orientation may be a significant precedent variable in their amount of life satisfaction. In addition, it should be noted that very little of the variance in life satisfaction can be attributed to sexual orientation and stage of illness.

An analysis of the effects of stage of illness and ethnicity on life satisfaction revealed that the main effects for this analysis were statistically significant ( $p$ $<.001)$. In addition both the effects of stage of illness $(\mathrm{p}<.001)$ and $(\mathrm{p}<=.001)$ ethnicity were statistically significant. HIV negative respondents had the highest life satisfaction scores across all other stages of illness (see Table 15). The two way interaction of these variables was 
Table 15

Mean Life Satisfaction Scores by Stage of Illness and Ethnicity

Stage of Illness

HIV negative
HIV positive asymptomatic
AIDS Related Complex
AIDS

Ethnicity

white

21.85

19.48

19.60

17.31
Black

17.74

23.87

18.76

16.90

17.82

15.00

20.46

17.48 
not significant $(\mathrm{p}=.109)$ and the multiple $\mathrm{R}$ squared was low $(.068)$. This means that there is variation in life satisfaction scores by stage of illness and that ethnicity is a significant precedent variable. In other words, a person's ethnicity may have an effect on their amount of life satisfaction in an HIV infected population. However very little of the variation in life satisfaction can be attributed to stage of illness and ethnicity.

In sum, life satisfaction scores, like depression scores, were found to vary by stage of illness. As previously noted, in depth analysis revealed that HIV negative respondents had significantly higher life satisfaction scores than all HIV infected respondents, regardless of stage of illness. The two way ANOVA revealed that gender was not a significant precedent variable for life satisfaction. Sexual orientation and ethnicity however, were found to be significant precedent variables. Homosexuals were found to have the highest life satisfaction scores with bisexuals having the second highest.

\section{Self-Efficacy}

Two way ANOVAs were also performed to determine if the precedent variables of gender, sexual orientation and ethnicity had any effect on the relationship between stage of illness and self-efficacy. Table 16 details the mean self-efficacy scores of respondents by stage of illness and 
Table 16

Mean Self-Efficacy Scores by stage

of Illness and Gender

Stage of Illness

HIV negative

HIV positive asymptomatic

AIDS Related Complex

AIDS
Male

65.52

62.57

59.88

60.81
Female

66.03

58.90

62.80

58.39 
gender. Women respondents were found to have higher average self-efficacy scores in both the HIV negative and AIDS related complex stages of illness. HIV negative respondents had higher average self-efficacy scores than any of the other stages of illness regardless of gender. The main effects for this analysis were found to be significant $(p<.001)$ as were the effects of stage of illness $(p<$ $.001)$. However, the effects of gender $(p=.479)$ were not significant. Nor were the effects of the two way interaction between stage of illness and gender $(p=.261)$. The multiple $R$ squared for this analysis was also low $(.035)$. This means that although there is variation in self-efficacy scores by stage of illness, gender is not a significant precedent variable. In other words, a person's gender does not have an effect on the amount of selfefficacy in an HIV infected population.

The main effects of the analysis of self-efficacy by stage of illness and sexual orientation were found to be statistically significant $(p<.001)$. In addition the effects of stage of illness $(p<.001)$ and sexual orientation $(p=.002)$ were also found to be significant. Table 17 details the mean self-efficacy scores by stage of illness and sexual orientation. At almost every stage of illness homosexual respondents had the highest self-efficacy scores. Respondents who were heterosexual showed a slow drop in self-efficacy as HIV disease progressed. This was 


\section{Table 17}

\section{Mean Self-Efficacy Scores by Stage of IIlness and Sexual orientation}

Stage of Illness

HIV negative

HIV positive asymptomatic

AIDS Related Complex

AIDS
Sexual Orientation

Hetero

Homo

Bi

63.43

67.40

62.59

59.73

63.64

60.00

59.00

59.18

65.69

57.70

62.05

62.46 
not the case for homosexual and bisexual respondents. The two way interaction of stage of illness and sexual orientation was not significant $(p=.239)$ and the multiple $\mathrm{R}$ squared was also low (.049).

This means that there is variation in life satisfaction scores by stage of illness and that sexual orientation is a significant precedent variable. In other words, a person's sexual orientation may have an effect on their amount of life satisfaction in an HIV infected population. More specifically, heterosexual individuals who are infected with HIV may have a larger drop in life satisfaction than homosexual or bisexual individuals. It should be noted however, that stage of illness and sexual orientation accounted for very little of the variation in life satisfaction.

The main effects were statistically significant in the analysis of self-efficacy by stage of illness and ethnicity $(p<.001)$. Mean self-efficacy scores are outlined in Table 18. Average self-efficacy scores are highest across all ethnic groups for HIV negative respondents. The effects of stage of illness $(\mathrm{p}<.001)$ and ethnicity $(\mathrm{p}=.02)$ were found to be significant, but the two way interaction effects were not $(p=.541)$. Multiple $R$ squared was also very low in this analysis $(.042)$. This means that there is variation in self-efficacy scores by stage of illness and that ethnicity is a significant precedent variable. In other words, a 
Table 18

Mean Self-Efficacy Scores by stage of IIness and Ethnicity

Stage of Illness

HIV negative

HIV positive asymptomatic

AIDS Related Complex.

AIDS
Ethnicity

White Hispanic Black

65.94

66.13

61.68

63.89

62.57

58.50

61.54

57.61

61.17

60.58

62.35

57.97 
person's ethnicity may have an effect on their amount of self-efficacy in an HIV infected population. In addition, stage of illness and ethnicity account for very little of the variation in self-efficacy.

In sum, self-efficacy scores were found to vary by stage of illness. As previously noted, in depth analysis revealed that HIV negative respondents had significantly higher levels of self-efficacy than all HIV infected respondents, regardless of stage of illness. The two way ANOVA revealed that gender was not a significant precedent variable for self-efficacy. Sexual orientation and ethnicity were found to be significant precedent variables. 


\section{CHAPTER V \\ DISCUSSION}

Within this chapter, the results are discussed. Possible implications for three major areas of social work (i.e. practice, education and research) are also detailed.

\section{Severity and Scope}

The most fundamental and primary of the research questions posed by this survey were about the average level and scope of depression, life satisfaction and self-efficacy for surveyed HIV infected individuals. This question was answered and the results have potential implications for social work practice, education and research. Implications

\section{Intervention and Practice}

The implications of these findings for intervention and practice in social work may be significant. In fact, given the numbers of individuals in the United States infected with the virus, as well as the likelihood that social workers will be intensely involved in the mental health treatment of these individuals, the results will hopefully have an effect on the practice of social work in the future.

The high incidence of depression, as well as lowered levels of life satisfaction and self-efficacy in the HIV infected population give social work practitioners vital information about the mental health components that are associated with HIV infection. The results of this study 
provide empirical information that is needed in the assessment and treatment of HIV infected individuals.

Clearly, given the high incidence of depression in this population, social work practitioners should assess for clinical depression whenever treating an HIV infected person. Given that there is evidence that depression can adversely effect compliance with medical care, activities of daily living and even prognosis (cf. Christensen, Turner, Slaughter \& Holman, 1989; Grassi, Rosti, Albier \& Marangolo, 1989; Leedom, Meehan, Procci \& Zeidler, 1991; Lustman, Clouse \& Carney, 1988; Peterson, Kimmel, Sacks \& Mesquita, 1991; Shulman, Pacey, Price \& Spinelli, 1987) this increase in understanding about the incidence of depression could have dramatic effects on the HIV infected individual. Taken with the finding that self-efficacy decreases dramatically after diagnosis, it will be important for social work practitioners to understand that the HIV infected individual will have greater difficulty finding help without assistance than they would normally have. This finding appears to indicate that there is a greater need for concrete services for the HIV infected population. The finding that life satisfaction decreases as HIV infected individuals become more ill found may also have practice implications. This finding indicates that HIV infected individuals may need assistance to improve the quality of their life by improving their life satisfaction. 
Cognitive therapy has been found to be the most effective treatment for depression to date (cf. Beck, Rush, Shaw \& Emery, 1979; Blackburn \& Bonham, 1980; McLean \& Hakstian, 1979; Rush, Beck, Kovacs \& Hollon, 1977). The findings of this survey indicate that self-efficacy and life satisfaction should also be addressed during the treatment of depression. A cognitive behavioral model might be tried to decrease depression and increase levels of self-efficacy by gradually having clients demonstrate to themselves that they can accomplish many of the things that they want to do. Specific cognitive therapy techniques such as graded task assignments and homework assignments (Beck, 1976) could decrease depression and increase self-efficacy at the same time. Graded task assignments involves having the patient perform small tasks in a progressive and sequential manner until a larger or more difficult task, that the client believed they could not accomplish, has been successfully completed.

Although there is evidence to show that cognitive behavioral therapy is effective in HIV infected homosexual men (Antoni et al., 1991; Ussher, 1990), this evidence is preliminary and the effectiveness of this treatment with an HIV infected population must be evaluated. Case management services may also be important given the low levels of selfefficacy found in this study and the concrete service needs of HIV infected individuals. The high incidence of 
depression and low self-efficacy found indicate that finding effective treatments may be important for the majority of HIV infected individuals.

On a macro practice level, these results indicate that the need for mental health services for HIV infected individuals is enormous. In light of the national health care plan that is being proposed by the Clinton administration, as well as numerous rumors that mental health services may be dramatically reduced before this plan is accepted (Rubin, 1993) there could be serious consequences for the HIV infected population.

From a social policy perspective, it will be important for social workers to be involved in advocating for mental health and concrete services for HIV infected individuals. Advocacy has traditionally been an important part of social work practice. The findings of a high incidence of depression as well as low levels of self-efficacy and life satisfaction indicate that advocacy for HIV infected individuals will be important as the national health care plan is changed and developed.

Education

It is the responsibility of social work educators to prepare social workers for the types of problems that they will have to work with once they begin practice. Research indicates that social workers have limited knowledge in working with HIV infected clients (Dhooper et al., 1987-88; 
Peterson, 1991; Wexler, 1989). Since most if not all social workers will work with HIV infected clients, training for the treatment of HIV infected individuals will become increasingly important. It will also be important for social work educators to incorporate what is known about the mental health problems of HIV infected individuals into social work curriculum. These results may also have other implications for the way in which practice and research methodology courses are taught. Given the high incidence of depression in this population as well as the serious potential consequences, these results demonstrate a need for social work educators to train students to effectively treat depression in this population. This is also true of increasing life satisfaction and self-efficacy in this population.

Training students to effectively treat depression, life satisfaction and self-efficacy problems involves not only the techniques and theories of psychotherapy, but also the research methodology background necessary to evaluate the effectiveness of these treatments. Only an empirically based clinical practice can ensure that the interventions are effective. Given that depression can adversely effect medical outcome (cf. Christensen et al., 1989; Leedom et al., 1991; Lustman et al., 1988; Peterson et al., 1991; Shulman et al., 1987), effective treatment not only will result in a better quality of life but also may result in 
increased longevity for a population that is chronically and terminally ill. The burden of educating social workers on the importance of, as well as how to apply empirical clinical practice falls directly on schools of social work. $\underline{\text { Research }}$

The results of this survey increase the knowledge base of mental health problems and HIV infection. Although there has been conflicting evidence in the literature about the incidence of depression (Donlou et al., 1985; Hoffman, 1986; Rabkin et al., 1991), this study provides much needed information about the incidence and severity of depression and is the largest survey conducted to date. Although not generalizable to the entire population of individuals infected with HIV, the large number of respondents involved increases the importance of this data. These results might be utilized to provide the necessary financial support for funding intervention research, which is costly and time consuming. Given the high incidence of depression in this population, this is an important direction for research in HIV to address.

Many HIV positive individuals will have to utilize this new national health care plan for access to medical care. As a result, any limitations in insurance coverage for mental health services could eventually apply to almost all individuals infected with HIV. With the incidence of clinical depression being high and the reduction in quality 
of life that results, it will be imperative for social workers to find effective and efficient means for treating depression in this population. If the effectiveness of these treatments can be proven empirically, the evidence could be utilized to advocate for continued insurance coverage for the mental health needs of HIV infected individuals. Therefore is will become increasing important for social work practitioners to empirically evaluate the effectiveness of their practice.

\section{Variance in Depression}

Another important question posed in this study was about variation in depression. This survey investigated whether or not depression scores varied by stage of illness, life satisfaction, self-efficacy, socioeconomic status and access to medical care for surveyed HIV infected individuals. This question was answered and the results have potential implications for social work practice, education and research.

Implications

\section{Intervention and Practice}

The results of this investigation demonstrate the relationship between depression and HIV infection. Although depression in this population would seem to be expected, there has been contradictory evidence in the literature to date (Donlou et al., 1985; Hoffman, 1986; Rabkin et al., 1991). Social work practitioners should assess all HIV 
infected clients for depression. In addition, self-efficacy and life satisfaction issues should also be addressed. As previously noted, cognitive therapy has been found to be the most effective treatment for depression to date (cf. Beck et al., 1979; Blackburn \& Bonham, 1980; McLean \& Hakstian, 1979; Rush et al., 1979). A cognitive behavioral model of treatment would allow for the inclusion of the goals of increasing self-efficacy and life satisfaction to the treatment of depression. Case management services could compensate for the lower levels of self-efficacy until an increase in self-efficacy is achieved. This would ensure that the client received the concrete services that they needed, such as assistance in procuring social security disability, food stamps and Medicare, despite low levels of self-efficacy. This study provides evidence that concrete social services, such as assistance in the procurement of Medicare, may have an effect on the amount of depression a HIV infected client experiences. These results stress the importance of assisting the client not only in mental health issues but also in practical issues such as access to medical care.

\section{Education}

Social work education has always included social policy. The results of this investigation increase support for the incorporation of social policy education into practice oriented programs. More specifically, the fact 
the access to medical care may contribute significantly to variance in depression documents the need for integrated social services for HIV infected individuals. Life satisfaction and self-efficacy are also important mental health components for HIV infected individuals.

Furthermore, the results demonstrate the interrelationship between multiple mental health problems and should be utilized to increase understanding of the complexity of mental health in social work practice courses. Medical social work courses should also incorporate the findings of this research into the curriculum. The findings of this study are the strongest empirical results to date on the mental health problems of depression, life satisfaction and self-efficacy in HIV infected individuals.

Research

The results of this investigation also add to the foundation of knowledge needed for intervention research. By accounting for over half of the variance in depression, the findings of this study provide key variables for future investigation. Given the time and expense of outcome research, this foundation of correlational level knowledge is important.

Furthermore, by demonstrating the relationship between depression and access to medical care, the results demonstrate the need for continued research into the effects of social policy. Specifically, since variance in 
depression can partially be accounted for by access to medical care future research should investigate potential mental health gains from increased access to medical care. The proposed national health care policy may be effected by research that demonstrated that there were multiple indirect benefits from increasing access to medical care. If increased access to care was found to buffer the severity of depression in a medically ill population, an additional benefit of preventative mental health could be attributed to the national health care policy.

Variance in Life Satisfaction and Self-Efficacy In addition, this research posed a question about variation in life satisfaction. This study investigated whether or not life satisfaction scores varied by stage of illness, depression, self-efficacy, socioeconomic status and access to medical care for surveyed HIV infected individuals.

As with depression and life satisfaction, this survey also evaluated variation in self-efficacy. More specifically, this study determined whether or not selfefficacy scores varied by stage of illness, depression, life satisfaction, socioeconomic status and access to medical care for surveyed HIV infected individuals. These questions were answered and the results have potential implications for social work practice, education and research. 
Implications

\section{Intervention and Practice}

clearly findings about variance in satisfaction with life relate to quality of life issues for the population under study. For individuals infected with HIV, quality of life issues may be the most important of all. Since medical science is unable to find a cure for this chronic and eventually fatal disease, quality of life may be all that is left for HIV infected individuals. By providing the first evidence of other variables that can account for variance in life satisfaction, these findings provide a basis from which a social work practitioner can begin treatment.

As previously noted there is evidence to show that cognitive behavioral therapy is effective in HIV infected homosexual men (Antoni et al., 1991; Ussher, 1990). Given this framework, the behavioral components of treatment should include a system of rewards for activities that the patient enjoys. It is difficult for some individuals to spend time and energy doing things that simply make them happy, yet it is these very behaviors that contribute to satisfaction with life. Perhaps a hierarchy of pleasurable activities that the patient wants to do or accomplish could be employed. This hierarchy could be developed in the same way that the hierarchy of fears is developed in systematic desensitization. Cognitive therapy techniques, such as the Socratic dialogue, could also be employed to eliminate the 
thoughts and feelings that prevent the client from engaging in the things he or she values most. The Socratic dialogue involves a role play between the clinician and client in which the roles are reversed (Dobson \& Block, 1988). Clearly the effectiveness of this intervention would have to be evaluated, but since there is no literature to date about life satisfaction in the HIV infected population this survey provides information which can assist in determining where to begin.

The finding that more than one third of the variance in self-efficacy can be accounted for by depression, life satisfaction and socioeconomic status could also have implications for social work practice. An increase in selfefficacy may be especially important to clients who, due to their illness, have justifiable feelings of having no control in their lives. Cognitive rehearsal could be employed to increase the client's level of self-efficacy by making the steps involved in accomplishing a given task more familiar (Dobson \& Block, 1988).

\section{Education}

The results of this study also provide data that is needed in order to teach social work students how to become more effective and efficient practitioners. By demonstrating the interrelationship between satisfaction with life and self-efficacy with other mental health issues such as depression, this investigation provides a basis for 
planning and implementing multifaceted treatment goals. Empirical clinical practice can have multidimensional goals for treatment, these findings provide preliminary evidence that this may be important for HIV infected clients. Medical social work and human sexuality course curriculum may also be improved by these findings. The knowledge base of medical and sexual problems is limited compared to other areas of social work practice. These results add to the knowledge base of these specialized areas and demonstrate the complexity of mental health in a medical population.

\section{$\underline{\text { Research }}$}

The findings also provide the correlational level knowledge base that is needed before beginning expensive intervention research. By accounting for a large proportion of the variance in life satisfaction and self-efficacy, the results provide key variables for future investigation. These findings imply that intervention research with HIV infected individuals should focus on depression and socioeconomic status. Given that all HIV infected individuals will eventually lose their jobs due to illness or disability, the contribution of socioeconomic status may be particularly important.

Social policy programs such as social security disability and other entitlement programs may need to be changed in order to increase their effectiveness. For 
example, it may eventually be demonstrated that the eligibility requirements for these programs cause emotional problems by failing to support individuals until they have been disabled for a prolonged period of time.

\section{Precedent Variable Effects}

And finally, this study posed a question about the effects of precedent variables on depression, life satisfaction and self-efficacy. For this question the precedent variables of gender, sexual orientation and ethnicity were analyzed. Significant precedent variables were found and the results have potential implications for social work practice, education and research.

\section{Implications}

\section{Intervention and Practice}

The finding that sexual orientation is a significant precedent variable in depression, life satisfaction and self-efficacy has important implications for social work practice. Given these findings, social work practitioners may need to tailor the delivery of treatments for these problems to the sexual orientation of the client being served. Clearly, there are differences in culture with respect to sexual orientation. As with any other minority population, social work practitioners will need to have an understanding of these cultural differences in order to be more effective. Future research should investigate why these differences exist. These differences may be important 
in the practice of group therapy. More specifically, it may be important to create groups whose members have the same sexual orientation.

The possible effects of being suspected to be homosexual or an intravenous substance abuser by friends, family and colleges should also be investigated. HIV infected heterosexual individuals may feel more isolated than HIV infected homosexual individuals due to these suspicions. This finding may also be due to social isolation. Given that the majority of the clients at the HIV nonprofit agencies are homosexual, some heterosexual clients may not feel comfortable being a minority and therefore may chose not to receive services at that agency.

Lower self-efficacy in heterosexuals with HIV infection may also be due to social isolation. Many social action organizations revolving around issues related to HIV and AIDS have been founded by homosexual men. These organizations may provide an outlet by which homosexual HIV infected individuals can increase their level of selfefficacy. Given that the findings of this investigation indicate that self-efficacy may contribute to some of the variance in depression and life satisfaction, membership in these social action organizations may provide some relief for these problems. Treatment for lower self-efficacy may also include increasing involvement in social action organizations or other nonprofit organizations. 
Certainly the finding that depression was higher and life satisfaction and self-efficacy lower in heterosexual respondents should alert social workers to evaluate all heterosexual HIV infected clients for these problems. Even though homosexual respondents were found to have the highest level of life satisfaction and bisexual respondents were found to have the lowest levels of depression, all HIV infected clients should be evaluated for these potential mental health problems.

The finding that gender was not a significant precedent variable is also important for social work practice. It may mean that social work interventions that are found to be effective for men may also be effective for women.

\section{Education}

Social work education has always attempted to incorporate understanding of different ethnic backgrounds in both practice and policy course work. The finding that ethnicity is a significant precedent variable in life satisfaction and self-efficacy but not depression is significant for social work education. Clearly differences in mental health issues across ethnic groups should be an integral part of social work education.

The finding that sexual orientation was a significant variable in depression, life satisfaction and self-efficacy is also important for social work education. It demonstrates the need to include sexual orientation as one 
of the potential differences that occur in the population and that like ethnic background these differences are beneficial not detrimental to society.

\section{Research}

The findings of this survey clearly indicate that more attention must be paid in future research to ethnicity and sexual orientation. Given that most of the research on HIV infection and AIDS has had a predominately white homosexual male sample, these findings indicate that less is known about the fastest growing populations of HIV infected individuals, specifically heterosexuals and minorities. These results provide evidence that knowledge about mental health issues in white homosexual men cannot be assumed true in other populations. 


\section{CHAPTER VI}

\section{CONCLUSION}

This chapter provides a detailed description of the limitations of this study. It also proposes future directions for social work research with HIV infected individuals.

\section{Limitations of the Research}

External Validity

Perhaps the largest limitation of this study is a lack of external validity, due to the sampling procedures. In short, a purposive sample cannot be generalized to the population from which it was drawn. Since the parameters of the population of HIV infected individuals are not known, however, a random generalizable sample was not possible. Without a known group of HIV infected individuals, only a purposive sample was possible. Multicollinearity

Multicollinearity exists when two or more independent variables are intercorrelated. It was evaluated in this survey because when multicollinearity exists it is not possible to determine the separate effects on the dependent variable. In other words, the Betas of the independent variables cannot be interpreted. The adjusted $R$ squared however, is not effected by multicollinearity.

Depression was found to be significantly correlated with both life satisfaction and self-efficacy (see Table 19) 


\section{Table 19}

Correlation Coefficients for Depression, Life Satisfaction and Self-Efficacy

Life

Satisfaction

Depression

Depression

Life Satisfaction

Self-Efficacy
1.00

$-.4224 *$

$-.6354 *$
1.00

.1232
Self-

Efficacy

* Statistically significant at the .01 level 
This significant correlation indicates that multicollinearity existed in the regression analysis performed where depression was treated as an independent variable with either life satisfaction or self efficacy. This correlation effects the data analysis for the research question regarding variance in self efficacy with respect to depression, life satisfaction and access to medical care. It also effects the question regarding variance in life satisfaction with respect to depression, self-efficacy and access to medical care. Therefore, although the specific contribution of each variable cannot be determined, the results regarding the total variance in both life satisfaction and self-efficacy are not effected. The correlational relationship between self-efficacy and life satisfaction was not found to be significant. Bias in Sample

Given that the sample in this study was purposive, the additional limitation of selection bias could have occurred. It is clear from the sampling procedures that the sample obtained in this investigation may have several biases. Pools of respondents from each of the sources may have their own unique bias. In an attempt to reduce the overall bias, multiple sources were included that should be unbiased in terms of at least one of the variables under consideration. Patients of medical doctors who specialize in the treatment of HIV infection and AIDS were recruited because 
this pool provides the greatest concentration of HIV infected individuals and persons with AIDS (PWAs) without known emotional problems. Although clients at the major nonprofit agencies that were founded to service HIV infected individuals were more likely to have some sort of mental health problem, they were less likely to have medical insurance. This was done to balance the respondents gathered from medical offices where they were likely to have medical insurance and did not necessarily have a mental health problem.

Participants recruited from convention events were not more likely to have a mental health problem or medical insurance. In this respect respondents from these sources may be the least biased pool of subjects in this survey. In addition, potential bias is apparent by close analysis of the demographic characteristics of respondents.

Respondents for the survey, regardless of stage of disease progression were most likely to be white nonhispanic homosexual men. Clearly these are not the demographic characteristics of all HIV infected individuals. They are however, representative of the largest proportion of individuals to have been reported to have AIDS to date (Centers for Disease Control, 1992). In addition, women, heterosexuals and minorities were better represented in the sample than any HIV literature to date (cf. Coates et al., 1989; Donlou et al., 1985; Huggins et al., 1991; Orgero \& 
Rodway, 1991; Rabkin et al., 1991).

Selection bias may also have existed due to the differences between individuals who chose to participate when recruited and those who refused. Overall response rate was calculated and found to be greater than 908 . This indicates that only a small proportion of individuals who were recruited refused and is an indication of less selection bias.

The methodology in this study attempted to build on and improve the methodology employed in other studies of sensitive subjects. With the literature on other sensitive topics in mind, it is argued that the methodology of this survey is not only substantially less biased than most other research on sensitive topics, but also is the best available methodology given the constraints of cost and a population with no empirically known parameters. Sample Size, Type I and Type II Errors

The statistical power of the analysis in this investigation was very high. In other words, the probability of a Type II error was very small. This is due to the large number (871) of responses collected. The statistical power of the analysis is in fact one of this study's major strengths. In fact, the majority of past surveys of sensitive subjects had insufficient power for the types of analysis that the researchers were performing (cf. Dancey, 1992; Duffy \& Rusbult, 1986; Gibbons et al., 1981; 
Scheider, 1986; Schullo \& Alperson, 1984). However, this strength leads to a potential problem with Type I errors.

Since the relationship between Type I and Type II errors is inverse, as the possibility of a Type II error decreases the possibility of a Type I error increases. A Type I error occurs when a true null hypothesis is rejected. In simpler terms, a Type I error occurs when a relationship is found to be statistically significant and it is not (the results could have occurred by chance) •

Given the low probability of a Type II error it was important to reduce the possibility of a Type I error. In order to do this both the Tukey's Honestly Significant Difference (HSD) test and the Scheffe test were utilized. The Tukey's Honestly Significant Difference (HSD) test was employed to determine exactly which group means were significantly different than the overall mean. This was important in this analysis because the $F$ ratio of an ANOVA only reflects whether some of the group means were significantly different than the overall mean (Vogt, 1993). The Tukey's Honestly Significant Difference (HSD) test is an individual comparison test and is therefore more conservative than an overall $\mathrm{F}$ ratio.

The Scheffe test was also utilized to reduce the possibility of a Type I error. This procedure was originally designed for post hoc analysis and is therefore a conservative test of significance. This procedure was 
employed despite the fact that all of the comparisons made in this analysis were determined a priori. The Scheffe test is also utilized to compensate for unequal cell frequencies.

Unequal cell frequencies always occur when ANOVA is employed in survey research. This is due to the fact that the examiner cannot control cell frequencies in survey research in the way that they can be controlled in experimental research where subjects are assigned. Unequal cell frequencies can cause an increase in within groups variance which can in turn lead to a Type I error. Again, the Scheffe test was employed to guard against this.

Although the data gathered by this study cannot be generalized to the entire population of HIV infected individuals and is only correlational level knowledge by design, it provides a solid foundation on which cost effective intervention research can be based.

Implications for Future Research

\section{Practice}

This investigation provides a basis for which more in depth analysis of the psychological components of HIV infection can begin. This may be necessary to ensure that social work practitioners have an accurate overview of potential mental health problems so that they can develop treatment strategies more effectively.

Perhaps more importantly, the results provide the correlational knowledge base necessary to begin intervention 
research geared at finding an effective and efficient treatment for depression, low life satisfaction and selfefficacy in the HIV infected population. Given the potentially serious consequences of leaving depression untreated in any medical population, this research direction is extremely important. These results also provide preliminary evidence that gender and ethnicity may not be significant precedent variables in depression and that they should not be controlled for initially. This is not to say that interventions for depression will not be effected by the gender or ethnicity of the clients involved.

Sexual orientation was found to be a significant precedent variable for depression, life satisfaction and self-efficacy. Future research should investigate whether or not the effects of intervention vary by the clients' sexual orientation. This may be particularly important research in light of the fact that heterosexuals were found to have higher levels of depression than homosexuals. In addition, most of the nonprofit agencies that provide mental health services for persons with AIDS were initially set up by homosexual men. Gay Men's Health Crisis Network is a primary example of this. If heterosexual victims of AIDS do not feel comfortable receiving services at agencies where the majority of the clients are homosexual and they have higher levels of depression, as well as lower levels of life satisfaction and self-efficacy, then the consequences of 
these mental health issues could be enormous.

The findings also indicate that over half of the variance in depression can be accounted for by selfefficacy, life satisfaction and access to medical care. Future practice oriented research should build on this knowledge and determine whether interventions aimed at increasing life satisfaction and self-efficacy also result in a decrease in depression. This type of research could lead to more efficient and cost effective practice. Policy

The results indicate that lower access to medical care may contribute significantly to depression. Future research should build on this knowledge base and determine whether or not increasing access to medical care can decrease depression. This research could play an especially important role in light of the proposed national health care policy. This policy is currently written to ensure access to medical care for all United States residents, including previously uninsurable HIV infected individuals. Given that many insurance companies now require HIV antibody screening before selling a policy and the fact that these companies generally refuse to insure individuals who are HIV infected, the national health care policy may be the only means by which HIV positive individuals can obtain medical insurance. The most important of all social policies that relates to AIDS is the Ryan White Comprehensive AIDS Resources 
Emergency (CARE) Act (United States Conference of Mayors, 1990). This Act provides for emergency assistance to metropolitan areas with large HIV infected populations and support for states to finance care related and early intervention programs. This Act is certain to play a key role in the administration of health care. In light of the findings of this survey, future research should investigate the effects of increased access to medical and mental health services that are provided by agencies funded through this Act. This future research may play an instrumental role in the continued funding of these agencies. Since one of the primary functions of social work is to aid in the procurement of necessary services, evidence of the benefits of the services delivered by the agencies may become vital. 


\section{References}

Ackerman, F. Family-systems therapy with a man with AIDSrelated complex. Family Systems Medicine, $7(3), 292-$ 304 .

Alcalay, R., Sniderman, P.M., Mitchell, J. \& Griffen, R. (1989-1990). Ethnic differences in knowledge of AIDS transmission and attitudes towards gays and people with AIDS. International Quarterly of Community Health Education, $\underline{10}(3), 213-222$.

Alonso, A.M. \& Koreck, M.T. (1989). Silences:

"Hispanics," AIDS and sexual practices. Differences, $1(1), 101-124$.

American Foundation for AIDS Research. (1992). AIDS/HIV Treatment Directory. St Louis: Missouri. Anthony, B.D. (1982). Lesbian client-lesbian therapist: Opportunities and challenges in working together. Homosexuality and Psychotherapy, $I(2-3), 45-57$. Antoni, M.H., Baggett, I., Ironson, G., LaPerriere, A., August, S., Klimas, N., Schneiderman, N. \& Fletcher, M.A. (1991). Cognitive-behavioral stress management intervention buffers distress responses and immunologic changes following notification of HIV-1 seropositivity. Journal of Consulting and Clinical Psychology, 59, 906-915.

Baker, F., Curbow, B. \& Wingard, J.R. (1991). Role retention and quality of life of bone marrow transplant 
survivors. Social Science and Medicine, 32(6), 697704.

Bandura, A. (1977). Self-efficacy. Toward a unifying theory on behavioral change. Psychological Review, 84, 191-215.

Barre-Sinoussi, F. Cherman, J.C. \& Rey, F. (1983).

Isolation of a T-lymphotropic retrovirus from a patient at risk for acuired immune deficiency sysdrome (AIDS). Science, 220, 868-871.

Beck, A.T. (1976). Cognitive Therapy and the Emotional

Disorders. International Universities Press, New York. Beck, A.T., Rush, A.J., Shaw, B.F. \& Emery, G. (1979).

Cognitive Therapy of Depression. New York: Guilford. Beckham, D. (1989). Group work with people who have AIDS. Journal of Psychosocial Oncology, 6(1/2), 213218 .

Bell, D., Feraios, A. \& Bryan, T. (1990). Adolescent males' knowledge about AIDS in the context of their social world. Journal of Applied Social Psychology, $\underline{20}(5), 424-448$.

Blackburn, I.M. \& Bonham, K.G. (1980). Experimental effects of a cognitive therapy technique in depressed patients. British Journal of Social and Clinical Psychology, 19(4), 353-363. 
Brody, C.M. (1989). Jenny: Treatment of a client who is HIV seropositive. Psychotherapy in Private Practice, 구(3), 95-101.

Brown, L.S., Chu, A., Nemoto, T. \& Ajuluchukwu, D. (1989). Human immunodeficiency virus infection in a cohort of intravenous drug users in New York City: Demographic, behavioral and clinical features. New York State Journal of Medicine, 89(9), 506-510. Busk, P.L. \& Marascuilo, L.A. (1988). Autocorrelation in single-subject research: A counterargument to the myth of no autocorrelation. Behavioral Assessment, 10, 229242 .

Califia, P. (1979). Lesbian sexuality. Journal of Homosexuality, $\underline{4}(3), 255-266$.

Campbell, N.K. \& Hackett, G. (1986). The effects of mathematics task performance on math self efficacy and task interest. Journal of Vocational Behavior, 28(2), $149-162$.

Carballo-Dieguez, A. (1989). Psychotherapy with AIDS patients. Psychotherapy in Private Practice, $I(3), 85-$ 89.

Carlson, B.E. \& Videka-Sherman, L. (1990). An empirical test of androgyny in the middle years: Evidence from a national survey. Sex Roles, 23 (5-6), 305-324. 
Catalan, J., Klimes, I., Bond, A., Garrod, A. \& Rizza, C. (1992). The psychosocial impact of HIV infection in men with haemophilia: Controlled investigation and factors associated with psychiatric morbidity. Journal of Psycosomatic Research, $36(5), 409-416$.

Centers for Disease Control, (1982). Update on acquired immunodeficiency syndrome (AIDS) - United States Morbidity and Mortality Report. Atlanta, Georgia. Centers for Disease Control, (1992) . 1993 Revised Classification System for HIV Infection and Expanded Surveillance Case Definition for AIDS amoung Adolescents and Adults. Morbidity and Mortality Weekly Report $\underline{41(R R-17), ~ A t l a n t a, ~ G e o r g i a . ~}$

Centers for Disease Control, (1993a). HIV/AIDS

Surveillance Year-End Edition. Atlanta, Georgia. Centers for Disease Control, (1993b). Surgeon General's Report to the American Public on HIV Infection and AIDS. Atlanta, Georgia. Chapman, B.E. \& Brannock, J.C. (1987). Proposed model of lesbian identity development: An empirical examination. Journal of Homosexuality, 14(3), 69-80. Christensen, A.J., Turner, C.W., Slaughter, J.R. \& Holman, J.M. (1989). Perceived family support as a moderator of psychological well-being in end stage renal disease. Journal of Behavioral Medicine, 12(3), 249-265. 
Coates, T., McKusick, L., Kuno, R. \& Stites, D.P. (1989). Stress reduction for men with HIV. Advances, $6(3)$, 7-8.

Cohen, M.A. (1990). Biopsychosocial approach to the human immunodeficiency virus epidemic: A clinician's primer. General Hospital Psychiatry, 12(2), 98-123. Comstock, G.D. (1989). Victims of anti-gay/lesbian violence. Journal of Interpersonal Violence, $\underline{4}(1)$, 101-106.

Corcoran, K. \& Fischer, J. Measures for Clinical

Practice. New York: The Free Press. Cotton, D. (1988). The impact of AIDS on the medical care system. Journal of the American Medical Association, 261, 519-523.

Curran, J.W., Morgan, W.M. \& Hary, A.M. (1985). The epidemiology of AIDS: Current status and future prospects. Science, 229, 1352-1357.

Dancey, C.P. (1982). The relationship of instrumentality and expressivity to sexual orientation in women. Journal of Homosexuality, $\underline{23}(4), 71-81$.

D'Augelli, A.R. (1988). Lesbian women in a rural helping network: Exploring informal helping resources. Special Issue: Lesbianism: Affirming nontraditional roles. Women and Therapy, $\underline{8}(1-2), 119-130$. 
Deevey, S. (1990). Older lesbian women: An invisible minority. Journal of Gerontological Nursing, 16(5), 35-37.

DeMaris, A. J Jackson, J.K. (1987). Batters' reports of recidivism after counseling. Social Casework, 68(8), $458-465$.

Descher, J.P. \& McNeil, J.S. (1986). Results of anger control training for battering couples. Journal of Family Violence, $1(2), 111-120$.

Dhooper, S.S., Royse, D.D. \& Tran, T.V. (1987-88).

Social work practitioners' attitudes towards AIDS victims. Journal of Applied Social Sciences, 12(1), 108-123.

Diaz, Y.E. \& Kelly, J.A. (1991) AIDS-Related training in United States schools of social work. Social Work, 36 , $38-42$.

Diener, E., Emmons, R.A., Larsen, R.J.\& Griffen, S. (1985). The satisfaction with life scale. Journal of Personality Assessment, 49, 71-75. DiPasquale, J.A. (1990). The psychological effects of support groups on individuals infected by the AIDS virus. Cancer Nursing, 13(5), 278-285.

Dobson, K.S. \& Block, L. (1988). Historical and philosophical bases of the cognitive-behavioral therapies. In K.S. Dobson (Ed.) Handbook of Cognitive- 
Behavioral Therapies. (pp 3-38), New York: The Guilford Press.

Donlou, J.N., Wolcott, D.L., Gottlieb, M.S.\& Landsverk, J. (1985). Psychosocial aspects of AIDS and AIDS relates complex: A pilot study. Journal of Psychosocial Oncology, $\underline{3}(2), 39-55$.

Drummond, M.F. (1989). The economic impact of AIDS. AIDS CARE, 1(2), 216-218.

Duffy, S.M. \& Rusbult, C.E. (1986). Satisfaction and commitment in homosexual and heterosexual relationships. Journal of Homosexuality, 12(2), 1-21. Eldridge, N.S. \& Gilbert, L.A. (1990). Correlates of relationship satisfaction in lesbian couples. Psychology of Women Quarterly, 14, 43-62. Evatt, B.L., Stein, S.F., Francis, D.P., Lawrence, D.N., McLane, M.F., McDougal, J.S., Lee, T.H., Spira, T.J., Cabradilla, C., Mullens, J.I.\& Essex, M. (1983). Antibodies to human $\mathrm{T}$-cell leukaemia virus associated membrane antigens in hemophiliacs: evidence for infection before 1980. Lancet, 24(2), 698-700. Faden, R.R. \& Kass (1988). Health insurance and AIDS: The status of state regulatory activity. American Journal of Public Health, 78, 437-438.

Feldman, H.W. \& Biernacki, P. (1988). The ethnography of needle sharing among intravenous drug users and implications for public policies and intervention 
strategies. National Institute on Drug Abuse Research

Monograph Series, Mono 80, 28-39.

Fernandez, F., Levy, J. K. \& Galizzi, H. (1988).

Response of HIV related depression to psychostimulants:

Case reports. Hospital and Community Psychiatry, $\underline{39}(6), 628-631$.

Finkelhor, D. (1980). Sex among siblings: A survey on

prevalence, variety and effects. Archives of Sexual

Behavior, $9(3), 171-194$.

Fischl, M.A., Richman, D.D., Grieco, M.H., Gottieb, M.S.,

Volberding, P.A., Laskin, O.L., Leedom, J.M., Groopman, J.E., Mildvan, D., Schooley, R.T., Jackson, G.G.,

Durack, D.T., Phil, D., King, D. \& the AzT

Collaborative Working Group. (1987). The efficacy of Azidothymindine (AZT) in the treatment of patients with AIDS and AIDS-related complex. New England Journal of Medicine, 317, 185-191.

Gallant, J.E., Somani, J., Chaisson, R.E., Stanton, D.,

Smith, M. \& Quinn, T.C. (1992). Diagnostic accuracy of three clinical case definitions for advanced HIV disease. AIDS, $\underline{6}(3), 295-299$.

Gallo, R.C., Salahuddin, S.Z. \& Popovic, M. (1984).

Frequent detection and isolation of cytopathic retroviruses (HTLV-III) from patients with AIDS and at risk for AIDS. Science, 224, 500-503. 
Gambe, R. \& Getzel, G.S. (1989). Group work with gay men with AIDS. Social Casework: The Journal of Contemporary Social Work, 70(3), 172-179.

Gelles, R.J. \& Harrop, J.W. (1989). Violence, battering, and psychological distress among women. Journal of Interpersonal Violence, $4(4), 400-420$.

Getzel, G.G. (1991). Survival Modes for people with AIDS in groups. Social Work, 36, 7-15.

Gibbons, F.X., Gibbons, B.N. \& Kassin, S.M. (1981). Reactions to the criminal behavior of mentally retarded and nonretarded offenders. American Journal of Mental Deficiency, $86(3), 235-242$.

Grassi, L. Rosti, G., Albier, G. \& Marangolo, M. (1989). Depression and abnormal illness behavior in cancer patients. General Hospital Psychiatry, 11(6), 404411.

Green, J. (1989). Counseling for HIV infection and AIDS: the past and the future. AIDS CARE, 1(1), 5-10. Handler, M., Ho, V., Whelan, M \& Budsilovich, G. (1983). Intracerebral toxoplasmosis in patients with acquired immune deficiency syndrome. Journal of Neurosurgery, 59(6), 994-1001.

Hart, G., Fitzpatrick, R., McLean, J., Dawson, J. \& Boulton, M. (1990). Gay men, social support and HIV disease: A study of social integration in the gay community A AIDS CARE, 2(2), 163-170. 
Harrison, D.F., Hudson, W.W. \& Thyer, B.A. (1992). On a critical analysis of empirical clinical practice: A response to Witkin's revised views. Social Work, 37 , $461-464$.

Harrison, D.F., Wambach, K.G., Byers, J.B. \& Imershein, A.W. (1991). AIDS knowledge and risk behaviors among culturally diverse women. AIDS Education and Prevention, $\underline{3}(2), 79-89$.

Harrison, L. \& Gfroerer, J. (1992). The intersection of drug use and criminal behavior: Results from the National Household Survey on Drug Abuse. Special Issue: Drugs and crime. Crime and Delinquency, $\underline{38}(4)$, $422-443$.

Harwood, H.J., Hubbard, R.L. \& Collins, J.J. (1988). The costs of crime and the benefits of drug abuse treatment: A cost benefit analysis using TOPS data. National Institute on Drug Abuse Research Monograph Series, Mono 86, 209-235.

Hedblom, J.H. \& Hartman, J.J. (1980). Research on lesbianism: Selected effects of time, geographic location and data collection technique. Archives of Sexual Behavior, $9(3), 217-234$.

Hindberg, B.O. (1988). Violence against women. Women and Health, $13(3-4), 151-158$.

Hinkle, D.E., Wiersma, W. \& Jurs, S.G. (1988). Applied Statistics for the Behavioral Sciences. Houghton 
Mifflin Company, Boston: Massachusetts. Hintz, S., Kuck, J., Peterkin, J.J. \& Volk, D.M. (1990).

Depression in the context of human immunodeficiency virus infection: Implications for treatment. Journal of Clinical Psychiatry, 51(12), 497-501.

Hoffman, A.S. (1986). Impact of AIDS. Hospital and Community Psychiatry, 37(9), 943-944. Holahan, C.K. (1988). Relation of life goals at age 70 to activity participation and health and psychological well being among Terman's gifted men and women. Psychology and Aging, $\underline{3}(3), 286-291$. Hollin, C.R. (1983). Young offenders and alcohol: A survey of the drinking behavior of a Borstal population. Journal of Adolescence, $6(2), 161-174$. Hollingshead, A.B. (1958). Social Class and Mental Illness. New York: Wiley. Hollingshead, A.B. (1975). Four Factor Index of Social Status. Unpublished manuscript, Yale University, Department of Sociology, New Haven. Honig, A.S. (1984). Risk factors in infancy. Early Child Development and Care, 16 (1-2), 1-8. Hudson, W.W. (1982). The Clinical Measurement Package: A Field Manual. Chicago: Dorsey. Huggins, J., Elman, N., Baker, C., Forrester, R.G. \& Lyter, D. (1991). Affective and Behavioral Responses 
of Gay and Bisexual Men to HIV Antibody Testing. Social Work, 36, 61-66.

Imagawa, D.T., Lee, M.H., Wolinsky, S.M., Sano, K., Morales, F., Kwok, S., Sninsky, J.J., Nishanian, P.G., Giorgi, J., Fahey, J.L., Dudley, J., Visscher, B.R. \& Detels, R. (1989). Human immunodeficiency virus tpye 1 infection in homosexual men who remain seronegative for prolonged periods. The New England Journal of Medicine, $\underline{320}(22), 1458-1462$.

Ivanoff, A. Blythe, B.J. Briar, S. (1987). The empirical clinical practice debate. Social Casework, $\underline{68}(5), 290-298$.

Jennison, K.M. (1986). The violent offender: A research note. Federal Probation, 50(3), 60-65. Kaplan, J.E., Spira, T.J., Fishbein, D.B. \& Lynn, H.S. (1992). Ten year follow-up of HIV infected homosexual men with lymphadenopathy syndrome: evidence for continuing risk for developing AIDS. Journal of Acquired Immune Deficiency Syndrome, $\underline{5}(6), 565-570$. Katoff, L. \& Dunne, R. (1988). Supporting people with AIDS: The Gay Men's Health Crisis model. Special Issue: AIDS. Journal of Palliative Care, $4(4), 88-95$. Kehoe, M. (1988). Lesbians over 60 speak for themselves. Journal of Homosexuality, $16(3-4), 111$. Kelly, K. (1987). AIDS and ethics: An overview. General Hospital Psychiatry, 9, 331-340. 
Kirkpatrick, M., Smith, C. \& Roy, R. (1981). Lesbian mothers and their children: A comparative survey. American Journal of Orthopsychiatry, 51(3), 545-551. Kolvin, I, Miller, F.J., Fleeting, M. \& Kolvin, P.A. (1988). Social and parenting factors affecting criminal offence rates: Findings from the Newcastle Thousand Family Study • British Journal of Psychiatry, 152, $80-90$.

Krause, N. (1990). Perceived health problems, formal/informal support and life satisfaction among older adults. Journals of Gerontology, 45(5), S193-S205.

Kurdek, L.A. (1988). Perceived social support in gays and lesbians in cohabitating relationships. Journal of Personality and Social Psychology, 54(3), 504-509. Kurdek, L.A. (1991). Correlates of relationship satisfaction in cohabitating gay and lesbian couples: Integration of contextual, investment and problem solving models. Journal of Personality and Social Psychology, 61 $(6), 910-922$.

Laumann, E.O., Gagnon, S., Michael, R.T.\& Coleman, J.S. (1989). Monitoring the AIDS epidemic in the United States: a network approach. Science, 244, 1186-1189. Leedom, L. Meehan, W.P., Procci, W. \& Zeidler, A. (1991). Symptoms of depression in patients with type II diabetes mellitus. Psychosomatics, 32(3), 280-286. 
Lewis, D.K. \& Watters, J.K. (1989). Human

immunodeficiency virus seroprevalence in female intravenous drug users: The puzzle of Black women's risk. Social Science and Medicine, 29(9), 1071-1076. Lewis, D.K. \& Watters, J.K. (1991). Sexual risk behavior among heterosexual intravenous drug users: Ethnic and gender variations. $\underline{\text { AIDS }} \underline{5}(1), 77-83$.

Lie, G.Y. \& Gentlewarrier, S. (1991). Intimate violence in lesbian relationships: Discussion of survey findings and practice implications. Journal of Social Service Research, $15(1-2), 41-59$.

Lloyd, G.A. (1990). AIDS and HIV: The syndrome and the Virus. In Ginsberg, L., Khinduka, S., Hall, J. A., Ross-Sheriff, F. \& Hartman, A. (Eds.), Encyclopedia of Social Work 18 th Ed. 1990 Supplement. Silver spring, MD: NASW.

Loulan, J. (1988). Research on the sex practices of 1566 lesbians and the clinical applications. Special issue: Women and sex therapy. Women and Therapy, 7(2-3), $221-234$

Luengo-Martin, A. (1985). Values and personality: A survey of their relationship in the case of juvenile delinquency. Personality and Individual Differences, $\underline{6}(4), 519-522$.

Lustman, P.J., Clouse, R.E. \& Carney, R.M. (1988). Depression and the reporting of diabetes symptoms. 
International Journal of Psychiatry in Medicine, 18(4), 295-303.

Lynch, R.D. (1989). Psychological impact of AIDS on individual, family, community, nation and world in a historical perspective. Family Community Health, $12(2), 52-59$.

Lynch, J.M. \& Reilly, M.E. (1986). Role relationships: Lesbian perspectives. Journal of Homosexuality, $\underline{12}(2)$, $53-69$.

Maslow, A. (1970). Motivation and Personality (2nd edition). New York: Harper \& Row.

McCann, K. \& Wadsworth, E. (1991). The experience of having a positive HIV antibody test. AIDS Care, $\underline{3}(1)$, 43-53.

McDonell, J.R. (1993). Judgements of personal responsibility for HIV infection: An attributional analysis. Social Work, 38, 403-409.

McLaughin, L. (1988). AIDS: An overview. New England Journal of Public Policy, $4,15-35$.

McLean. P.D. \& Hatstian, A.R. (1979). Clinical

depression: Comparative efficacy of outpatient treatments. Journal of consulting and Clinical Psychology, 47, 818-836.

Montaner, J.S., Le, T.N., Craib, K.J. \& Schecter, M.T. (1992). Application of the World Health Organization system for HIV infection in a cohort of homosexual men 
in developing a prognostically meaningful staging system. AIDS, $\underline{6}(7), 719-724$.

Morin, S.F. (1977). Heterosexual bias in psychological

research on lesbianism and male homosexuality.

American Psychologist, 32, 629-637.

Murphy, S.A. (1984). After Mount St. Helens: Disaster

stress research. Journal of Psychological Nursing and

Mental Health Services, 22(7), 9-18.

Nicholson, W.D. \& Long, B.C. (1990). Self-esteem, social

support, internalized homophobia and coping strategies

of HIV+ gay men. Journal of Consulting and Clinical

Psychology, 58(6), 873-876.

O'Dowd, M.A. (1988). Psychosocial issues in HIV

infection. AIDS, $\underline{2}(1), 201-205$.

Orgero, M.I. \& Rodway, M.R. (1991). AIDS and social work

treatment: A single system analysis. Health and

Social Work, 16, 123-141.

Ozawa, M.N., Auslander, W.F. \& Slonim-Nevo, V. (1993).

Problems in financing the care of AIDS patients.

Social Work, 38, 369-377.

Passannante, M.R., Wells, D.V., Quinones, M.A., Jackson,

J.F. \& Rotkiewicz, L.G. (1991). AIDS Education in

drug user treatment programs. International Journal

of the Addictions, $26(5), 577-594$. 
Pavot, W. \& Diener, E. (1993). Review of the

Satisfaction with Life Scale. Psychological

Assessment, $\underline{5}, 164-172$.

Penka, C.E. \& Kirk, S.A. (1991). Practitioners

involvement in clinical evaluation. Social Work, 36 , 513-518.

Peplau, L.A., Cochran, S., Rook, K. \& Padesky, C. (1978).

Loving women: Attachment and autonomy in lesbian

relationships. Journal of Social Issues, 34 (3), 7-27.

Perry, S., Fishman, B., Jacobsberg, L., Young, J.\&

Frances, A. (1991). Effectiveness of psychoeducational

interventions in reducing emotional distress after

human immunodeficiency virus antibody testing.

Archives of General Psychiatry, 48, 143-147.

Peterson, K.J. (1991). Social workers' knowledge about

AIDS: A national survey. Social Work, 36, 31-37.

Peterson, J.L. \& Bakeman, R. (1989). AIDS and IV drug

use among ethnic minorities. Journal of Drug Issues, $19(1), 27-37$.

Peterson, R.A., Kimmel, P.L., Sacks, C.R., Mesquita, M.L.

(1991). Depression, perception of illness and

mortality in patients with end stage renal disease.

International Journal of Psychiatry, 21(4), 343-354.

Pirog-Good, M. \& Stets, J. (1985). Male batters and

battering prevention programs: A national survey. 
Response to the Victimization of Women and Children, $\underline{8}(3), 8-12$.

Politzer, R.M. \& Davis, C.H. (1991). The incidence of AIDS: Evidence of a multidimensional epidemic. AIDS and Public Policy Journal, $\underline{5}(4), 181-185$. Rabkin, J.G., Williams, J.B., Remien, R.H., Goetz, R., Kertzner, R. \& Gorman, J.M., (1991). Depression, distress, lymphocyte subsets and human immunodeficiency virus symptoms on two occasions in HIV positive homosexual men. Archives of General Psychiatry, $\underline{48}$, 111-119.

Reamer, F.G. (1993). AIDS and social work: The ethics and civil liberties agenda. Social Work, 38, 412-417. Redfield, R.R. \& Burke, D.S. (1988). HIV infection: The clinical picture. The science of AIDS: Readings from Scientific American (pp. 64-73). New York: W.H. Freeman.

Richman, D.D., Fischl M.A., Grieco, M.H., Gottlieb, M.S., Volberding, P.A., Laskin, O.L., Leedom, J.M., Groopman, J.E., Mildvan, D., Hirsch, M.S., Jackson, G.G., Durack, D.T., Phil, D., Nusinoff-Lehrman, S., \& the AZT Collaborative Working Group. (1987). The toxicity of azidothymidine (AZT) in the treatment of patients with AIDS and AIDS-related complex. The New England Journal of Medicine, 317(4), 192-197. 
Riley, J.L. \& Greene, R.R., (1993). Influence of education on self perceived attitudes about HIV/AIDS among human services providers. Social Work, 38, 396401 .

Rose, S. \& Roades, L. (1987). Feminism and women's friendships. Psychology of Women Quarterly, 11(2), 243-254.

Rosenzweig, J.M. \& Lebow, W.C. (1992). Femme of the streets, butch in the sheets? Lesbian sex-roles, dyadic adjustment and sexual satisfaction. Journal of Homosexuality, 23(2), 1-19.

Rosser, S.V. (1991). AIDS and women. AIDS Education and Prevention, $3(3), 230-240$.

Rubin, A.J. (1993). Health care's hour: The problem, the plan and the politics behind the call for change. Congressional Quarterly, 51(2), 1-66.

Rush, A.J., Beck, A.T., Kovacs, M. \& Hollon, S. (1977) . Comparative efficacy of cognitive therapy and imipramine in the treatment of depressed outpatients. Cognitive Therapy and Research, 1, 17-37.

Sadovsky, R. (1991). Psychosocial issues in symptomatic HIV infection. American Family Physician, $44(6)$, 2065-2072.

Shaw, B.F. (1985). Closing commentary: Social cognition and depression. Special Issue: Depression. Social Cognition, $3(1), 135-144$. 
Schaerf, F.W., Miller, R.R., Lipsey, J.R. \& McPherson, R. W. (1989). ECT for major depression in four patients infected with human immunodeficiency virus. American Journal of Psychiatry, 146(6), 782-784.

Scheider, B.E. (1986). Coming out at work. Work and Occupations, 13(4), 463-487.

Schilling, R.F., El-Bassel, N., Schinke, S.P. \& Nichols, S. (1991). Sexual behavior, attitudes toward safer sex and gender among a cohort of 244 recovering IV drug users. International Journal of the Addictions, $\underline{26}(8), 859-877$.

Schoenbaum, E.E., Hartel, D., Selwyn, P.A. \& Klien, R.S. (1989). Risk factors for human immunodeficiency virus infection in intravenous drug users. New England Journal of Medicine, 321(13), 874-879.

Schneider, B.E. (1982). Consciousness about sexual harassment among heterosexual and lesbian women workers. Journal of Social Issues, 38(4), 75-97. Schullo, S.A. \& Alperson, B.L. (1984). Interpersonal phenomenology as a function of sexual orientation, sex, sentiment and trait categories in long term dyadic relationships. Journal of Personality and Social Psychology, 477(5), 983-1002.

Seltzer, R. \& Smith, R.C. (1988). Racial differences and interracial differences among Blacks in attitudes 
toward AIDS. AIDS and Public Policy Journal, $3(3)$, 31-35.

Seltzer, R. (1989). Race, age, education and knowledge of AIDS. Sociology and Social Research, $\underline{73}(4), 189-$ 193.

Sherer, M., Maddox, J. E., Mercandante, B., Prentice-Dunn, S., Jacobs, B. \& Rogers, R.W. (1982). The Self Efficacy Scale: Construction and validation. Psychological Reports, 51, 663-671. Sheridan, K., Phair, J.P. \& Sheridan, E.P. (1990). Practice and research in HIV disease: a modern hydra. Journal of Community Psychology, 18, 316-324. Shichor, D. \& Korbrin, S. (1978). Criminal behavior among the elderly. Gerontologist, 18(2), 213-218. Sholevar, G.P.\& Perkel, R. (1990). Family systems intervention and physical illness. General Hospital Psychiatry, $12(6), 363-372$. Shulman, R., Pacey, I., Price, J.D. \& Spinelli, J. (1987). Self-assessed social functioning on long term hemodialysis. Psychosomatics, 28(8), 429-433. Singer, M. (1991). Confronting the AIDS epidemic among IV drug users: Does ethnic culture matter? AIDS Education and Prevention, $3(3), 258-283$. Sivak, S.L. \& Wormser, G.P. (1984). How common is HTLV III infection in the United States? New England Journal of Medicine, $313,1352$. 
Smith, M.D. (1989). Woman abuse: The case for surveys by telephone. Journal of Interpersonal Violence, $4(3)$. 308-324.

Stark, M.J.\& Campbell, B.K. (1991). A

psychoeducational approach to methadone maintenance treatment: A survey of client reactions. Journal of Substance Abuse Treatment, $\underline{8}(3), 125-131$.

Stein, S.M., DeMiranda, S. \& Stein, A. (1988). Birth order, substance abuse and criminality. Individual Psychology Journal of Adlerian Theory, Research and Practice, $\underline{44}(4), 500-506$.

Stuntzner-Gibson, D. (1991). Women and HIV disease: An emerging social crisis. Social Work, 36, 22-28. Taylor, D.G., Aday, L.A. \& Anderson, R. (1975). A social indicator of access to medical care. Journal of Health and Social Behavior, 16(1), 39-49.

Taylor, S.E., Helgeson, V.S. Reed, G.M. \& Skokan, L.A. (1991). Self-generated feelings of control and adjustment to physical illness. Journal of Social Issues, $47(4), 91-109$.

Townsend, M.H., Wallick, M.M. \& Cambre, K.M. (1991). Support services for homosexual students at United States medical schools. Academic Medicine, $\underline{66}(6), 361-363$. 
Triggs, J. \& McDermott, D. (1991). Short term counseling strategies for university students who test HIV positive: The case of John Doe. Journal of College Student Development, 32, 17-23.

Trute, B., Sarsfield, P. \& McKenzie, D.A. (1988).

Medical response to wife abuse: A survey of physicians' attitudes and practices. Special Issue: Wife battering: A Canadian perspective. Canadian Journal of Community Mental Health, $I(2), 61-71$. United States Conference of Mayors, (1990). Landmark Ryan White CARE Act enacted. AIDS Information Exchange, $\underline{7}(4)$.

Ussher, J.M. (1990). Cognitive behavioral couples therapy with gay men referred for counselling in an AIDS setting: A pilot study. AIDS CARE, $2(1), 43-51$. Van-Burskirk, S.S. \& Cole, C.F. (1983). Characteristics of eight women seeking therapy for the effects of incest. Psychotherapy Theory Research and Practice, $\underline{20}(4), 503-514$.

Vogt, W.P. (1993). Dictionary of Statistics and Methodology. Newbury Park: Sage Publications. Wasileski, M., Callaghan-Chaffee, M.E. \& Chaffee, R.B. (1982). Spousal violence in military homes: An initial survey. Military Medicine, 147(9), 761-765. 
Watters, J.K., Cheng, Y. \& Lorvick, J.J. (1991). Drug use profiles, race, age and risk of HIV infection among intravenous drug users in San Francisco. Special Issue: AIDS and injection drug use in Asia, Europe and the United States. International Journal of the Addictions, 26 (12), 1247-1261.

Weber, J.N., Wadsworth, J., Rogers, L.A., Moshtael, O., Scott, K., McManus, T., Berrie, E., Jeffries, D.J., Harris, J.R., Pinching, A.J. (1986). Three year prospective study of HTLV-III/LAV infection in homosexual men. Lancet, 24 (1), 1179-1182. Wexler, S. (1989). Social welfare students and AIDS: A survey of knowledge, attitudes and professional preparation. Journal of Teaching in Social Work, $\underline{3}(1)$, 131-149.

White, J.C., Christensen, J.F. \& Singer, C.M. (1992). Methylphenidate as a treatment for depression in acquired immunodeficiency syndrome: An n-of-1 trial. Journal of Clinical Psychiatry, 53(5), 153-156. Wood, L.A. \& Johnson, J. (1989). Life satisfaction among the rural elderly: What do the numbers mean? Social Indicators Research, 21(4), 379-408.

World Health Organization (1991). World Health Organization global AIDS statistics. AIDS CARE, $3(2)$, 229-232. 


\section{Appendix A}

\section{Medical Definitions}

The human immunodeficiency virus (HIV) is a retrovirus which slowly destroys the immune system. Retroviruses make deoxyribonucleic acid (DNA), so as to reproduce, by utilizing ribonucleic acid (RNA) as a template (American Foundation for AIDS Research, 1992). The name was officially chosen in 1986. Other names include HTLV-III, LAV AND ARV (Barre-Sinoussi, Cherman \& Rey, 1983; Gallo, Salahuddin \& Popovic, 1984). The HIV virus is unique in a number of ways. Perhaps the most important unique feature of the HIV virus is that it multiples within the DNA of Tcells. Because the virus replicates within the DNA of a cell, it has a high mutation rate (Barre-Sinoussi et al., 1983; Gallo et al., 1984). This is a problem because it makes medical research very difficult. There are already 2 classes of HIV (HTLV-1 and HTLV-2) and several different strains (Lloyd, 1990). HIV-1 is the class that is responsible for most cases of AIDS in pattern 1 countries, including the U.S. and Eastern Europe. HIV-2 was discovered in 1985 and is responsible for most cases in west Africa.

All viruses are living organisms or complex proteins that are ultramicroscopic or submicroscopic. They act as infective agents that cause various diseases in plants and animals (American Foundation for AIDS Research, 1992). 
Viruses can only multiply in connection with living cells (American Foundation for AIDS Research, 1992). Some examples of better known diseases caused by viruses are measles, mumps and the common cold. The HIV virus is unique in that it slowly destroys the immune system.

HIV does not cause death by itself. Instead, it renders the immune system so weak that a slight infection can overtake the body (Centers for Disease Control, 1993b). Consequently, those infected with the virus are likely to develop what is known as opportunistic infections which rarely or never occur in individuals with healthy immune systems. According to the Centers for Disease Control (1993b), the most common opportunistic infections in HIV infected individuals include: Kaposi's sarcoma, Pneumocystis carinii pneumonia, Cytomegalovirus (disease and retinitis), Mycobacterium tuberculosis and HIV encephalopathy •

The immune system is a system of cells in the body that find and kill foreign substances such as germs, viruses and bacteria in order to protect the individual from disease. It is comprised of a variety of cells. T-cells and lymphocytes are especially important in the function of the immune system and are also directly affected by HIV (American Foundation for AIDS Research, 1992).

Lymphocytes are a type of white blood cell that produce antibodies. They are found in the lymph nodes and bone 
marrow. T-cells are lymphocytes that have matured in the thymus and have acquired the ability to mediate delayed hypersensitivity and the rejection of foreign transplanted tissue. They play a major role in the body's defense against viruses, fungi and certain bacteria. They are also known as t-lymphocytes (American Foundation for AIDS Research, 1992).

There are 3 basic types of T-cells: T-4 or CD-4 (also known as $t$-helper cells); T-8 or CD-8 (also known as suppressor cells); and cytotoxic cells (American Foundation for AIDS Research, 1992). The T-4 cell orchestrates the immune system. More specifically, it gives instructions to the T-8 cells which in turn tell other cells when to stop producing antibodies. The cytotoxic cells kill other cells that are infected with any given antigen. HIV disrupts this process because it multiplies in the $\mathrm{T}-4$ cell. Because HIV multiplies in the T-4 cell, the activation of the immune response, which normally fights infection, produces more cells for the virus to reproduce in and assists in HIV viral replication (Redfield \& Burke, 1988).

Antibodies are complex proteins that are produced by the body to kill foreign substances (antigens) (American Foundation for AIDS Research, 1992). They are found in the blood. HIV antibodies are the means by which HIV infection is detected. Although HIV antibodies are not effective in killing the virus, they serve as markers which are easier to 
detect than the virus itself. The ELISA (Enzyme-Linked Immunosorbent Assay) and Western Blot are blood tests that detect the presence of HIV antibodies (Centers for Disease Control, 1993b).

\section{Medical Treatment}

The major treatment for HIV infection is antiviral medication (Fischl et al., 1987). All antiviral medication attempts to stop the replication of the virus; unfortunately in doing so it interferes with a number of other normal cell functions. The most common drug in the treatment of HIV infection is Azidothymidine (AZT) (American Foundation for AIDS Research, 1992).

AZT, also known as zidovudine or Retrovir, was the first antiviral drug proven to slow the rate of the disease (Fischl et al., 1987). In 1989 it was discovered that lower doses of AZT could benefit asymptomatic HIV positive individuals. This was an especially important discovery due to the serious side effects caused by AZT toxicity (Richman et al., 1987); it meant that individuals could benefit from the drug prophylacticly for longer periods of time before toxicity occurred. Side effects include: muscle myopathy (severe pain and inflammation), anemia (red blood cell deficiency), leukopenia (white blood cell deficiency), fatigue, rashes, nausea, insomnia and headaches (Richman et al., 1987). Muscle myopathy, anemia and leukopenia are main 
causes for discontinuing AZT (American Foundation for AIDS Research, 1992).

Other common antiviral medications are alpha interferon, Dideoxyinosine (ddI) and Dideoxycytidine (ddC) (Centers for Disease Control, 1993b). Alpha interferon is an antiviral drug that shows signs of promise. Although there are far fewer studies on this medication than AzT, preliminary reports indicate that is effective. Side effects are remarkably similar to flu-like symptoms; fever, chills, fatigue, muscle pain and headache (American Foundation for AIDS Research, 1992).

DdI, also known as didanosine or Videx, inhibits HIV though DNA chain termination. It has been approved by the FDA for individuals who have developed toxicity to AZT and have advanced HIV disease. The most serious side effects of ddI toxicity are potentially fatal pancreatitis and peripheral neuropathy. Diarrhea is a less serious, but common side effect (American Foundation for AIDS Research, 1992).

DdC, also known as zalcitabine and Hivid, inhibits HIV though termination of DNA-chain synthesis (similar to ddI). DdC does not appear to be more effective than AZT, but has shown good results in combination with AZT. The most frequent side effect of ddC toxicity is peripheral neuropathy, but pancreatitis, oral ulcers, fever, rash and 
stomatitis have also been reported (American Foundation for AIDS Research, 1992).

Acyclovir, Dapsone, Gamma Interferon and Pentamidine are drugs that are commonly prescribed for HIV infected individuals. They are treatments for the opportunistic infections that routinely occur as a result of HIV infection and are not treatments for HIV itself (American Foundation for AIDS Research, 1992). It should be noted that the most current methods of drug treatment often include various combinations of these and other drugs and that when prescribed in this manner the effectiveness and toxicity side effects may be different.

The rate of approval of medications by the food and drug administration (FDA) for the treatment of HIV has been a political and ethical debate. Typically the FDA takes a very long time to approve new medications. The drug must be proven to do no harm long term. This is a problem for medications that are designed to kill specific types of cells. Drugs for treating cancer, as well as HIV, typically serve the purpose of killing certain types of cells, but also are not totally specific and kill healthy cells as well. This is why there are so many significant side effects to the medications for both cancer and HIV. It is also part of the problem in approving new drugs. The FDA has recently sped up the review process for AIDS drugs (Centers for Disease Control, 1993b). 
The expense of medical treatment is certain to have an enormous impact on the social welfare system of the U.S.. AZT treatment currently costs about $\$ 3,500$ annually (American Foundation for AIDS Research, 1992). Although the cost of treatment for AIDS is not significantly higher than other terminal illness the numbers of those infected is sure to cause a strain on the medical system (Cotton, 1988; Lloyd, 1990). Perhaps the new national health care plan will assist in curbing the effects on patients. More than likely the cost of treatment will be so high that it will have an impact on all medical services in the new health plan. It may cause a policy limiting the amount of or type of services for the terminally ill. Although most of every health care dollar is spent on those that are terminal, the ethical implications are enormous.

\section{Modes of Transmission}

The AIDS virus is transmitted though body fluids. This means though anal, vaginal or oral intercourse, blood or blood product transfusions, breast feeding or sharing of IV needles (Centers for Disease Control, 1993b). In each mode of transmission there is direct contact of one person's body fluid (ie blood, breast milk, vaginal secretions, semen) to another. Although HIV has also been found in saliva, tears and urine, it is believed that these fluids are not the common form of transmission (Lloyd, 1990). This is due to the fact that sexual activity involving urine rarely 
includes contact to a mucous membrane (ie inside the mouth, vagina, anus) and there is too small of an amount of virus in both tears and saliva for transmission.

Although the least effective mode of transmission is sexual intercourse, it is also the most common. In fact, of the total cases of AIDS reported to the Centers for Disease Control to date in the United states 628 were exposed to HIV through sexual intercourse, $55 \%$ of these were homosexual men and 78 were men and women exposed through heterosexual contact (Centers for Disease Control, 1993a).

The most effective and second most common, mode of transmission is through the exchange of infected blood and blood products (ie. blood transfusion or infected needles) (Lloyd, 1990). This can be further broken down into hemophilia or coagulation disorders $(1 \%)$, recipients of blood transfusions (2\%) and intravenous drugs (24\%) (Centers for Disease Control, 1993a). 


\section{Appendix $B$ *}

Dear Participant,

I am a doctoral candidate in the department of social work at Florida International University. In order to better understand the way that people who are HIV positive feel, I am asking you to fill out the attached questionnaire. I would like for you to complete the questionnaire regardless of your HIV status. It will only take about 10 minutes to complete and will give me much needed information. The information gathered in this survey will be useful in helping HIV positive individuals.

Your participation is voluntary. You are under no obligation to complete this survey. Should you chose to participate, you may stop answering the questions at any time. This information is completely confidential and your identity is anonymous. DO NOT WRITE YOUR NAME ON ANY OF THE FORMS.

Please answer the questions on the following four pages as honestly as possible. There are no right or wrong answers. Please do not skip any questions.

If you are interested in the results of this survey, please contact me on or after April of 1994. You can reach me at 932-8994 during normal business hours. Your time and effort in completing this survey is greatly appreciated. Thank You, Toni M. DiDona, L.C.S.W. 
Please answer each question by circling the appropriate response or filling in the blank.

Sex: 01 male 02 female Age:

Your Annual Income:

Sexual Orientation:

01 heterosexual 02 homosexual 03 bisexual 04 other

Your Occupation: (type of job only)

Education: 01 did not complete high school

05 B.A.

02 high school graduate (or GED)

06 M.A.

03 some college (no degree)

$07 \mathrm{Ph} . \mathrm{D}$.

04 A.A. degree (two year degree)

Ethnicity:

01 White NonHispanic

02 Hispanic White

03 Hispanic Nonwhite

04 African American

05 NonAfrican Black
06 Native American

07 Asian or Oriental

08 Pacific Islander

09 Other

10 I don't know 
Please answer the following questions on a scale of 1 to 10 (01 is the least and 10 is the most for each question)

How much do you consider yourself part of your ethnic background?

$\begin{array}{lllllllll}1 & 2 & 3 & 4 & 5 & 6 & 7 & 8 & 9\end{array}$

How financially secure are you?

$\begin{array}{lllllllll}1 & 2 & 3 & 4 & 5 & 6 & 7 & 8 & 9\end{array}$

How much access do you have to medical care?

$\begin{array}{lllllllll}1 & 2 & 3 & 4 & 5 & 6 & 7 & 8 & 9\end{array}$

What is the quality of the medical care you receive?

$$
\begin{array}{lllllllll}
1 & 2 & 3 & 4 & 5 & 6 & 7 & 8 & 9
\end{array}
$$

How much access do you have to the latest experimental treatments?

$$
\begin{array}{lllllllll}
1 & 2 & 3 & 4 & 5 & 6 & 7 & 8 & 9
\end{array}
$$

Do you have medical insurance?

01 yes 02 no (if no skip next question)

What type of insurance do you have?
01 private
04 Medicaid
02 Нмо
05 other
03 Medicare
06 None

Excluding medicine, about how much do you spend a month on medical care?

About how much do you spend a month on medicine? 
Do you receive any financial assistance from the government?

01 yes 02 no

(if no skip the next question)

What type of government assistance do you receive?

$\begin{array}{ll}01 \text { disability/SSI } & 05 \text { WIC } \\ 02 \text { foodstamps } & 06 \text { money for housing } \\ 03 \text { transportation } & 07 \text { other } \\ 04 \text { AFDC } & 08 \text { none }\end{array}$

What is your risk factor?

01 homosexual male 06 partner of IV substance user

02 bisexual male 07 multiple heterosexual partners

03 IV substance user 08 none of the above

04 received blood before $1985 \quad 09$ I don't know

05 partner of bisexual male

Have you tested positive for the HIV virus?

01 yes 02 no 03 don't know

***(If you are HIV negative please skip to the next page)***

How many years ago did you test HIV positive?

Are you asymptomatic? (no symptoms)

01 yes 02 no 03 don't know 
Do you have ARC?

$$
01 \text { yes } 02 \text { no } 03 \text { don't know }
$$

Do you have full blown AIDS?

01 yes 02 no 03 don't know

Do you have less than 200 T-cells?

01 yes 02 no 03 don't know

Have you ever had an opportunistic infection?

01 yes 02 no 03 don't know

Have you told anyone in your family your diagnosis?

01 yes 02 no 03 don't know

For each of the following items please describe how each has changed since your diagnosis.

Your relationship with your family:

01 better 02 same 03 worse $04 \mathrm{NA}$

Your relationship with your friends:

01 better 02 same 03 worse $04 \mathrm{NA}$

Your relationship with your lover/partner:

01 better 02 same 03 worse $04 \mathrm{NA}$

Your standard of living:

01 better 02 same 03 worse $04 \mathrm{NA}$

Your quality of medical care:

01 better 02 same 03 worse $04 \mathrm{NA}$

Your insurance coverage:

01 better 02 same 03 worse $04 \mathrm{NA}$ 
Your income:

01 more 02 same 03 less 04 NA

Your access to medical care:
01 more
02 same
03 less
04 NA

Your interest in sex:

01 more 02 same 03 less 04 NA

Your religious beliefs:
01 more
02 same
03 less
$04 \mathrm{NA}$

Your spiritual beliefs:
01 more
02 same 03 less
$04 \mathrm{NA}$

This questionnaire is designed to measure the way you feel about your life and your surroundings. It is not a test, so there are no right or wrong answers. Answer each item carefully and as accurately as you can by placing a number beside each one as follows.

$$
\begin{aligned}
& 1=\text { None of the time } \\
& 2=\text { Very rarely } \\
& 3=\text { A little of the time } \\
& 4=\text { Some of the time } \\
& 5=\text { A good part of the time } \\
& 6=\text { Most of the time } \\
& 7=\text { All of the time }
\end{aligned}
$$

1.__ I feel powerless to do anything about my life.

2. I feel blue.

3._ I think about ending my life. 
4. I have crying spells.

5 . It is easy for me to enjoy myself.

6 . I have a hard time getting started on things that I need to do.

7. I get very depressed.

8. I feel there is always someone I can depend on when things get tough.

9. I feel that the future looks bright for me.

10 . I feel downhearted.

11. I feel that I am needed.

12 . I feel that I am appreciated by others.

13. I enjoy being active and busy.

14 . I feel that others would be better off without me. 15 . I enjoy being with other people.

16 . I feel that it is easy for me to make decisions.

17. I feel downtrodden.

18. I feel terribly lonely. 19. I get upset easily.

20 . I feel that nobody really cares about me.

21 . I have a full life.

22 . I feel that people really care about me.

23. I have a great deal of fun.

24 . I feel great in the morning.

25 . I fell that my situation is hopeless. 
Below are five statements with which you may agree or disagree. Using the scale below, indicate your agreement with each item by placing the appropriate number on the line preceding that item. Please be open and honest in your responding.

$$
\begin{aligned}
& \text { 1=Strongly disagree } \\
& 2=\text { Disagree } \\
& 3=\text { Slightly disagree } \\
& 4=\text { Neither agree nor disagree } \\
& 5=\text { Slightly agree } \\
& 6=\text { Agree } \\
& 7=\text { Strongly agree }
\end{aligned}
$$

1. In most ways my life is close to my ideal.

2. The conditions of my life are excellent.

3. I am satisfied with my life.

4. So far I have gotten the important things I want in life.

5. If I could live my life over, I would change almost nothing. 
This questionnaire is a series of statements about your personal attitudes and traits. Each statement represents a commonly held belief. Read each statement and decide to what extent it describes you. There are no right or wrong answers. You will probably agree with some of the statements and disagree with others. Please indicate your own feelings about each statement below by marking the number that best describes yourself as you truly are, not as you would like to be.

$$
\begin{aligned}
& \text { 1=Disagree strongly } \\
& \text { 2=Disagree moderately } \\
& \text { 3=Neither agree or disagree } \\
& 4=\text { Agree moderately } \\
& \text { 5=Agree strongly }
\end{aligned}
$$

When I make plans, I am certain I can make them work. One of my problems is that I cannot get down to work when I should.

If I can't do a job the first time, I keep trying until I can.

When I set important goals for myself, I rarely achieve them.

I give up on things before completing them. I avoid facing difficulties.

If something looks too complicated, I will not even bother to try i.t. 
When I have something unpleasant to do, I stick to it until I finish it.

When I decide something, I go right to work on it.

When trying to learn something new, I soon give up if

I am not initially successful.

When unexpected problems occur, I don't handle them well.

I avoid trying to learn new things when they look too difficult for me.

Failure just makes me try harder.

I feel secure about my ability to do things.

I am a self reliant person.

I give up easily.

I do not seem capable of dealing with most problems that come up in life.

*Please note that due to formatting restrictions in the dissertation, these questionnaires were presented differently. The survey utilized to collect data was 5 pages in length. The GCS was purchased and used in its original format. 


\section{Appendix C}

Demographic Characteristics of Entire Sample

Characteristics

N ( $(8)$

Sex

Male

$654 \quad(76.7)$

Female

$199 \quad(22.8)$

Race

White

$481 \quad(56.3)$

Black

$133(15.6)$

Hispanic

$175(21.0)$

Sexual Orientation

Heterosexual

$250 \quad(29.7)$

Homosexual

$490 \quad(58.2)$

Bisexual

$93(11.0)$

Risk factor

Homosexual male

$449(52.6)$

Bisexual male

$66 \quad(7.7)$

Partner of bisexual male

$17 \quad(2.0)$

Blood before 1985

$14(1.6)$

IV substance user

$54(6.3)$

Partner IV substance user

$19 \quad(2.2)$

Multiple hetero partners

$87(10.2)$

None

$107(12.5)$

Don't know risk

$40 \quad(4.7)$ 


\section{Appendix D}

Socioeconomic Factors for Entire Sample

Characteristics

Income

$$
\begin{aligned}
& <10,000 \\
& 10,001-20,000 \\
& 20,001-30,000 \\
& 30,001-40,000 \\
& 40,001-50,000 \\
& >50,000
\end{aligned}
$$

Education

< high school graduate

High school graduate

Some college no degree

Associates degree

Bachelors degree

Master or doctorate

Occupation Category

Menial \& unskilled

Semi \& skilled manual

Clerical and sales

Semiprofessionals

Minor professionals

Lesser \& major professionals

other*

*other includes disabled, retired and unemployed

$231(29.9)$

$153(19.8)$

$183(23.7)$

$103(13.3)$

$51(6.6)$

$51(6.6)$

$102(11.8)$

$152(17.7)$

$222(25.8)$

$101(11.7)$

$194(22.5)$

$90(10.5)$

85 (13.9)

$136(22.4)$

$53(8.7)$

$73(12.0)$

$57 \quad(9.4)$

$59 \quad(9.7)$

$146 \quad(23.9)$ 


\section{Appendix $\mathbf{E}$}

Demographic Characteristics of HIV negative Respondents Characteristics

N

(8)

Sex

Male

Female

Race

White

Black

Hispanic

Sexual Orientation

Heterosexual

Homosexual

Bisexual

Risk factor

Homosexual male

Bisexual male

Partner of bisexual male

Blood before 1985

IV substance user

Partner IV substance user

Multiple hetero partners

None

Don't know risk
$230(69.3)$

$102(30.7)$

$215(64.4)$

$34(10.2)$

$61(18.3)$

$109(32.9)$

$187(56.5)$

$34 \quad(10.3)$

148 (44.3)

$21 \quad(6.3)$

$6 \quad(1.8)$

$9 \quad(2.7)$

$9 \quad(2.7)$

$4 \quad(1.2)$

$38 \quad(11.4)$

$85 \quad(25.4)$

$14(4.2)$ 


\section{Appendix F}

Socioeconomic Factors for HIV negative Respondents

Characteristics

Income

$$
\begin{aligned}
& <10,000 \\
& 10,001-20,000 \\
& 20,001-30,000 \\
& 30,001-40,000 \\
& 40,001-50,000 \\
& >50,000
\end{aligned}
$$

Education

< high school graduate

High school graduate

Some college no degree

Associates degree

Bachelors degree

Master or doctorate

Occupation Category

Menial \& unskilled

Semi \& skilled manual

clerical and sales

Semiprofessionals

Minor professionals

Lesser \& major professionals

other*

*other includes disabled, retired and unemployed

N $(\%)$

$\begin{array}{ll}49 & (15.7) \\ 80 & (25.6) \\ 82 & (26.3) \\ 47 & (15.1) \\ 27 & (8.7) \\ 27 & (8.7)\end{array}$

$21 \quad(6.2)$

$58 \quad(17.2)$

$83(24.6)$

$42(12.5)$

84 (24.9)

$49 \quad(14.5)$

$32(15.9)$

$58(28.8)$

$19(9.5)$

$34 \quad(16.9)$

$18 \quad(9.0)$

$22(11.0)$

$18 \quad(9.0)$ 


\section{Appendix G}

Demographic Characteristics of HIV positive Respondents Characteristics

N

Sex
Male
$184(81.4)$
Female
$42(18.6)$

Race
White
126 (55.3)
Black
$42(18.4)$
Hispanic
$44 \quad(19.3)$

Sexual Orientation

Heterosexual

$62(27.9)$

Homosexual

$127 \quad(57.2)$

Bisexual

$29 \quad(13.1)$

Risk factor

$\begin{array}{lrr}\text { Homosexual male } & 124 & (55.1) \\ \text { Bisexual male } & 23 & (10.2) \\ \text { Partner of bisexual male } & 5 & (2.2) \\ \text { Blood before } 1985 & 3 & (1.3) \\ \text { IV substance user } & 23 & (10.2) \\ \text { Partner IV substance user } & 5 & (2.2) \\ \text { Multiple hetero partners } & 27 & (12.0) \\ \text { None } & 7 & (3.1) \\ \text { Don't know risk } & 8 & (3.6)\end{array}$




\section{Appendix H}

Socioeconomic Factors for HIV positive Respondents Characteristics
$\mathbf{N}$
(\%)

Income
$<10,000$
$57(29.1)$
$10,001-20,000$
$30(15.3)$
$20,001-30,000$
$59(30.1)$
$30,001-40,000$
$27 \quad(13.8)$
$40,001-50,000$
$13(6.6)$
$>50,000$
$10 \quad(5.1)$

Education
$<$ high school graduate
$30 \quad(55.1)$
High school graduate
$41 \quad(18.1)$
Some college no degree
$53(23.3)$
Associates degree
$32(14.1)$
Bachelors degree
$50 \quad(22.0)$
Master's or doctorate
$21 \quad(9.2)$

Occupation Category

Menial \& unskilled

$26(15.1)$

Semi \& skilled manual

$45(26.0)$

Clerical and sales

$16(9.2)$

Semiprofessionals

$17(9.8)$

Minor professionals

$19(11.0)$

Lesser \& major professionals 22 (12.7)

Other*

$28(16.1)$

* other includes disabled, retired and unemployed 


\section{Appendix I}

Demographic Characteristics of Respondents with ARC

Characteristics

Sex

Male

Female

Race

White

Black

Hispanic

Sexual Orientation

Heterosexual

Homosexual

Bisexual

Risk factor

$\begin{array}{lcc}\text { Homosexual male } & 70 & (66.7) \\ \text { Bisexual male } & 10 & (9.5) \\ \text { Partner of bisexual male } & 2 & (1.9) \\ \text { Blood before } 1985 & 0 & (0.0) \\ \text { IV substance user } & 5 & (4.8) \\ \text { Partner IV substance user } & 3 & (2.9) \\ \text { Multiple hetero partners } & 6 & (5.7) \\ \text { None } & 4 & (3.8) \\ \text { Don't know risk } & 5 & (4.8)\end{array}$

$42(40.4)$

$19(18.3)$

$36(34.6)$

$90(85.7)$

$15(14.3)$

$22(21.6)$

$65 \quad(63.7)$

$14(13.7)$ 


\section{Appendix $\mathrm{J}$}

Socioeconomic Factors for Respondents with ARC

Characteristics

Income

$$
\begin{aligned}
& <10,000 \\
& 10,001-20,000 \\
& 20,001-30,000 \\
& 30,001-40,000 \\
& 40,001-50,000 \\
& >50,000
\end{aligned}
$$

Education

$<$ high school graduate

High school graduate

Some college no degree

Associates degree

Bachelors degree

Master's or doctorate

Occupation Category

$\begin{array}{lrr}\text { Menial \& unskilled } & 7 & (8.0) \\ \text { Semi \& skilled manual } & 13 & (14.9) \\ \text { Clerical and sales } & 0 & (0.0) \\ \text { Semiprofessionals } & 6 & (6.9) \\ \text { Minor professionals } & 5 & (5.7) \\ \text { Lesser \& major professionals } & 3 & (3.4) \\ \text { Other } & 50 & (57.5) \\ \text { *other includes disabled, retired and unemployed }\end{array}$

$\begin{array}{rc}56 & (58.3) \\ 15 & (15.6) \\ 12 & (12.5) \\ 8 & (8.3) \\ 3 & (3.1) \\ 2 & (2.0)\end{array}$

N

$\begin{array}{rr}16 & (15.2) \\ 20 & (19.0) \\ 35 & (33.3) \\ 7 & (6.7) \\ 20 & (19.0) \\ 7 & (6.7)\end{array}$


Appendix $\mathrm{K}$

Demographic Characteristics of Respondents with AIDS Characteristics

N

(

Sex

Male

Female

Race

White

Black

Hispanic

Sexual Orientation

Heterosexual

Homosexual

Bisexual

Risk factor

Homosexual male

Bisexual male

Partner of bisexual male

Blood before 1985

IV substance user

Partner IV substance user

Multiple hetero partners

None

Don't know risk
$123(80.9)$

$29 \quad(19.1)$

$80 \quad(52.6)$

$33 \quad(21.7)$

$28 \quad(18.5)$

$50 \quad(32.7)$

$86 \quad(56.2)$

$14 \quad(9.2)$

$86 \quad(56.2)$

$11 \quad(7.2)$

$3(2.0)$

$2(1.3)$

$16(10.5)$

$6 \quad(3.9)$

$15(9.8)$

$4(2.6)$

$10 \quad(6.5)$ 


\section{Appendix I}

Socioeconomic Factors for Respondents with AIDS

Characteristics

Income

$$
\begin{aligned}
& <10,000 \\
& 10,001-20,000 \\
& 20,001-30,000 \\
& 30,001-40,000 \\
& 40,001-50,000 \\
& >50,000
\end{aligned}
$$

Education

$$
\text { < high school graduate }
$$

High school graduate

Some college no degree

Associates degree

Bachelors degree

Master's or doctorate

Occupation Category

Menial \& unskilled

Semi \& skilled manual

Clerical and sales

Semiprofessionals

Minor professionals

Lesser \& major professionals

Other*

*other includes disabled, retired and unemployed
$60 \quad(45.5)$

$18(13.6)$

$26(19.7)$

$16(12.1)$

$6 \quad(4.5)$

$6 \quad(4.5)$

$28(18.1)$

$27 \quad(17.4)$

$42(27.1)$

$16(10.3)$

$31(20.0)$

$11 \quad(7.1)$

$16(12.9)$

$15(12.1)$

$13(10.5)$

$13(10.5)$

$14(11.3)$

$8 \quad(6.4)$

$45 \quad(36.3)$ 
VITA

1965

1985

1987

$1988-89$

1988-89

1989

1991-present

1992-present

1992
Born, Miami Beach, Florida

A.A., Oxford College, Emory University, 1985

B.A., University of Miami

Academic Excellence Award, Florida International University, Miami, Florida.

National Dean's List of Graduate Students, Florida International University, Miami, Florida.

M.S.W., Florida International

University, Miami, Florida

Director of Social Services, Biscayne Rehabilitation Institute, Miami, Florida

Field Instructor, Florida International University; Barry University, Miami, Florida

Florida License: SW 0002844

PRESENTATIONS AND PAPERS

Berger, J., McCarthy, M., Levine, B., DiDona, T., Lo, E., Klimas, L., Resnick, L. \& Fletcher, M. (1989). Neurological and cognitive correlates of T4 lymphocyte counts in asymptomatic HIV seropositive adults. Satellite Conference to the 5 th International Conference on AIDS, Quebec, Canada.

Rey, G., Levin, B., DiDona, T. \& Sheremata, W. (1990). Neuropsychological deterioration in multiple sclerosis. 4/2/90 American Academy of Neurology, Miami Beach, Florida 40 (Suppl 1) 141 .

Levin, B., Berger, J., DiDona, T., Black, R. \& Duncan, R. (1990). Subtle cognitive changes in HIV infection. Sixth International Conference on AIDS, San Francisco, California. 